\title{
Diane Ghirardo
}

\section{(University of Southern California)}

Diane Ghirardo, chair of the History and Theory of Architecture at the University of Southern California, Los Angeles. She is also a former President of the Association of Collegiate Schools of Architecture (ACSA, 1993 - 1996) and from that position she can relate to European Architectural education. As a Fellow of the American Academy in Rome (1988), translator/editor of several books on Aldo Rossi, and author of an extensive oeuvre on among others on European Renaissance, she has a strong European base for her teachings in the US. As such she reflects on the transmission/dissemination of culture, architecture and education.

Diane Yvonne Ghirardo received her master and doctorate degrees in History and Humanities from Stanford University in 1983. She has taught and lectured widely in North America, Europe, Africa and Australia. She is also an ACSA Distinguished Professor (1998), a Guggenheim Fellow (2002), National Endowment for the Humanities Senior Fellow (2001), and Fulbright Scholar (1976, 2001). 


\section{Laura Lee}

\section{(Carnegie Mellon University Pittsburgh)}

Laura Lee is a registered architect and Professor of Architecture most notably at Carnegie Mellon University in Pittsburgh where she served as Head of the School from 2004-2008. Laura has also taught at the Higher Institute of Architecture Henry van de Velde in Antwerp, Belgium; the Royal Danish Academy in Copenhagen, Denmark and the Swiss Federal Institute of Technology in Zurich, Switzerland. In 2009-2010, she was the Cass Gilbert Visiting Professor at the University of Minnesota. Laura is an international voice for integrated design education, practice and research. Her work focuses on the development and implementation of integrated design strategies and collaborative programs between the academy, government, industry and the profession. She has lectured globally on issues concerning the relationship between design education, policy, practice and research. For many years, Laura has served on award juries and has been an accreditation chair, advisor and an international consultant for numerous academic institutions and professional organisations. 
Merete Ahnfeldt-Mollerup

(Royal Danish Academy of Fine

Arts Schools of Architecture,

Design and Conservation)

Merete Ahnfeldt-Mollerup is an architect and associate professor at the The Royal Danish Academy of Fine Arts, Schools of Architecture, Design and Conservation. From 1986 - 2004, she was a practitioner, working primarily in Copenhagen and Berlin, with housing, landscape and interior design. After finishing her Phd on Mies van der Rohe and radical art in the early twentiest century, she has been working as an associate professor at Copenhagen University, dept of Comparative Literature, at the Denmarks University of Technology and at the Royal Academy. She has also worked as a critic and journalist at the daily Dagbladet Information. Merete Ahnfeldt-Mollerup is chairman of the Danish Architectural Press and has been a member of the Danish Council for Research in the Humanities.

\section{Thomas Bock}

(Technische Universität München) Thomas Bock, chair Baurealisierung und Baurobotik at Technische Universität München. Research activities of Thomas Bock focus on the automation and robotisation in building industry, from planning through construction production, phases of use to the conversion and dismantling. $\mathrm{He}$ is both director of the International Association for Automation and Robotics in Construction in Eindhoven, and more societal-oriented the Asian Habitat Society in Beijing. Thomas Bock studied architecture at Stuttgart and Chicago, doctorate at Tokyo. He is also director of the International Institute of Information Construction in Tokyo, and as a consultant, in the Ministère de l'Emploi, de la Cohesion Sociale et du Logement active in France. He is also a member of the Academy of Architecture and Building Sciences, the Petrovischen Academy of Sciences and the Academy of computer science in Belarus. In addition, Thomas Bock is on the editorial board of "Robotica", "Automation in Construction", the "International Journal of Construction Management" and the magazine "ACADEMIE".
Maria Rubert de Ventós

(Urbanism Laboratory of

Barcelona, Escola Tecnica Superior

d'Arquitectura de Barcelona)

Maria Rubert de Ventós, represents a school from the Iberian Peninsula. Most interesting for the debate is her position as both a principal scientist of the Urbanism Laboratory of Barcelona (LUB), and associate professor of urban planning and design at ETSAB. She has also been professor of an International Laboratory of Architecture and Urban Design in Italy. Her work focuses on reading the city, understanding metropolitan landscapes, analyzing public space, improving urban transportation, designing infrastructure. In her field, she confronts ideologies with reality. She lectured at New York University (NYU), and a few schools in Latin America and Europe, like Winterthur, Kassel, Ferrara, Palermo, Venice, Paris, Versailles.

\section{Peter Staub}

(Institute of Architecture and Planning of the University of Liechtenstein)

Peter Staub is professor and chair Design and Theory at the Institute of Architecture and Planning of the University of Liechtenstein where he will be head of school starting from September 1th, 2016. He has completed his architectural studies at the Accademia di Architettura di Mendrisio, Switzerland, and at the Architectural Association School of Architecture in London. In addition, he completed a Master City Design and Social Science at the London School of Economics and Political Science. Next to his activities in research and teaching, Peter Staub curated in October 2014 with the international students of the University of Liechtenstein the first appearance of Liechtenstein at the Architecture Biennale in Venice. 
16.00

- Poster Exhibition in BK-exposition space next to Coffee Bar 'Sterk'

- Welcome \& Opening exhibition by Susanne Komossa, Maurice Harteveld

\subsection{0-17.30}

Orange Tribune, Oostserre

- Workshop 'Perspectives \& Possibilities of Open Access in Architecture \& Urbanism'

Frank van der Hoeven, Roberto Cavallo

\subsection{0-18.00}

Registration Oostserre

\section{$18.00-18.15$}

Orange Tribune, Oostserre

- Conference Opening by Roberto Cavallo, vice-dean of education

\section{$18.15-19.15$}

Orange Tribune, Oostserre

- Keynote lecture prof. Laura Lee (Carnegie Mellon University Pittsburgh) 'The Future of Architecture Education in the USA and Europe / view from a distance I'

\subsection{0 - 20.30 Opening}

- Reception/little snacks Oostserre

After the reception people can walk to the Delft city center to find a restaurant according to their 'gusto'

\subsection{0 onward}

Informal encounters at

Café Restaurant Vlanderen, Beestenmarkt 16 or Café Lef, Doelenplein 2, both in Delft
$8.30-9.00$

Late registers in front of Lecture Room A

EAAE Conference

$9.00-9.15$

Lecture Room A

- EAAE president Karl-Otto Ellefsen introducing the conference theme

\section{$9.15-10.00$}

Lecture Room A

- Keynote Peter Russel, dean Faculty of $A+B E$, 'For example Delft'

\subsection{0-11.15}

Lecture Room A

- Keynotes ofThomas Bock and Maria Rubert de Ventós presenting the profile specificities of the Technische Universität München and the Urbanism Laboratory of Barcelona (LUB), Escola Tecnica Superior d'Arquitetura de BarceIona

\subsection{5 - 11.45 Coffee break}

\section{$11.45-13.00$}

\section{Lecture Room A}

Keynotes of Peter Staub and Merete Ahnfeldt-Mollerup presenting the profile specificities of the Universität Liechtenstein and The Royal Danish Academy of Fine Arts, Schools of Architecture, Design and Conservation, Copenhagen

$13.15-14.15$

lunch Berlage Rooms

\subsection{5-15.30 2}

Parallel sessions Room $P \& Q$

- Discussion and responses by Thijs Asselbergs and Inge Bobbink to the morning keynotes of Thomas Bock (P) and Maria Rubert de Ventós (Q) addressing profiles, research and pedagogies in architectural education

Moderators: Roberto Cavallo and Eirene Scheurs

15.30 - 16.00 coffee break, in front of Lecture Room A

\section{$16.00-17.15$}

Parallel sessions Room P\&Q

- Discussion and responses by Daniel Rosbottom and Willemijn Wilm Floet to the morning key-notes of Peter Staub $(P)$ and Merete Ahnfeldt-Mollerup (Q) addressing profiles, research and pedagogies in architectural education

Moderators: Maurice Harteveld and Olindo Caso

\section{$17.30-18.30$}

Lecture Room A

- Keynote lecture prof. Diane Ghirardo (University of Southern California) 'The Future of Architecture Education in the USA and Europe / view from a distance II'

$19.00-21.00$

Diner Buffet, Berlage Rooms

\subsection{0 onward}

Informal encounters at

Café Restaurant Vlanderen, Beestenmarkt 16 or Café Lef, Doelenplein 2, both in Delft 
Friday, 2 September, General Assembly and Academies Day

$8.30-9.00$

- Late registers in front of Lecture Room A

EAAE General Assembly 9.00-10.45 Lecture Room A

Agenda

1. Presidents address to the GA

2. Report on membership and economy from the treasurer

3. New membership.

4. Organisational development

- Administration and management

- The EAAE Web

5. Elections

10.45 - 11.15 Coffee break

$11.15-12.45$

Continuation EAAE

General Assembly

6. Short reports, EAAE

Academies and

Projects:

- Report - Academy on Education

- Report - Academy on Research

- Erasmus+ program

7. Bordeaux 2017.

8. Work-plan 2016-2017

12.45 - 14.00 lunch, Berlage Rooms
$14.00-15.30$

Room $A$ and Rooms $P \& Q$

Presentations \& Work-

shops of:

- EAAE Academy on Education $(P)$

Moderator: Sally Stuart, Oya Atalay Frank and Johan De Walsche

- EAAE Academy on Architectural Research (Q)

Moderator: Johan Verbeke and Susanne Komossa

15.30 - 16.00 Coffee break

$16.00-17.00$

Concluding session

- Short presentations and round tables discussions addressing the EAAE academies, advocacy \& EAAE collaborations with the Architects Council of Europe (ACE), Dubravko Basic and Association of Collegiate Schools of Architecture (ACSA), Michael Monti.

Moderator: Adalberto Del Bo

$19.00-23.00$

Conference Closing Diner in Delft, Armamentarium, Korte Geer 1

23.00 - onward Informal encounters at Café Restaurant Vlanderen, Beestenmarkt 16 or Café Lef, Doelenplein 2, both in Delft
Saturday 3 September 2016, Excursion Day

$9.30-15.30$

Excursion to Rotterdam,

- Architectural Highlights Vis-a-vis a 'sustainable' future

Excursion to Amsterdam,

- Urban Experiments Vis-a-vis a 'sustainable' future

$15.30-17.00$

Encounters with Dutch professionals

In Rotterdam an encounter and discussion will be organized on the future architectural education with representatives of 'arrivé' architectural at The New Institute (HNI), the former Netherland Architecture Institute.

Dirk van den Heuvel, HNI, Susanne Komossa

In Amsterdam a central meeting will be organized to encounter and discuss the urban future with urban designers and planners from practice/municipalities at the Amsterdam Institute for Advanced Metropolitan Solutions (AMS).

Arjen van Timmeren, AMS, Maurice Harteveld, Roberto Cavallo 


\section{MAPS OF THE FACULTY}

\section{FIRST FLOOR}

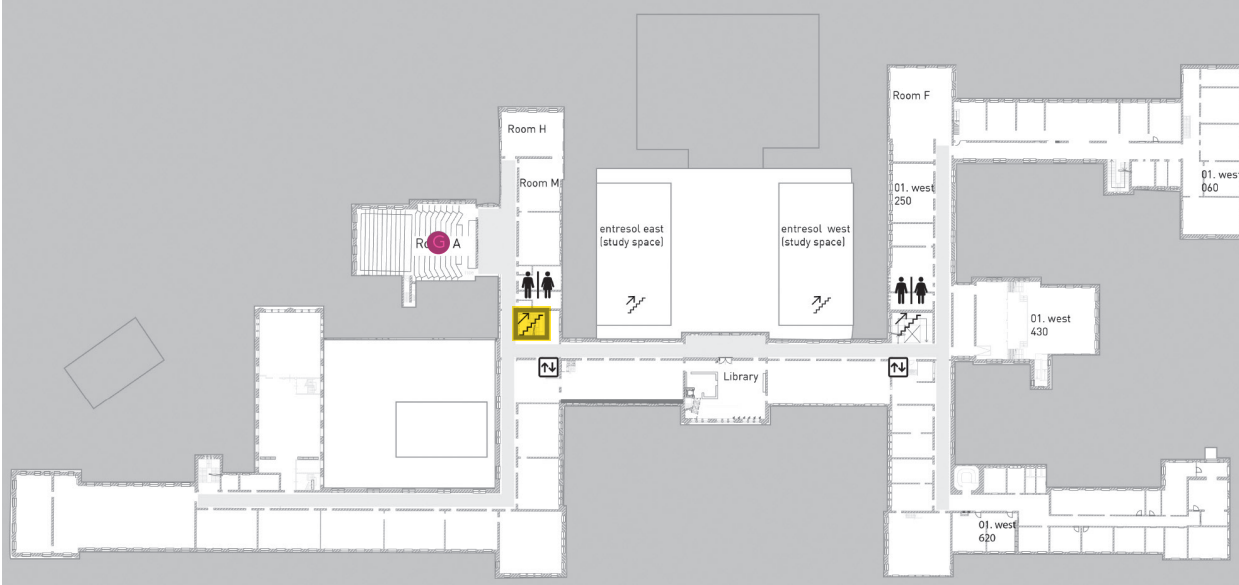

GROUND FLOOR

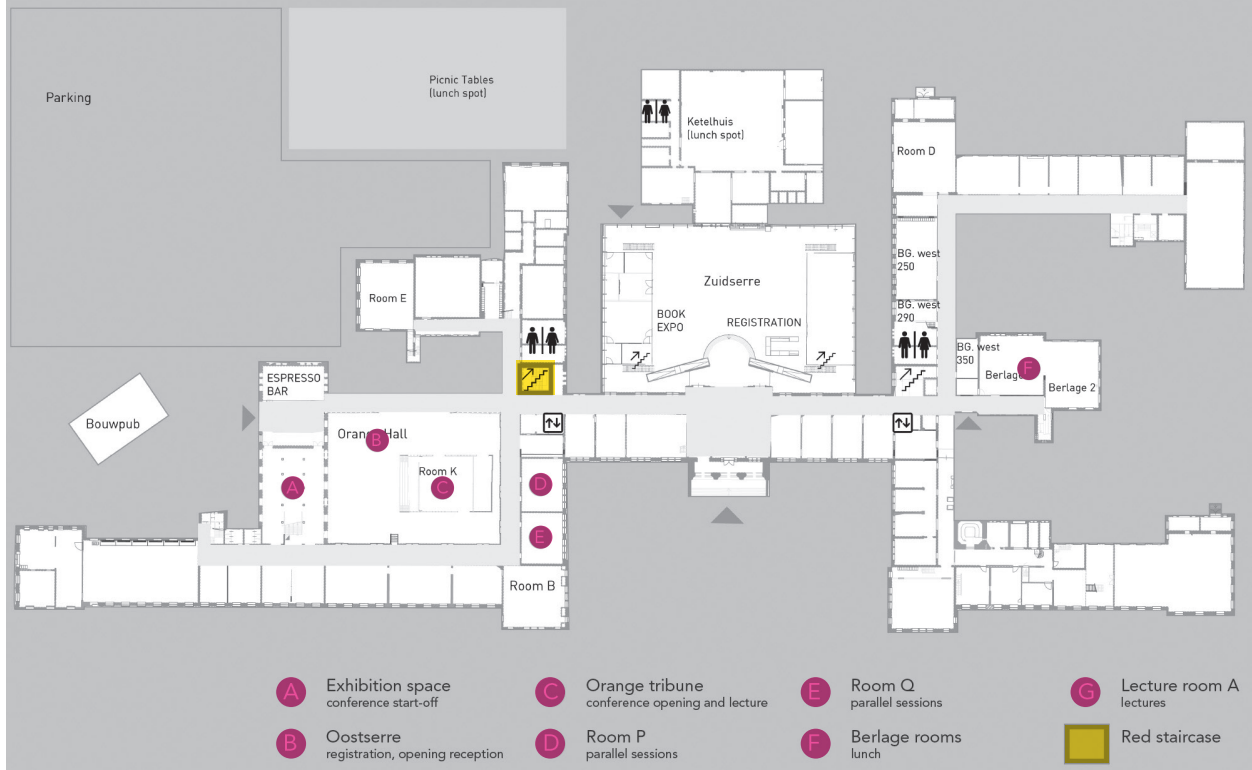




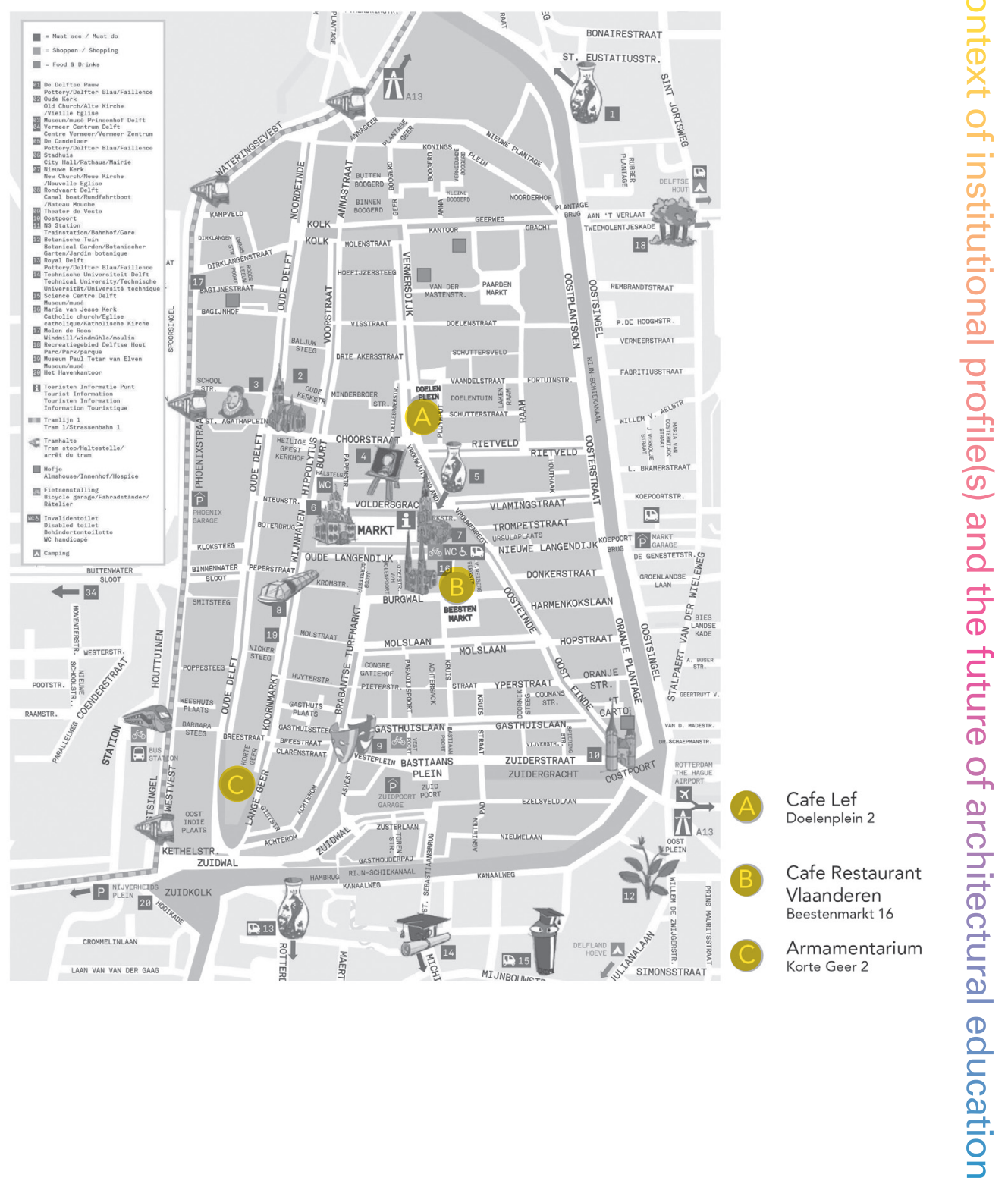




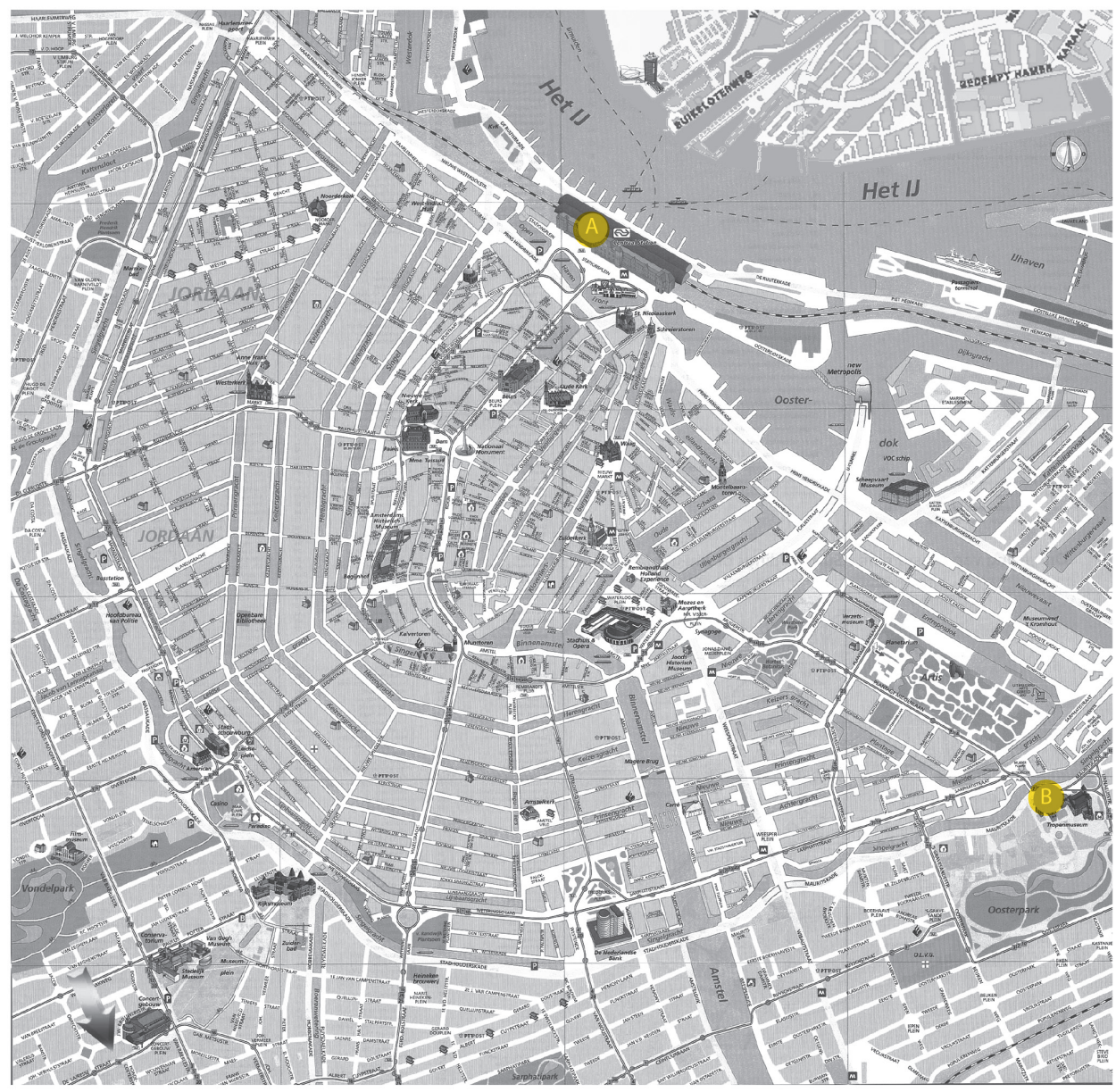

A Central train station

transportation hub

B Amsterdam Institute for

Advanced Metropolitan

Solutions (AMS)

located at in the Royal

Tropical Institute (KIT)
address: Mauritskade 63 


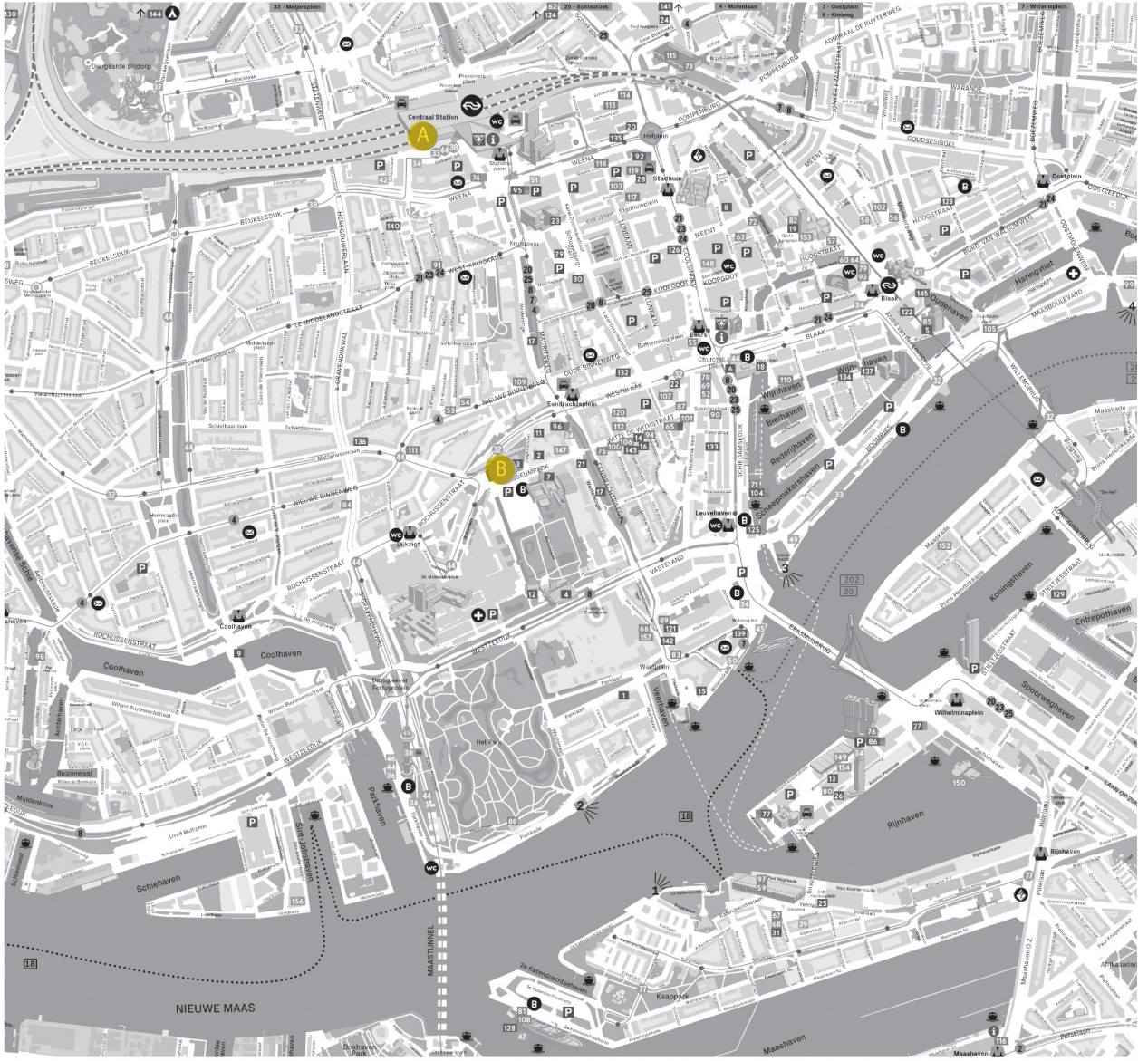

A Central train station

transportation hub

B The New Institute ( $\mathrm{HN}$ )

iscussion

$\frac{\text { D }}{\frac{2}{2}}$ 
9:00

Meeting at the entrance by Bus station in Delft Station NS

$$
9: 10-9: 20
$$

Taking train to the Rotterdam Central Station

$$
9.30-10.00
$$

Walking tour Rotterdam Central Station and a look at the Groothandelsgebouw

$$
10.00-10.45
$$

Walking to Schieblok, Luchtsingel and Water Retention Square $10.45-11.45$

Walk to Stadstimmerhuis and Market Hall

$$
11: 15-11: 45
$$

Have a coffee and look around in the Market Hall

$11: 45-12.15$

Walk to Erasmusbridge 12.19 (dep.)

Boat trip by Acqualiner from Erasmusbrug, Willemskade to Heijplaat RDM campus

$$
12.40-13.40
$$

Lunch in Dokkaffee, Heijplaatstr 3 (tel. 010-4291834)

$$
13.50 \text { (dep.) }
$$

Taking Acqualiner back from Heijplaat RDM to Erasmusbrug $14.10-15.00$

Walking to The Rotterdam on the Wilheminapier

$$
\text { 15:00 - 15:30 }
$$

Walking back to the New Institute along Kunsthal and through Museumpark $15.30-17.00$

Het Nieuwe Instituut (HNI) Encounters with professional Robert-Jan de Kort, Anne Loes Nillesen and Juliette Bekkering 17.00

Drinks

EAAE $2016 /$

HNI DISCUSSION:

Statements / paradoxes / challenges for future architectural education

1.

THE FUTURE OF ARCHITECTURAL EDUCATION IS RESEARCH-BASED

The only way to counter the fragmentation of architectural practice that we see around us, the diversity of clients and their demands, in combination with the different perspectives and backgrounds of 'nomadic' students and professors, the acceleration in technological developments, is by a research-based approach of architectural design.

2.

THE FUTURE OF ARCHITECTURAL EDUCATION WORKS TRANS-DISCIPLINARY

The power of new practices lies in inventive and effective ways of synthesizing knowledge from the most disparate disciplines and fields: from sociology and marketing survey to territorial control and geomatics, from visual studies and neuro-aesthetics to concerns of climate change and environmental design, architects need to understand the travelling of ideas. More than ever architects need to be able to operate in networks that bring together an array of specialists and stakeholders.
3.

THE FUTURE OF ARCHITECTURAL EDUCATION LIES IN THE PRODUCTION OF MEANINGFUL DIFFERENCES

The globalization of both architectural education and practice requires that we develop our capacity to produce meaningful differences (rather than spectacle and hype); context, culture and history are among the natural allies of architectural design here, but also new technologies need to be geared to generate diversity and specificity in response to people's needs. Paradoxically, new generic formats of information exchange and spatial organization might be the way to accommodate such diversity, like a new Classicism or International Style.

Dirk van den Heuvel, Susanne Komossa, August 2016 


\section{Rotterdam encounters:}

Robert-Jan de Kort (1979) received a master degree in architecture from the TU Delft in 2006. In 2003 he studied at the ETH Zürich in the studio of Christian Kerez. Driven by a journalistic interest in his profession, he has written in various media on architecture for over ten years. After winning the Europan 9 competition in 2008 he developed his own practice in which design and appraisal are constantly querying, competing and influencing one another. Besides working on commissions and competitions, Robert-Jan contributed to ArchiNed, Architectenweb Magazine and (later) to the Dutch Design Yearbook and the publication of the Prix de Rome 2014. He was also part of the juries of the Rotterdam Architecture Award (2011) and the Hedy d'Anconaprize for healthcare architecture (2010-2016). As from 2016 Robert-Jan is editor of the Yearbook Architecture in the Netherlands.

In 2011 together with

Sander van Schaik he founded the Rotterdam based architecture office De Kort Van Schaik. De Kort Van Schaik aims to realize carefully crafted architecture projects with a significant public impact.

Websites:

www.dekortvanschaik.nl www.TALKS-about-architecture.eu
Anne Loes Nillesen is the founder and owner of DEFACTO Architecture \& Urbanism. The company is specialized in urban research and design in the domain of water and flood risk management. Anne Loes has worked on large-scale complex urban design and flood risk management projects. Examples are the Dutch Delta Programme and the Bangladesh Deltaplan. She also worked on local scale adaptation projects such as a land barrier design for Houston. DEFACTO was founded in 2006 and is located in Rotterdam, The Netherlands.

In 2009 Anne Loes founded the Climate Adaptation Lab and the Delta Interventions integral MSc graduate studios at Delft University of Technology, Faculty of Architecture. As a PhD candidate, she studied the relation between urban design and flood defence strategies. She graduated with honours as an Architect and Urban Designer in Delft, and undertook postdoctoral studies in Landscape Architecture and Urbanism at the Berlage Institute in Rotterdam.

Anne Loes is the author of multiple books and articles. Key books are 'Amphibious Housing in the Netherlands' and 'Delta Interventions, Design and Engineering in Urban Water Landscapes'; the article 'Improving the Allocation of Flood-Risk Interventions from a Spatial Quality Perspective' is among the most-read from the Journal of Landscape Architecture (JOLA).
For more information on projects and publications, see www.d.efac.to

Juliette Bekkering graduated as an architect from Delft University of Technology in 1989. In 1993 she completed a postgraduate course in urban design at the Polytechnic University in Barcelona. Having worked with a variety of architectural firms, including OMA (Office For Metropolitan Architecture) and Neutelings Riedijk, she founded her own firm in 1997, now called Bekkering Adams Architects that she heads together with Monica Adams. Renowned designs of hers are the headquarters of Esprit in Amstelveen, the Boostergemaal Oost in Amsterdam, the headquarters of the Schuurman Group in Alkmaar and the fire stations and school in Doetinchem and Rheden.

Recently the project for a school campus in Peer (Belgium) was completed.

Different designs are at the cutting edge of architecture and engineering, and her work combines design and research into an inseparable whole. Since 2013 she is Professor at Eindhoven University of Technology, leading the chair of Architectural Design and Engineering. The synthesis between architecture and research, as developed in her work, establishes a profound basis for education and research within her chair. Core themes are research into sustainability, shifting typologies and innovative architectural technologies. 
Furthermore she is vice-chairman of the department of Architecture and Urbanism (AUDE).

Her work is published worldwide and she has been represented at various national and international exhibitions. Her designs have won a wide range of awards and was exhibited at the Architecture Biennale of Venice 2014. Previously Juliette Bekkering was visiting professor of Architecture at the Czech Technical University in Prague.

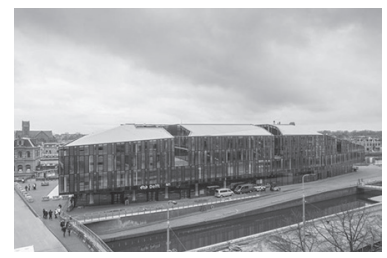

Station Building Delft

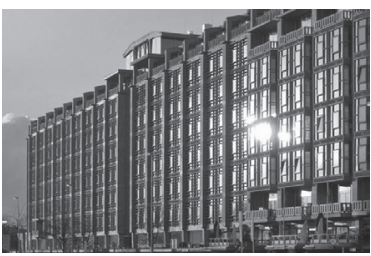

Groothandelsgebouw

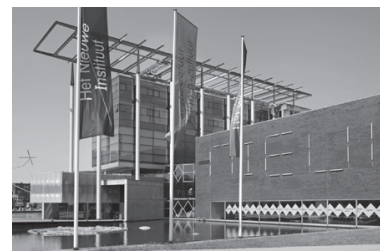

The New Institute

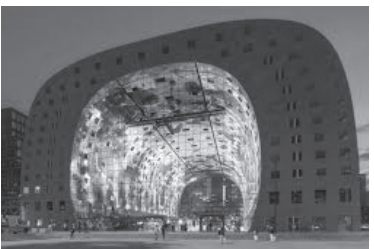

The Market Hall

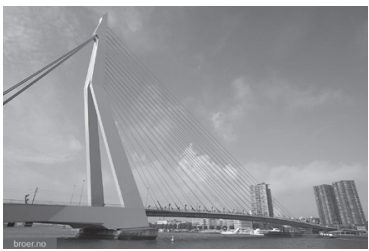

Erasmus Bridge

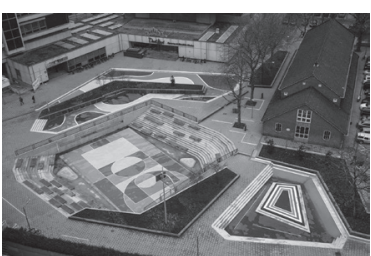

Water Square Rotterdam

Benthemplein



Rotterdam Centraal



Schieblock

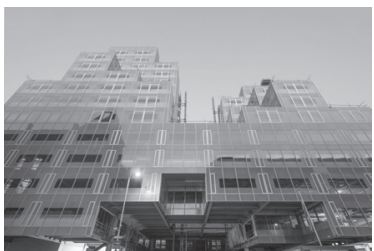

Stadstimmerhuis

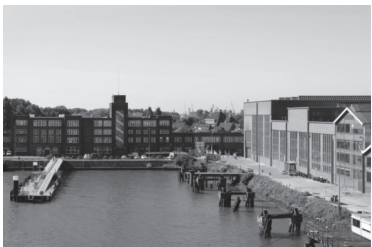

RDM

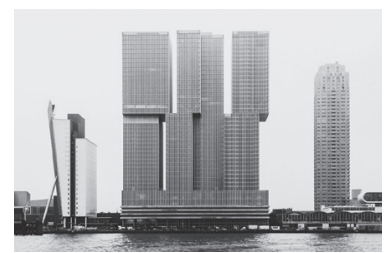

De Rotterdam 
9:00

Meeting at the main hall of

Delft Station NS 9:19

Departure Intercity train to Amsterdam Central Station, platform 1 10:17

Arrival Amsterdam Central Station, platform 2a 10:17 - 10:40

Look in and around the renewed station; walk towards exit Noord (beyond platform 15) and reach the Public Ferry Terminal at the northern side of the station $10: 45$

Departure Ferry to NDSM Werf (NDSM wharf) From the ferry look at Eye, Westerdokseiland, Westerdok, Overhoeks, Silodam)

11:00-11:30

Quick visit at the NDSM werf 11:30-11:45

Ferry back to Central Station

$$
\text { 11:45-12:30 }
$$

Visit to Eye (including

2x ferry), project by

Delugan Meissl Associated

Architects, Vienna

www.dmaa.at/projekte/

detail-page/eye-film-

institute.html

$12: 30-12: 50$

Walk along the IJ, under railway track to

Oosterdokseiland 12:50

Arrival at the OBA Public Library Amsterdam by Jo Coenen Architects \& Urbanists www.jocoenen.com/jcau/ index5.html\#
13:00-13:45

Lunch at La Place, upper floor OBA building (nice view of Amsterdam city centre)

\section{3:45-15:00}

City walk passing by Nemo (Renzo Piano), Arcam (Rene' van Zuuk), Artis, arriving at AMS (alternatively by tram \#9, stop at Alexanderplein) 15:00

Arrival at AMS

www.ams-amsterdam. com/home/ 15:10

Welcome by Arjan van Timmeren, scientific director AMS $15: 20$

Presentation by Wil Zonneveld (the city, old and new challenges) 15:40-17:00

Encounter with practitioners; presentation and discussion with 3 offices:

- Jo Coenen, Architects \& Urbanists

- Machiel Spaan, principal at $\mathrm{M} 3 \mathrm{H}$ www.m3h.nl

- Wouter Valkenier, principal at Studio Valkenier studiovalkenier.nl 17:15

\section{Drinks}

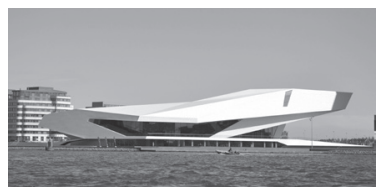

Amsterdam Eye

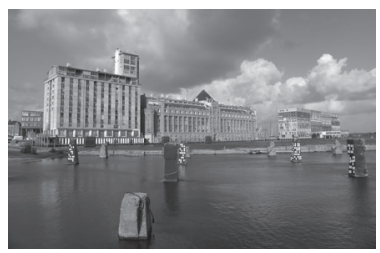

Silodam

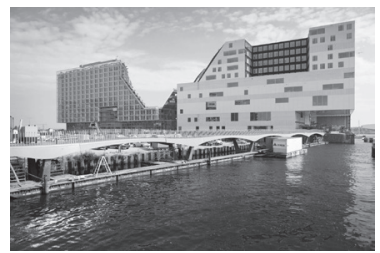

Oosterdokseiland

$\&$ Courthouse

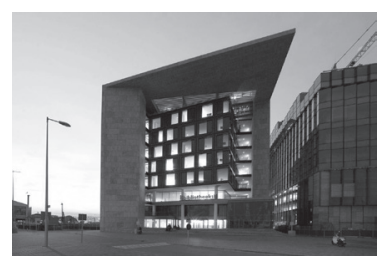

Public Library



Arcam

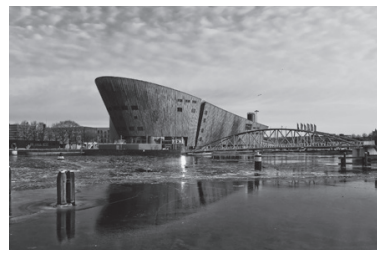

Nemo 
Faculty of Architecture and Arts, Hasselt University, Belgium

\section{universiteit $\rightarrow$ hasselt KNOWLEDGE IN ACTION}

\begin{abstract}
DESIGN FOR LIFE
The faculty of Architecture and Arts organizes education, fundamental and applied research, and community service within the disciplines of architecture and interior architecture, and research and community service within the arts. The faculty offers students, teaching staff, and researchers a context to develop to a level of excellence in an international context, with a clear focus on social responsibility. In all activities of our faculty, humans are the focal point - Design for Life is our motto.
\end{abstract}

HAND, HEAD, HEART The faculty of Architecture and Arts educates architects with a wide variety of skills, architects who know how to design well based on a research attitude and who know how to manage projects. In our study programme we bring together hand, head, and heart. Designing is a work of the hand, that needs fuel from images in the head - Images that require reflection, context, and knowledge. But design is also a work of the heart. Our bachelor and master students are educated as architects who design with passion, empathy, and generosity.
RESEARCH WITH A GENUINE IMPACT

The research activities of the faculty are structured in two research groups: ArcK for research related to (interior) architecture and MAD-Research for research related to the arts. Our research has a clear vision: we perform spatial research on topics that are societally relevant, from an international, academic perspective, but with the ambition to have a genuine impact. Our engagement towards society is evident in the themes of the main lines of research in ArcK: Adaptive Reuse/Trace, Spatial Capacity Building, Sustainability, Designing for More and FRAME. More info: www. fac-ark.be/arck

\section{DATA AND STATISTICS}

Student numbers: Approximately 550 students in architecture and interior architecture and over $30 \mathrm{PhD}$ students in (interior) architecture or the arts.

Staff size: Over 130 staff members: full-time and part time teaching staff, visiting lecturers, guests, researchers, and administration.

Facilities: Library, campus bookshop, cafeteria, extensive modeling workshop, plot center, printing facilities, drawing studio, photo studio, computer rooms,...

Curriculum \& Degrees in short: Bachelor in de architectuur (Bachelor of Architecture

- 3 years - 180 ECTS)

Bachelor in de interieurarchitectuur (Bachelor of
Interior Architecture - 3 years - 180 ECTS)

Master in de architectuur (Master of Architecture 2 years - 120 ECTS)

Master in de interieurarchitectuur (Master of Interior Architecture - 1 Year - 60 ECTS)

Master of Interior Architecture (International master with focus on adaptive reuse - 1 year 60 ECTS)

PhD programme in (interior) architecture and the arts

\section{ADDRESS \& PRACTI-} CALITIES

Hasselt University - Faculty of Architecture and Arts Campus Diepenbeek Agoralaan gebouw $\mathrm{E}$ 3590 Diepenbeek - Belgium 003211292101

architectuur@uhasselt.be www.fac-ark.be www.uhasselt.be/fac-architectuur-en-kunst http:// www.uhasselt.be/Master-of-interior-architecture-adaptive-reuse KU Leuven, Faculty of Architecture, Campuses Sint-Lucas Brussels and Ghent

Faculty of Architecture, Campuses Sint-Lucas Brussels and Ghent, KU Leuven, Belgium

\section{KU LEUVEN}

FACULTEIT ARCHITECTUUR

NEW FACULTY, OLD SCHOOL

Sint-Lucas School of Architecture was founded in 1862. In 2012, the school 
was integrated in the $\mathrm{KU}$ Leuven framework as the Faculty of Architecture. It has campuses in two cities, Brussels and Ghent. Each campus offers different contexts for study. The Brussels campus is smaller and the urbane atmosphere in the capital of Europe offers the experience of studying in a vibrant multicultural city with a rich programme of events. The Ghent campus places students in a larger school in a smaller city. This diverse multicampus context makes the school more interesting and dynamic.

ACADEMIC DESIGN OFFICES: USING EDUCATION AS BRIDGE BETWEEN THEORY AND PRACTICE

The KU Leuven Faculty of Architecture is developing Academic Design Offices (ADO): multidisciplinary collaborations where practice and research meet in practice based research studios. By learning students their own strengths and roles in a multidisciplinary framework, ADOs prepare them for their future role in a professional context. Too much focus has been put on the distinction between theory and practice, between research and design. The Faculty of Architecture wants to dissolve these distinctions by bringing both worlds together in the educational setting of the ADO.
ARCHITECTURAL RESEARCH BASED ON AN ARTISTIC TRADITION WITH A HUMANE AND SOCIO-SCIENTIFIC DIMENSION

At KU Leuven, Campus Sint-Lucas shares a research department with the architectural engineers. Research at the Department of Architecture strongly believes in the wide spectrum of topics and wideranged view on the many ways in which research in architecture can be generated. It departs from the disciplines of architecture, interior architecture, urban development and spatial planning themselves, and nurses design as a shared focus. The connection and interaction with the professional design practice is crucial, because within the practice as well, knowledge is generated.

DATA AND STATISTICS

Student numbers: 1853 students

Staff size: 247 staff members

Facilities: The Faculty of Architecture has campuses in 2 cities, Brussels and Ghent. In both cities, we share facilities with LUCA School of Arts. In Ghent, our main facilities are in an old monastery building. In Brussels, our campus is housed in a converted warehouse building. Both cities are centrally located and are easily accessible from anywhere in Europe or beyond. Both Ghent, the historic heart of Flanders, and Brussels, the capital of Europe, provide students with a particularly invigorating environment, combining the most diverse aspects of architecture with unexpected cultural opportunities to widen

one's own frame of reference. Both Brussels and Ghent are historical and dynamic cities, modern architectural and cultural centres, offering a full-option architectural, social and historical landscape. The Sint-Lucas

campuses are wellequipped base points from which students develop and engage in the contemporary discourse on architecture from multiple critical vantage points.

Students services are organised by Stuvo in cooperation with LUCA School of Arts. Stuvo tries to provide the best possible study environment for their students and is active in different extracurricular domains such as health, accommodation, sports and culture, financial aspects and psychosocial guidance.

Curriculum \& Degrees in short: The Faculty of Architecture organises two Dutch-taught bachelor programmes: architecture and interior architecture. After obtaining their bachelor degree in architecture, students follow the Dutch or English-taught Master of Architecture or choose the Master in Urban Design and Spatial Planning (in Dutch). 
Students with a bachelor degree in interior architecture follow the Master in Interior Architecture (in Dutch).

All bachelor and master programmes have a clear balance in theoretical and practice oriented courses. The design process is the core of our education. It also defines the trajectory of our graduates' later practice or research career. The courses in Mixed Media offer the students the chance to develop their own personal visual language.

\section{ADDRESS \& PRACTI- CALITIES}

KU Leuven

Faculty of Architecture Hoogstraat 51 9000 Ghent (Belgium) Paleizenstraat 65-67 1030 Brussel (Belgium) http://arch.kuleuven.be

LOCI Faculté d'architecture, d'ingénierie arch., d'urbanisme, Université Catholique de Louvain UCL, Belgium

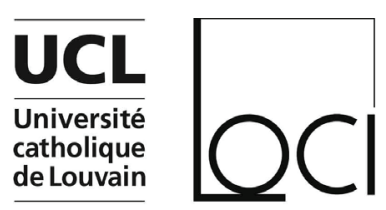

THE FACULTY IN ITS 3 DIFFERENT CAMPUSES ENVIRONNEMENT

Louvain Catholic University has played a part in the European Higher Education system since 1425 . LOCl (latin for locations) is one of its latest innovations resulting from the inclusion in 2010, of its existing architecture, architectural engineering and urban planning curricula (LLN), with those of two internationally renown schools of architecture, the former St-Luc Institutes of Brussels (BXL) and Tournai (TRN).

The Faculty boasts its new geographic location and the choice of diverse disciplines available, open to visitors and regular students on equal terms.

WHEN THE RICH DIVERSITY OF EACH LOCATION SERVES THE TEACHING PHILOSOPHY AGENDA

$\mathrm{LOCl}$ was founded in 2010

thanks to a legislation which allowed the partners to implement their eagerness to nurture closer relationships between the fields of research and searching.

Each of the campuses keeps its own identity, which gained them acknowledgment, but share a common concern for the ethical responsibilities of the design professions of nowadays.

The coexistence of different programmes in the same Faculty allows each campuses to benefit from their individual strengths, thus broadening the course offers and favouring the possibilities for students, faculty and researchers mobility.
WHEN RESEARCH \&

PHD PROGRAMMES

SUCCEED IN INFLU ENCING THE INSTITUTIONS

$\mathrm{LOCl}$ organizes research and PH D curricula in most of the major fields of architecture, architectural engineering, and urban planning. Faculty and researchers enjoy a variety of regional, national and international joint ventures with their colleagues in Europe, in North and South America, and around the world. Competitive in the search for funding at all levels, LOCI influences strongly the environment of architectural and urban research.

Principal research topics:

- Environmental sustainable development,

- ArchitecturalTheory and History

- Urban planning, Urban Design and Planning

DATA AND STATISTICS

Student numbers: 1550 students (1100 Bachelor degrees, 400 Master degrees, $50 \mathrm{PhD} 30 \%$ foreign students

Staff size: 91 Staff members (33 full-time and approx. 58 visiting lecturers and critics)

Facilities: Architecture and Urban planning students at LOCI have the opportunity to participate in a large variety of special activities beyond the strict framework of the course curriculum. Some of these - parties, "charrettes, " film viewings - are organized by the students themselves. 
Others - such as study trips, lectures, exhibitions - are organized by the school itself.

Both regular and visiting students have access to facilities and courses at all three campuses, although they are expected to be registered with one particular campus, and any design studio assignment will normally be carried out at that particular campus.

CAD - Lab, Library, Model shop, Plot centre, Structures Lab

Curriculum \& Degrees in short: For the international students of the recognized partner schools, standard application requirements include grade reports and portfolios. For the regular diploma-seeking students, requirements vary according to the level of their studies and background.

Working Language:

French; very few architecture courses are given in English, but some other curricula (mainly Engineering and Management studies) have more thorough offers.

Please contact the school for further information.

Bachelor degrees curriculum : 3 years Architect or Architect-Engineer (180 ECTS) Master degrees : 2 years Architect or Architect-Engineer (120 ECTS)

Additional Master : 1 year (or 2 half-times) Urban planning (60 ECTS)
ADDRESS \& PRACTICALITIES

UCL/LOCI Faculté d'Architecture d'Ingéniérie Arch. d'Urbanisme 1 place des Sciences bte L6.05.01 1348 Louvain-la-Neuve Belgium

Contact person : France Pecher Administrative DirectorT +32 (0)10 472815 $\mathrm{F}+32(0) 10472829$

Email: doyen-loci@uclouvain.be www.uclouvain.be/ loci.html

\section{Faculty of Architecture \\ La Cambre Horta, Université libre de Bruxelles, Belgium}

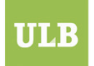
Faculté
d'Architecture
La Cambre Horta

TAKING PART IN SOCIETY PROGRESS IN PHASE WITH

THE EMERGENCE OF A NEW SCENE OF ARCHITECTURE IN BXL

In 2012 the Faculty of Architecture of Université libre de Bruxelles was founded by merging two important French speaking schools of Architecture in Brussels: La Cambre and Victor Horta Institutes. It gave rise to a leading education and research institution in the field of architecture, urbanism and landscape design located in the heart of the European Capital. The Faculty looks at grounding its training and research by design approach on current social, economic and ecologic problems posed by our contemporary spatial environment.
A TRANSDISCIPLINARY AND MULTICULTURAL CURRICULUM ENGAGING

THE MULTIPLE PRACTICES OF ARCHITECTURE

In our Faculty, design is a practice where disciplines meet and strive for mediation. More than ten design studios are vertically organized across the third bachelor and the two master levels. The studios confront students to the different ways of understanding the profession of architect, ranging from studios taking the autonomy of the discipline as a viewpoint to those exploring inclusionary working styles and open to less established practices and knowledge. It is a priority goal of the Faculty to bring our students in contact with the diversity of practicing architecture.

AN EXPERIMENTAL RESEARCH ENGAGING THE CULTURAL, SOCIAL AND ECOLOGICAL CHALLENGES OF EUROPE

The two research centers of the Faculty, Clara \& Habiter, take part in large scale regional and European interuniversity research projects (e.g. micmarc. ulb.ac.be, www.metrolab. brussels, modscapes.ulb. be) which focus on primordial contemporary cultural, social or ecological challenges of Europe. A part of these research projects includes also the active collaboration with institutions from countries of sub-Saharan Africa (Congo, Ethiopia, Benin) and aims to contribute to sustainable 
capacity building in the

global South.

DATA AND STATISTICS

Student numbers: 1191

students in architecture

(766 Bachelor, 375 Mas-

ter, $50 \mathrm{PhD}$ )

172 students in landscape architecture (88 Bachelor, 84 Master)

$49 \%$ female, $51 \%$ male, $57 \%$ foreign (45 different nationalities)

Staff size: 173 Staff members, mostly part-time. The staff members reflect the aim for diversity of the architecture practice, and include academic staff members and professionnals

Facilities: Library of $500 \mathrm{~m} 2$ with numerous titles and subscriptions to numerous periodicals. Archive center with private collection of numerous belgian modern architects. CAD - lab, cafeteria, cook \& book, copy center.

Fablab workshop: including 3D printers, laser cutters and CNC milling machines. Photographic studio, plot center, and printing facilities.

Curriculum \& Degrees in short: Bachelor of Architecture, 3-year program, (180 ECTS), Bachelor of Landscape Architecture, 3-year program, (180 ECTS), Master of Architecture, 2-year program (120 ECTS),

Master of Landscape Architecture, 2-year program (120 ECTS), Doctoral degree in architecture and urbanism (4 years),

Forthcoming Post-master program in Urban management \& Restaura- tion of Cultural Heritage

(60 ECTS each)

ADDRESS \& PRACTICALITIES

Université libre de Bruxelles

Faculty of Architecture La

Cambre Horta 19 Place

Flagey

1050 Bruxelles Belgium

archi.ulb.ac.be

Faculty of Design Sciences, University of Antwerp, Belgium

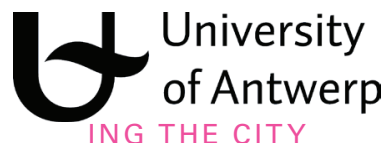

The school is a place for academic education oriented towards a profession which values: taking care of the built and non-built environment; creativity; passion for design as a socio-cultural act and matter; intellectual ambition; multidisciplinary collaborations; international orientation; synergy with the Antwerp metropolitan and old harbor context. It is a place where the student develops into a strategic thinker and designer who conceives realizable architecture, who contributes to the architectural debate, and who takes ownership and accountability in a multidisciplinary context.
BY DESIGN, EDUCATING CREATIVE CRITICAL CITIZENS

The academic bachelor programme aims to stimulate intellectual ambition in the students and realizes the basic competencies to take care of the built environment as a designer, from a humanistic perspective and an openness to the world. The academic master programme focuses on an investigative disposition and research capacities. From generic academic and subject-specific competencies, the master student is able to specialize and to prepare himself to multidisciplinary practice. Keywords are: integrality; process and strategy; heuristics; reflective practice; confrontation; communication.

A HUMAN-CENTERED APPROACH TO DESIGN Research at the Faculty of Design Sciences is aimed at a human-centered approach to design in its full breadth, from cultural value and empirical research to user-based prototypes and design scenarios. It is structured in four research groups: Henry van de Velde (architectural sciences); Product Development; Heritage and Sustainability; Center for Urban Development. The Henry van de Velde research group has a strong focus on design and urban culture. The research unit ONTO (ONTwerpend Onderzoek) is dedicated to research by design, exploring the notion of urbanity in West European cities. 
DATA AND STATISTICS

Student numbers: 1535

students: 468 Architec-

ture; 314 Interior Ar-

chitecture; 410 Product

Development; 153 Con-

servation-Restoration;

90 Heritage studies; 100

Urban and Regional

Development

Staff size: 254 colleagues:

226 Teaching staff; 28

Administration

Facilities: Library of the University of Antwerp; Institutional Repository of the University of Antwerp; two : modeling workshops, including model making tools, 3D-cutters, 3D-printers, CNC milling machines; Light lab; cafeteria; print, plot and copy services. Computer classes.

\section{Curriculum \& Degrees in} short: Bachelor of Science, 3-year program (180 ECTS) : BSc in Architecture; Bsc in Interior Architecture; BSc in Product Development; BSc in Conservation-Restoration;

Master of Science, 1-year program (60 ECTS): MSc in Interior Architecture; MSc in Conservation-Restoration;

Master of Science, 2-year program (120 ECTS): MSc in Architecture, MSc in Product Development, MSc in Conservation-Restoration, MSc in Heritage Studies, $\mathrm{MSc}$ in Urban and Regional Development;

3rd cycle doctoral degree (Antwerp doctoral School): dr in architecture, dr in interior architecture, dr in urban and regional development, $\mathrm{dr}$ in conservation-restoration, $\mathrm{dr}$ in product development.

ADDRESS \& PRACTICALITIES

University of Antwerp Faculty of Design Sciences

Campus Mutsaard

Mutsaardstraat 312000

Antwerpen

Belgium

+3232651958

www.uantwerpen.be/en/

faculties/design-sciences/

Architectural Institute in Prague, Czech Republic



ARCHITECTURAL INSTITUTE IN PRAGUE

EUROPEAN URBANITY ORIENTATED SCHOOL OF ARCHITECTURE AND URBANISM

The first private college in Central and Eastern Europe offering state accredited BSc. and MA degrees in architecture and urbanism with English as language of instruction. The team consists of experts from academia, practice, construction and development industry and policy makers. Bachelors program in Architecture provides complex polytechnic, artistic and humanities-oriented basis of knowledge. Master program in Architecture and Urbanism offers education in humanities and urban studies related to planning, design and development of post-socialist European cities in a global context.
A TRANSDISCIPLINARY EDUCATION FOR COMPLEX BUILT ENVIRONMENT

Architecture design education is based on the scheme of vertical studios across three years Bachelors and two years Master program. Studio chairs are architects with wide experience in processes and problems of contemporary architectural practice. Education includes courses in philosophy, studies in theory and history architecture, contemporary discourses as well as basics in urban studies, social studies, public policies, building sciences, technology, infrastructure, landscape and territorial issues to prepare graduates to work in the complexity of the built environment.

DESIGN RESEARCH WITHIN STUDIO-ORIENTED EDUCATION Design research is currently conducted on the level of conceptual and practical investigations in vertical studios across Bachelor and Master Programs. New lines of theoretical research are being currently defined across themes of urban studies, development and policies; infrastructure, landscape, territory; contemporary discourses in architecture and heritage with the focus on Center-East European urbanity researched in global context. 
DATA AND STATISTICS

Student numbers: 60 students $58 \%$ female, $42 \%$ male

$90 \%$ foreign, $10 \%$ local

Staff size: 48 Staff members

full-time core faculty and academic management, mostly part-time tutors and lecturers regular visiting lectures and critics

Facilities: 2 open space studio workshops

Library with 1,500 titles and subscriptions to numerous periodicals, digital map archive. CAD - lab, copy center, 3D printer

Modeling, sculpture and painting studio

Curriculum \& Degrees in short: Bachelor in Architecture, 3-year program, (180 ECTS) Master in Architecture and Urbanism, 2-year program (120 ECTS)

The plan to start a new international school of architecture in Prague was born in 2005 in a group of people around architect Martin Roubik (1949-2008).

ARCHIP is a private college operating with permission on state authority under Section 39 of the Act No. 111/1998 Coll., on higher education, taking the form of a decision of the Ministry of Education, Youth and Sports of the Czech Republic dated on April 29, 2010.

ADDRESS \& PRACTI-

ARCHIP CALITIES

Frantiska Krizka 1

17000 Prague 7

Czech Republic
+420240201161

info@archip.eu

www.archip.eu/

Faculty of Architecture, Czech Technical University, Czech Republic
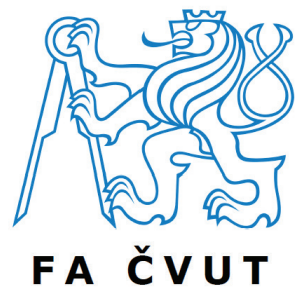

FACULTY OF ARCHITECTURE AS A CROSSPOINT OF TECH NIQUE AND ART

Faculty of architecture is one of eight faculties of an old technical university, only one with mixed curriculum - technical $x$ artistic. Strong tradition reaching till the period of Czech functionalism is enriched by personal approach of best country's architects in "vertical studios" after 1989. The basic architectural program $(\mathrm{A}+\mathrm{U})+$ Industrial design (D) and Landscape architecture (LA) during last years. The largest Faculty of architecture in Czechia is a platform for new ideas in the field of architecture, landscape and design.

\section{EDUCATIONAL AP- PROACH BASED ON LONG TERM TRADI- TION AND EXPERI- MENT}

The study curriculum based on three components knowledge of technique - ethical consciousness - design ability in design studios - constitutes the main line in the 3 years of Bachelor study. During two years of Master study the student can follow "general course" A+U / D

/ LA, or specific additional "modules" in Monumental Care or Spatial Planning. The main task in whole study is designing in one of 35 design studios bringing very different experience from traditional to experimental (see website www. fa.cvut.cz).

\section{FACULTY RESEARCH} PROFILE RELATED TO COUNTRY'S SPECIFIC PROBLEMS

Research program related to specific interest of 16 departments from large scale planning problems to detailed design and environmental questions. The activities concentrated in Research Center of FA - internal and external research grants. Specific activities related to the historical heritage in the VCPD. Center is recognized as advanced laboratory specialized in rich history of Czech Industry 19th and 20th century. The activities of Urban Design and Spatial planning related to the problems of Czech post-war housing estates and problems of Urban planning methods.

\section{DATA AND STATISTICS}

Student numbers: 1800 students (940 Bachelor, 700 Master, $160 \mathrm{PhD}$ )

Staff size: 166 Academic staff members, 85 visiting lectures and critics +50 supporting staff

Facilities: Study center, library and subscriptions to numerous pe- 
riodicals, map archive.

Archive of historical documents.

Archi-café, CAD - lab, copy center, mensa, documentation center, Modeling workshop: including 3D printers, laser cutters \& other machines. Photographic studio, plot center, and printing facilities

Sculpture \& painting studios. Faculty is across the road to Czech National Technical Library.

Curriculum \& Degrees in short: Bachelor of Science, 3-year program, (180 ECTS),

- Bachelor of Science in Architecture degree $=$ Bc. Arch. Bachelor of Art, 3-year program, (180 ECTS),

- Bachelor of Art, Industrial design $=$ Bc. Art. Master of Science, 2-year program (120 ECTS),

Master of Science in Architecture degree $=$ ing. arch. Master of Art, 2-year program (120 ECTS),

Master of Industrial design $=$ Mg. Art. Research:

4 accredited PhD programs (Doctor of Philosophy):

ArchitecturalTheory \& history

Monumental Care \& Reconstruction

Urbanism (incl. Spatial Planning)

Building Technology

Research Center of Industrial Heritage (VCPD) Research Center of Faculty of Architecture (VCFA) Different courses of Lifelong education
ADDRESS \& PRACTICALITIES

Czech Technical University

Faculty of Architecture

Thákurova 9

CZ 16663 Praha www.

fa.cvut.cz

National School of

Architecture and Landscape of Bordeaux, France

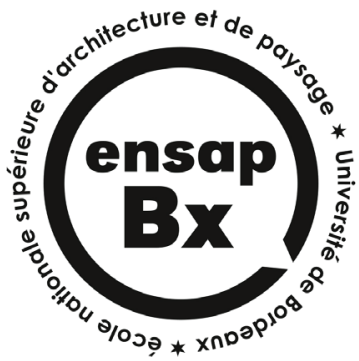

A PUBLIC SCHOOL OF ARCHITECTURE, LANDSCAPE AND

PLANNING, ORIENTED TOWARD SOCIETAL CHALLENGES

Located in Bordeaux, ensapBx has developed a strategy of partnerships with other schools and universities, with local and regional authorities, with cultural actors and professional organizations, linking pedagogy and research to social and global changes. It offers multidisciplinary environment for studies and research, being for example the first French ENSA to create a landscape architecture program. The school is also open on the world with several joint-programs abroad. We believe that our responsibility is to participate in meeting societal challenges at all levels.
A PEDAGOGY FO CUSED ON DESIGN, MULTIDISCIPLINARY KNOWLEDGE, AND

ON A CULTURAL AP. PROACH

Offering distinct programs in architecture and landscape architecture, leading to accredited national master degrees, the school also offers several multidisciplinary post-graduate programs in planning, ambiance and international practice. Pedagogy is focused on design, with a real emphasis on studios and on-site exercises. 70\% of teachers are involved in practice, ensuring that student skills are adapted to professional situations. Initiation to research is compulsory, as good design should be based on solid reflexive capacity.

DOCTORAL AND RESEARCH ACTIVITIES AFFILIATED WITH THE NATIONAL CENTRE FOR SCIENTIFIC RESEARCH (CNRS)

With 3 research teams composed of academics and professionals, research activity is based on contracts and institutional programs mainly focused on 3 topics: spatial reconfiguration facing global changes (UMR Passages), social dynamics from the dwelling to the metropolis (PAVE laboratory), ambiances and environmental issues (GRECCAU laboratory). Findings are directly transferred to pedagogy, with each research team being involved in the bachelor and master programs. Doctoral students are integrated in research activity and teaching, and have access to laboratory 
and University resources.

DATA AND STATISTICS

Student numbers: 1050

students (Architecture

800 / Landscape 150 /

80 Master of University

of Bordeaux / $20 \mathrm{PhD}$ )

Staff size: Teaching staff members: 110

Architecture $(78+7$ Professors) / Landscape $(23+$ 2 Professors) Administration staff members: 50

Facilities: Library: documentary collection of 17,500 books - monographs and research reports - 1700 degrees, 120 periodical subscriptions, 1000 maps, aerial photos, slides 15000 , 190 videos, 210 DVDs and $200 \mathrm{CDs}$.

Model's Atelier: equipped to work wood, cardboard, polystyrene and Plexiglas.

Stationary machines: saw a format, band saw , jointer planer, handset , suction unit for dust, lapidary, shaft grinder , polystyrene cutters , saws Fret, radial saw, drill column, reel.

Digital part: 1 cutter and size $1000 \times 700 \mathrm{~mm}$ laser engraver. $13 \mathrm{D}$ $600 \times 400 \mathrm{~mm}$ size milling machine using 3D software.

Curriculum \& Degrees in short: Architecture studies: DEEA - Bachelor of Architecture (180 ECTS)

DEA - diploma of architect equ. Master of Architecture (120 ECTS)

HMONP - habilitation to work in his own name, exercice's licence of architecture.

Landscape design studies:
CPEP - preparatory course for landscape studies (120 ECTS)

DEP - diploma of landscape designer equ. Master of landscape design(180 ECTS) Research, postdoc and PhD programs.

3rd cycle doctoral degree (3 years): PhD of architecture and $\mathrm{PhD}$ of landscape design.

Participation in 3 masters of university of Bordeaux: "Urban planning" master

“Environment, landscape and urbanism" master "Environment and comfort in architecture" master

Post master "ReBuilding the World" (bottom-up design strategy in developing countries).

\section{ADDRESS \& PRACTI-} CALITIES

Ecole nationale supérieure d'architecture et de paysage de Bordeaux 740 cours de la Libération CS70109

33405 Talence cedex -

France $T+33$ (0)5.57.35.11.00 ensapbx@bordeaux.archi.fr www.bordeaux.archi.fr

MSA | Münster School of Architecture, Fachhochschule Münster, Germany

\section{MSA $\begin{aligned} & \text { Architektur } \\ & \text { Münster School of Architecture }\end{aligned}$}

A PLACE FOR REFLECTING THE BUILT ENVIRONMENT

The roots of the MSA go back to the foundation of the Royal School of Construction over a century ago. On the basis of its long tradition and the rec- ognised quality of its training, the MSA introduced tiered five-year Bachelor and Master studies of Architecture according to the UNESCO Standards of the Union Internationale des Architectes (UIA). The leading role played by the MSA with regard to the Bologna Process is substantiated by the fact that the MSA was the first school of architecture in the whole of Germany to be accredited up to 2011 and notificated to the EU-Derective.

DESIGN STUDIES AS A PROCESS OF ARTS AND SCIENCES

It is a distinctive feature of the MSA that the teaching is conducted in small groups and led directly by the professors. The seminars are complemented and enriched by the support of experienced students who serve as project-orientated tutors. This model of student tutors contributes significantly to the efficiency and sucess of the programmes in the school. The students are intensively supervised in small groups by a team of 19 professors, 30 guest professors and assistants and over 60 tutors. With this structure, direct contact and dialogue with the professors remain in the foreground.

DESIGN BASED RESEARCH EVALU ATES TEACHING In view of a constantly and rapidly changing market and an increasing complexity of the architecture profession, the MSA is very concerned with permanent- 
ly and innovatively expanding and further developing its competencies in teaching, research and the corresponding infrastructure. Most of the staff-members are active in research with their own international architectural projects or are involved in research of renowned offices.

\section{DATA AND STATISTICS}

Student numbers: 850 students (550 Bachelor, 300 Master), 49\% female, $51 \%$ male

Staff size: 19 staff-members (14 full-time, 5 part-time), 64 tutors, 38 associate lecturers, 21 visiting lecturers, 8 scientific-technical staff

Facilities: library with about 50.000 titles and digital collection, material-library with over 600 objects, Bachelor- and Master-theses collection, CAD-Pool (over 50 Apple iMac's), DigiLab (robotic arm, lasercutters, 3D-printers, 3D-scanner, virtual-reality-lab, 3D-Pool (over 20 Apple iMac's), photographic studio, model workshop (wood, metal, concrete, plastic, spray booth), study center (150 seats), 11 studios

Curriculum \& Degrees in short: Bachelor of Arts, 3-year program, (180 ECTS), Bachelor of Arts in Architecture degree;

Master of Arts, 2-year program, (120 ECTS), Master of Arts in Architecture degree
ADDRESS \& PRACTICALITIES

University of Applied

Sciences Muenster MSA | Muenster School of Architecture Leonardo-Campus 5 48149 Muenster Germany www.arch.fh-muenster.de

Department of Architecture, Technical University of Munich (TUM), Germany

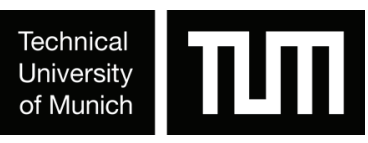

A DIVERSE, ENTRE-

PRENEURIAL AND

RESEARCH-ORIENTED APPROACH WITH AN INTENTION TO BUILD The Department of Architecture atTUM takes a research-oriented approach to teaching also in cooperation with businesses and public institutions - embedded in the vibrant living and research environment of the Greater Munich Area. It has a diverse portfolio of subject areas and good infrastructure. Its inner-city location in the artistic quarter of Munich is ideal for a school of architecture. TUM is one of Europe's top universities. We proactively bring results from research into market-oriented innovation processes and encourage an entrepreneurial spirit in all aspects of university life.
A TECHNICALLY-ORIENTED EDUCATION WITH A STRONG FOCUS ON CONSTRUCTIONAL DESIGN Our education is directed towards an intention to build. The exploration of complex aesthetic and spatial solutions is our primary objective. The Department gives architects the broad expertise to enable them to develop future strategies for the spatial and material evolution of society. The combination of the fields of energy-efficient construction, landscape architecture, restoration, timber construction, industrial design and curatorial practice sets TUM apart from other architecture schools. The basic education consists an integrated academic year abroad for all architecture students.

\section{LINKING SCIENTIFIC RESEARCH, DESIGN RESEARCH AND GO- ING REAL}

The Department lists more than 200 research and development projects that have been undertaken in the last three years. The TUM has a strong reputation for scientific research. At QS World University Ranking the Department ranks Top 1 in Germany and among Top 40 world wide. It is particularly well-connected with the other engineering disciplines at the TUM. Main areas of research include Digital Methods for the Built Environment, Rebuilding of Architecture, Timber Architecture, Urban and Landscape Transformation, Climate Responsive Design 
and Human Centered Design.

DATA AND STATISTICS

Student numbers: 1450 students (700 bachelor architecture, 600 master programs, 150 doctoral students), $55 \%$ female, $45 \%$ male, $35 \%$ foreign

Staff size: 29 full professors, 185 research associates, 35 staff, 20 adjunct professors and private lecturers, 50 lecturers, currently 10 visiting professors, 100 tutors

Facilities: Students can benefit from a professional working environment in the center of Munich. The teaching and research units together with the associated studios cover an area of nearly $19,000 \mathrm{~m} 2$ and the department provides some

1.000 student workplaces. These are equipped with high-speed internet, which are linked directly to the central IT services of the Leibniz Computing Center. The department is well equipped with technical facilities including the Technical Center (TZ) with workshops, labs and 24-hour services for students. Each year over 4.000 prototypes and models are built here. It includes workshops for woodworking, plastics, metalworking, computer-aided manufacturing, as well as the Solar Station, Artificial Sky Lab, High Performance Computer Working Center, Building Informa- tion Modeling Lab, and Robotics Laboratory.

The Architekturmuseum

is one of the most significant historical archives and platforms for curating architecture worldwide.

The TUM Graduate School offers an attractive further education programme and best possible support for doctoral students.

The Oskar von Miller Forum comprises spaces for events, 54 apartments for students and 8 apartments for visiting professors.

The Vorhoelzer Forum serves as a social venue and bel étage for the Department of Architecture. The top floor of TUM hosts more than 200 events each year and a café with a view - the Alps are almost within reach.

Curriculum \& Degrees in short: Architecture B.A. (4-year program, 240 ECTS) Architecture M.A. (2-year program, 120 ECTS)

Landscape Architecture B.A. (4-year program, 240 ECTS) Landscape Architecture M.A. (2year program, 120 ECTS) Industrial Design M.Sc. (2-year program, 120 ECTS) Conservation-Restoration M.A. (2-year program, 120 ECTS) Urbanism M.Sc. (2-year program, 120 ECTS)

Energy-efficient and Sustainable Building M.Sc. (2-year program, 120 ECTS) ClimaDesign M.Sc. (2-year program, 120 ECTS)
ADDRESS \&

PRACTICALITIES

Technical University of Munich Department of Architecture Arcisstraße 21 80333 Munich www.ar.tum. de

\section{Faculty of Architecture, Budapest University of Technology and Economics, Hungary}



\section{HIGH-QUALITY IN INTERNATIONAL ARCHITECTURAL EDUCATION}

The Faculty of Architecture BME for almost 150 years stands for high-quality in Hungary. We have several international contacts in researches, education and trainee programs, but we would like to enlarge our collaborational network all over the world, towards widespread perspective. By these we would like to keep and produce our remarked position in our students, academic environment and the labour market. We are proud of our students who are success in international competitions and there are also many remarkable innovations by our teachers.

$$
\begin{aligned}
& \text { PROFESSIONALISM, } \\
& \text { PRACTICABILITY } \\
& \text { The Faculty of Architecture } \\
& \text { BME focuses on training } \\
& \text { highly professional experts }
\end{aligned}
$$


in architectural engineering who are aware of the social and cultural implications of their profession. Versatility is emphasised so that students will gain fundamental knowledge and abilities in every possible field of architecture and be able to find work in a highly competitive job market, and in any building- or design-related area of consulting, construction, and management. In the early semesters students gain theoretical basis, in the last two years the emphasis is on the design by doing practical works.

\section{PERFECT ENVIRON - MENT FOR VARIETY OF RESEARCHES} Departments of the Faculty of Architecture, BME are involved in high variety or research projects related to historical, social, theoretical and scientific aspects of architecture and building construction. On one hand, the distinguished historical and contemporary architecture of Budapest provides a perfect background for many of these research activities. On the other hand, being a Faculty of an university devoted to cutting edge engineering research provides a perfect environment for intense exploration even at frontiers of architecture.

DATA AND STATISTICS Student numbers: 1500 Hungarian +300 International students

Staff size: 205 members

Facilities: Study center, computer lab, library (over 2 million titles), sport centre, extensive modeling work- shop: including 3D printers, laser cutters and $\mathrm{CNC}$ milling machines.

Curriculum \& Degrees in short: Integrated MSc (Master Program in Architectural Engineering): 5-year program (300 ECTS), M.Sc. in Architecture and Engineering degree BacheIor of Science Degree Pr. in Architectural Engineering Program: 4-year program (120 ECTS), Architectural Engineer degree

Master of Science (M.Sc)

Degree Program: 1,5year program (90 ECTS) M.Sc. in Architecture and Engineering degree

DLA Program: 3-year program, Doctor of Liberal Arts degree PhD Program: 3-year program, PhD degree

\section{ADDRESS \&}

PRACTICALITIES Address: $\mathrm{H}-1111$ Budapest Hungary Muegyetem rakpart 3. Phone: +36 1463 3521 / Fax: +3614633520 Email: titkarsag@epitesz. bme.hu

Faculty of Engineering and Information Technology, University of Pecs, Hungary

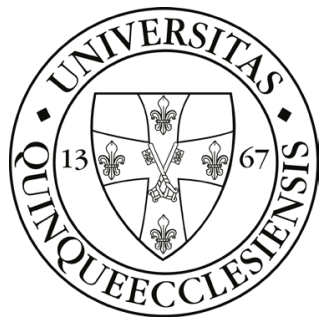

FLEXIBILE AND HIGH QUALITY EDUCATION

As one of the largest and most vibrant institutions of technical higher education in Hungary, we adhere to a contemporary approach towards education which is recognised internationally. Our objective is to provide a flexible and high quality education producing specialists in the field of architecture, who are able to meet the demands of the technical, cultural, artistic and social transformation taking place in 21st century European society.

SPECIAL TEACHING METHODS, PERSONAL COMMUNICATION Our strength lies in our teaching methods; first-rate teaching in small classes combined with individual student counselling â $€$ "like an architectural manufactory in natural scale. Most of the courses are taught in small groups and the best students are invited by lecturers to take part in their projects so that they can gain practical experience. The school uses teaching methods similar to those of the worldwide known Bauhaus School: looking for connections with practical life, crafts and liberal arts. Bauhaus masters born in Pecs include Marcell Breuer, Farkas Molnar and Alfred Forbat.

BREUER MARCELL DOCTORAL SCHOOL OF ARCHITECTURE The primary task of the doctoral school is to provide high quality educational program which comply with the requirements of 
the Bologna declaration for students who already have an MA or MSc degree in architecture or a related field.

The school is the most important centre of multidisciplinary research and postgraduate study in the field of architecture in the region, offering degree courses at all levels of higher education. Students participating in the doctoral program have the chance to study full-time or part-time in order to attain their DLA or $\mathrm{PhD}$ in architecture.

\section{DATA AND STATISTICS}

Student numbers: The Faculty of Engineering and Information Technology has almost 3000 students.

Staff size: 135 lecturers, 82 of them have a PhD or DLA degree and 29\% have reached the qualification of habilitation.

Facilities: The refurbishment of the 20,000 $\mathrm{m} 2$ educational and research building complex was completed in 2007-2008. The Janos Szentagothai Research Centre of the University of PÃ®cs is a new research institute established on the basis of modern international science organizational and management normatives. It covers all aspects of education, research and innovation at the fields of biomedical, natural and environmental sciences. The infrastructure, instrumentation and expertise of the 22 research groups operating in the building provide an excellent basis to become a well-known, leading research facility in Hungary, as well as in Central-Europe with an extensive and fruitful collaboration network. The Smart City Technologies Research Group is located in this building in connection with the Faculty.

Laboratories, Instruments: AAS, ICP-OES, portable gas chromatograph, water quality analyzing and measuring system, measuring equipment for analysing the emission of diffuse air pollution sources, digital sieve shaker machine, emission measuring laboratory, gas analysers (SO2-CO-NOx-O3), noise technology laboratory. RELUX, Solar computer, Shell solar path, Meteonorm, Ecotecht, Wis, 3D studiomax, Archicad

Curriculum \& Degrees in short: Bachelor programs: Architect (MSc, 10 semesters), Civil Engineer, Computer Science Engineer, Architectural Designer (BA), Architectural Engineer, Electrical and Computer Engineer, Environmental Engineer, Industrial Design Engineer,Mechanical Engineer

Master programs:

Architect, Computer

Science Engineer, Structural Designer, Architectural Designer (MA), Architecture in Construction Design, Interior Designer (MA), Architectural Designer (MA), Urban System
Engineer

Doctoral programs: Architectural Doctoral School in $\mathrm{PhD}$, Architectural Doctoral School in DLA

\section{ADDRESS \&} PRACTICALITIES University of Pecs Faculty of Engineering and Information Technology Hungary / 7624 Pecs Boszorkany street 2. www.mik.pte.hu

Department of Architecture and Territory (dArTe), Mediterranea University of Reggio Calabria, Italy

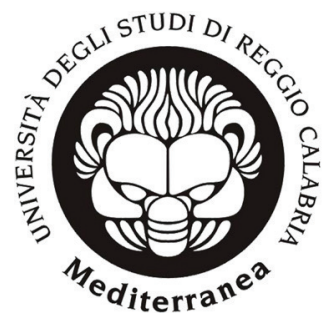

ART AS THE PLACE OF THE MOST ELEVATED SYNTHESIS BETWEEN ARCHITECTURE AND TERRITORY

The acronym "dArTe" implies a double interpretation as it indicates the mutual and inseparable connection between Architecture and Spatial Planning, thus elevating art to a higher plain. The $\mathrm{dArTe}$ is concerned with the improvement and management of our architectural heritage and design. The main objective is the furthering of urban civilization and culture, offering the maximum knowledge and optimum skills aimed at obtaining a significant positive impact on territorial 
development, in close relation to the salient issues of international debat on architectural planning and the city.

\section{AN EXPRESSION \\ OF HUMAN VALUES \\ AND A CONTEXT FOR HUMAN ACTIVITY}

The dArTe offers a One-Cycle degree course in Architecture (Class LM-4). The Study of Architecture aims at forming a professional with the general architectural skills as laid down by the European Union Directive 2005/36. Training is divided into two parts. The first, theoretical, aimed at the acquisition of knowledge, methods and tools related to the practice of architecture and its history. The second, more operational, is geared to the "know-how".The dArTe completes its training framework offering 1st and 2nd level specilization Masters. The final programme is the PhD in Architecture.

\section{IN THE MODERN EVOLUTIONARY SCENERY RESEARCH AS PROLIFERATION OF INTERCONNECTED ACTIONS AND VISIONS}

The dArTe promotes basic and applied research, technology transfer with reference to the areas of architectural, urban and landscape design. The research activity is carried on by School Ph.D and laboratories. Ph.D themes: spatial development, land use, urban planning, environment, sustainable design, cultural heritage, landscape design. The laboratories are:
LAMA: Materials for Architecture Lab LAB.PRO.COM.: Community Planning Lab StUTeP: Urban and Territorial Strategies for Planning Lab Survey and Representation of Mediterranean Architecture Building Future Lab Landscape in_Progress

DATA AND STATISTICS

Student numbers: 1220 students

Staff size: 283 Staff members (283 full-time and approx. 0 visiting lectures and critics).

Facilities: 3D point measurement, 3D-printing, 3D-scanning, Architecture Model Lab, Architecture Studio, Audio-Lab, Audio Visual Lab, Blackboard learn platform, Building Information Modeling Lab, Building Material Lab, Building Technology Laboratory, Built Environment Lab, CAD-Lab.

Curriculum \& Degrees in short: Master degree of Architecture, Quinquennale one-cycle (300 ECTS);

Research and Postdoc Programs;

I Level Master (March) in Health and safety management in temporary building sites, (60 CFU); II Level Master (MArch) in Management and development of experimental research for sustainability in the building industry, funded by PONa3_00309 Building Future Lab. (60 CFU); Doctoral Degree, 3 years, multidisciplinary program: Phd (Doctor of Philosophy) and Title: $d r$.

\author{
ADDRESS \& \\ PRACTICALITIES \\ Mediterranea University \\ Dipartimento dArTe Ar- \\ chitettura eTerritorio Salita \\ Melissari - Feo di Vito 89124 \\ Reggio Calabria. http:// \\ www.darte.unirc.it
}

\section{School of Architecture, Politecnico di Torino, Italy}



HISTORY AND FUTURE IN A GROWING, OPEN, INTERDISCIPLINARY ARCHITECTURE SCHOOL

Politecnico di Torino School of Architecture is part of a global research university focused on design in all technical fields.

After a 3-years broad Bachelor program in Architecture, students choose one of the three 2-years Master programs focusing on History and Heritage Preservation, Sustainability or Construction \& City. All programs are offered in Italian and English.

Students are encouraged to explore courses and laboratory training offered by the Schools of Engineering, Design and Planning, building their unique learning path thanks to a wide and reach educational offer. 
HANDS-ON RESEARCH BY DESIGN AND

TEAMWORK: THE

ATELIER IS THE CORE OF ARCHITECTURAL EDUCATION

Architecture is a practical knowledge that is expanded, enriched and transmitted by design.

At the very core of teaching in the School of Architecture of Politecnico diTorino is the intense learning experience of interdisciplinary design ateliers: professors and experts from different fields work together with students in imagining, designing and developing solutions to complex urban, social, economical and technical problems. Specific scientific fields start their formalization from the issues arising in the design process, constantly bridging theory and practice, history and innovation.

$$
\begin{gathered}
\text { RESEARCH AND } \\
\text { EDUCATION IN, FOR } \\
\text { AND BY DESIGN: } \\
\text { FROM BACHELOR TO } \\
\text { MASTERS, PHD AND } \\
\text { TRAINING }
\end{gathered}
$$

Humanities, history, social sciences, economy, natural sciences, information and technology are the ingredients of a structurally interdisciplinary education, training and research in Architecture at Politecnico diTorino, where future innovation is always linked and rooted in awareness and knowledge of the past. Research and education share a common design-oriented approach and are deeply connected at all levels, from bachelor to $\mathrm{PhD}$, allowing students to accede to the most inno- vative research topics and experiences, while acquiring a deep and solid background based on history and theory.

DATA AND STATISTICS

Student numbers: Student numbers: 3836 students (2150 Bachelor, 1588 Master, $98 \mathrm{PhD}$ ),

$53 \%$ female, $47 \%$ male, $13 \%$ foreign.

Staff size: Staff size: 140 full-time staff members +56 part time staff members +3 international visiting professors + invited lecturers and critics

Facilities: The School of Architecture of Politecnico di Torino is based in the XVIlth century baroque Valentino Castle, where Politecnico was founded in 1853, recently expanded in the 1927 modernist Lingotto, will soon grow to occupy the refurbished Pier Luigi Nervi's 1950 Torino Expo buildings, merging modern and antique architectures in an unique campus along the Po river, immersed in the gorgeous greenery of the Valentino Park and facing the lively San Salvario neighborhood.

Facilities and services include:

the "Roberto Gabetti" Architecture Library with 110.000 books $(10.000$ rare and/or antique),

15.000 dissertations, 2120 periodicals

Maps archive, Modeling \& 3D lab, Computer lab, Building Physics and measurements lab, Heritage Survey lab,
Self building lab, Building technology lab, Multimedia lab, Virtual reality lab

study rooms, cafeteria, copy center, exhibition hall

Curriculum \& Degrees in short: Bachelor of Science in Architettura, 3 years, 180 ECTS, in Italian

Bachelor of Science in Architecture, 3 years, 180 ECTS, in English

Master of Science in Architecture, Heritage Preservation and Enhancement, 2 years, 120 ECTS, in Italian

Master of Science in Architecture, Construction and City, 2 years, 120 ECTS, in Italian and English

Master of Science in Architecture for Sustainable Design, 2 years, 120 ECTS, in Italian and English

All Masters programs lead to the European Master degree in Architecture and are recognized by the EU.

3 years $\mathrm{PhD}$ courses in: Architecture History and Project

Architectural and Landscape Heritage Urban and Regional Development

\section{ADDRESS \&}

PRACTICALITIES

Politecnico diTorino School of Architecture

Department of Architecture and Design (DAD) Viale Mattioli 39 10125 Torino Italia www. polito.it www.dad.polito.it 
Faculty of Architecture, Sapienza University of Rome, Italy


UNIVERSITÀ DI ROMA

\section{ARCHITECTURAL STUDIES}

Study architecture means bringing the history and contemporary life through the creation of space at different levels: the object, the house, the city, the virtual space. The Faculty of Architecture Sapienza, first in Italy since 1920 proposes the joint teaching of construction, restoration and urban planning. The training areas are in the field of architecture declined both in predominantly generalist form for efficient use of existing assets and historical construction, landscape, industrial design, the management of the building process.

\section{OUR COURSES}

The training is divided into a master's degree in one cycle five-year, four-year degree programs, four master's degree programs. The title obtained with one cycle five-year degree as that achieved the degree allow to access the exame of qualification to practice the profession of architect, recognized by the European Union.

\section{RESEARCH AND POST BACHELOR ACTIVITIES}

The faculty coordinates a large third-level training program with a complex picture in terms of master, $\mathrm{PhD}$ courses and gradu- ated school. The program of such courses is an expression of the different disciplines and expertise available within the Faculty of Architecture. Their purpose is to provide a high education with aim at the development of critical and theoretical reflections in the different disciplines of architecture

DATA AND STATISTICS

Student numbers: Student: 4154 students (3721 bachelor; 132 master; $225 \mathrm{PhD} ; 76$

specialization) $65 \%$ female, $45 \%$ male

Staff size: 283 members, 65 part-time

Facilities: 4 departments with library and 1 central library, with ancient book, map archive, drawing archive, periodical, repository of PhD theses. Literary cafè, plot service in the faculty. Ce.S.M.A. Laboratory aim at encourage, promote and develop the use of information technology in all activities of the Architecture Faculty. eLab (e-learning): finalized the additional courses with the use of interactive tools for e-learning and web conference

$\mathrm{mLab}$ (models): is aimed at the realization of physical models iLab (information technology): is aimed at computer applications

bLab (physical computing): is aimed at automation by building of responsive models with the aid of microcontrollers

Curriculum \& Degrees in short: Bachelor in
Architecture 5-year program Bachelor in Science of Architecture 3-year program; Industrial Design 3-year program; Project Management 3-year program; Planning and design of landscape and environment

3-year program; Architectural of landscape 2-year program; Architectural Restoration 2-year program; Design, Visual Communication and Multimedia 2-year program

Product Design 2-year program

Master in: Building information modeling (B.I.M.); Exhibit \& public design; Lighting design; Valorization and managing of minor historical centers; MAM - museum production;

Bio-ecological Architecture and sustainable technologies for the environment; Architecture for archaeology. Project for valorizing cultural heritage (interfacoltà); Architectures for health; McBE.C - Communication of cultural heritage; Managing architectural project; Architectural design of sports facilities; PARES - architectural design for the recovery of historic buildings and public spaces; Design of buildings for worship; Advanced structural design according to Eurocodes (EuroProject); Restoration and highly complex consolidations, design and construction in civil and religious architecture; 
Theater and television scenography; URBAM The urban planning in public administration: management of the city and territory

PhD: Architecture and construction; Theory and project; Structural and geotechnical engineering; Planning, design and architecture technology; History, design and restoration of architecture

\section{ADDRESS \& PRACTICALITIES SAPIENZA UNIVERSITÁ DI ROMA \\ Faculty of Architecture Via Emanuele Gianturco 2 00196 Roma http://www.architettura. uniroma1.it/}

\section{Politecnico di Milano,} Italy

\section{ocer \\ POLITECNICO MILANO 1863}

\section{DESIGN, TRADITION, AND INNOVATION: AN ITALIAN SCHOOL ON THE \\ INTERNATIONAL SET}

The complexity of the transformation of cities, territories, and contemporary living requires advanced training that combines the best traditions of the involved disciplines with experimentation and innovation, to enable future graduates to compete nationally and internationally in the world of Architecture, Urban Planning and Construction Engineering. The School intends to differentiate and forms cultural and professional profiles in the field of activities, based on a typical polytechnic matrix and tradition: architectural and urban design, construction, and building engineering, planning

\section{TOWARDS A}

POLYTECHNIC DESIGN IDEA

The focus of the School Study Programmes is the project, as a synthesis of multiple knowledge. The background is set up in the founding principles of polytechnic education, which integrate the scientific and technical disciplines with the humanities and the arts, with the history and criticism, in the line of the tradition of the Italian culture. At the same time, the School promotes the dealing with the contemporary issues: territorial coherence, environmental sustainability, protection and enhancement of heritage and landscape, building technologies innovation.

THE SCHOOL AS A FIELD FOR MAKING KNOWLEDGE

The School promotes the continuous interweaving of teaching and research, thus considering the School as a place of making knowledge as well of transmitting it. The Programmes of the School enforce, particularly at the Master level, an experimental approach that critically tackles the issues imposed by the changing of the architectural practices as well as the modifications of the contemporary territories. The programs combine research and design activities on case studies, fueled by a successful relationship with actors and institutions.

\section{DATA AND \\ STATISTICS}

\section{Student numbers:}

B.(Architecture and Urbanism):4673; M.(Architecture and Urban Planning and Policy Design):3544; B.(Building Engineering):728; M.(Building Engineering):688; M.Sc. (Building EngineeringArchitecture):814

Staff size: 376 Staff Members; 50 International Visiting Professors; 458 Professors with a temporary appointment.

Facilities: Libraries and Archives: Architecture Central Library (Leonardo Campus), Durando Campus Library (Architecture and Design); Campus Libraries at Lecco, Mantova, Piacenza. The Architecture Central Library possesses Italian and foreign scientific works mainly dedicated to architecture, art, town planning, design, interior design, landscapes, restoration and museology. The Historical Section includes general reference works, books published before 1970, antique, rare and valuable books, out of print books. This section includes collections of periodicals published prior to 1979. Didactical and Research Labs: ARCHITECTURAL MODELLING LAB (MOA), in Leonardo Campus, and Modelling and Fablab in Lecco, Mantova, Piacenza Cam- 
puses. The Departments of Architecture and Urban Studies (DASTU), Architecture Built Environment and Construction Engineering (DABC), Civil and Environmental Engineering (DICA) dispose of several research laboratories, clusters, and hubs, that represent a solid support also to the teaching activity.

\section{Curriculum \& Degrees in} short: Bachelor of Science, 3-year programmes, 180 ECTS: Architectural Design, taught in Italian and English (Milano, Mantua, Piacenza Campus); Building Engineering and Technology for Architecture, taught in Italian (Milano Campus); Urban Planning: Cities Environment \& Landscapes, taught in Italian (Milano Campus); Master of Science, 2-year programmes, 120 ECTS: Architecture; taught in Italian and English (Milano Campus) Architecture-Architectural Design; taught in Italian and English (Milano Campus) Architecture-Building Architecture, taught in Italian and English (Milano Campus) Sustainable Architecture and Landscape Design, taught in English (Piacenza Campus) Architectural Design and History, taught in English, (Mantua Campus) Building and Architectural Engineering, taught in English (Milano Campus, Lecco Campus) Building Engineering, taught in Italian (Milano Campus) Management of Built Environment, taught in English (Milano Campus) Urban Planning and Policy Design, taught in English (Milano Campus) Master of Science- 5-years- single cycle programme, 300 ECTS: Building Engineering Architecture, taught in Italian (Lecco Campus)

Ph.D. Programmes: Architecture, Built Environment and Construction Engineering Architectural, Urban and Interior Design Preservation of the Architectural Heritage Urban Planning, Design, and Policy

\section{ADDRESS \&} PRACTICALITIES

Politecnico di Milano School of Architecture Urban Planning Construction Engineering Office of the Dean

Via Ampère 2 20133 Milano presidenza-aiuc@polimi.it www.auic.polimi.it

Alghero School of
Architecture - Dip. di
Architettura, Design e
Urbanistica, Università di
Sassari, Italy

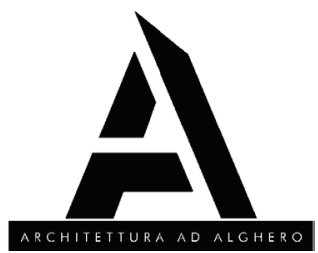

AN

INTERDISCIPLINARY AND PROCESS -

ORIENTED LEARNING ENVIRONMENT

The Alghero School of Architecture was founded at the Sassari University in 2002 as the first architecture faculty in Sardinia, and immediately scored the top positions in the independent CENSIS evaluation of Italian Architecture schools.
Its teaching model is based on "learning by doing" and closely connected to interdisciplinary research.

The School offers programs in Architecture (with a sub-program on Concept Design) and Urbanism, whose international Masters are based on agreements with foreign Universities. The School also offers an international PhD in Architecture and Environment.

\section{A PRAGMATIC} APPROACH TO THE TEACHING OF DESIGN The school provides training on architectural design and planning, considered both as means of knowledge and tools to induce beneficial transformations in an environment made of intricate natural and artificial processes. Accordingly, students learn to refine their design skills in interdisciplinary design studios, whose topics relate to the department's research and cover the whole realm of design. Students face a broad scope of design topics and challenges, and are given the opportunity to study abroad, participate in international summer schools, complete their work experience worldwide.

DESIGN AND

PLANNING AS

DRIVERS OF

INTERDISCIPLINARY RESEARCH

Our environment is marked by interacting natural and artificial processes. In order to face this complexity, researchers should move beyond the secure 
border of their disciplines. The pragmatic and synthetic attitude of Design plays a key role in mapping common interdisciplinary fields, calling different disciplines around relevant environmental topics. The focus on real spatial situations, instead of bare theory, minimizes potential conflicts arising from diverse disciplinary lexicons. Design then helps to build a unitary vision that balances theoretical investigation and pragmatism.

DATA AND STATISTICS

Student numbers: 520 students ( 174 Bachelor Architecture, 142 BacheIor Urbanism, 126

Master Architecture, 68 Master Urbanism, 15 PhD). $45 \%$ female, $55 \%$ male.

Staff size: 45 Professors and researchers permanently enrolled (4 from foreign countries), 40-50 foreign visiting professors and scientists per year, about 40 teaching assistants.

Facilities: The School materializes both in the physical and in the digital space through its buildings and its digital infrastructure.

Classrooms, design studios and staff offices are located in three recently refurbished buildings into the historic centre of Alghero, close to the Mediterranean Sea.

All the buildings are linked through a wireless network, open to teachers and students. The Students' association, located in the most important among the
School's buildings, provides working spaces and offers a printing workshop.

The Library contains approximately 6,000 printed books and 60 printed periodicals/scientific journals covering the large scope of the School. Moreover, the Library online resources offer approximately 30,000 full text journals and books. Additional digital resources feature PhD theses and student graduation works, lecture recordings, and a large collection of inhouse online courses offered to part-time students and for further training.

A co-working space and modeling workshop with rapid-prototyping tools will open in 2017.

Curriculum \& Degrees in short: Architecture program: Bachelor in Architecture and Design, 3-year (180 ECTS), Master in Architecture, with the international track European Master in Integrated Sustainable Design in The Mediterranean World, with Universidad de Alcalá (Spain) and Universidade de Lisboa (Portugal), 2-year (120 ECTS).

Urbanism and Planning program: Bachelor in Urban, Territorial, \& Environmental Planning, 3-year (180 ECTS); European Master in Planning \& Policies (international, with Universitat Autonoma de Barcelona , Universitat de Girona (Spain), Universidade de Lisboa
(Portugal), Università IUAV di Venezia (Italy), 2-year (120 ECTS).

PhD: Doctoral program in Architecture and Environment ( 3 years, international, with the Inst. of Natural and Applied Sciences and the Dep. of Architecture of the Univ. of Karabuk, Turkey). Post master programs: different postgraduate Master programs with international partners. Life-long learning: the school cooperates with local institutions and professional organizations through seminars and lectures held by its staff or visiting professors.

\section{ADDRESS \&} PRACTICALITIES Università degli Studi di Sassari Dipartimento di Architettura Design e Urbanistica

Palazzo del Pou Salid Piazza Duomo

6

I-07100 Alghero (SS) www. architettura.uniss.it www.youtube.com/user/ ArchitetturaAtetturaAlghero twitter.com/Architettura_AA www.flickr.com/photos/architettura_alghero 
School of Architecture, University of Cagliari, Italy



ARCHITECTURE \& LANDSCAPE, HISTORY \& INNOVATION:

SARDINIA FOR THE SCHOOL, THE SCHOOL FOR THE WORLD

Cagliari offers a research approach deeply related to didactics, focused on issues such as Architectural and Urban Design, Urban Planning, Landscape Rehabilitation and Restoration of Historical Architecture. They are the strengths of the School of Architecture, which carries out its research and educational activities supported by a broad range of technological equipment. After a three-year Bachelor program, which aims to provide a basic level of architectural knowledge, students are able to choose between two biennial Master degree programs, Architecture or Architectural Restoration.

\section{A LEARNING BY}

DOING APPROACH TO DESIGN EDUCATION

The didactic approach is founded on the central role of design studio teaching, combining educational needs with the questions arising in the territory. Thus, students are learning by doing, developing design experiences able to reinforce their sense of ethics. Education includes courses in geography, sociology, history, building and physical environmental technology, and also diagnostic techniques and materials with activities in specialized laboratories. The teaching staff is enriched by the continuous presence of visiting professors from Europe, US and Latin America.

$$
\begin{gathered}
\text { POST MASTER, } \\
\text { PHD, POSTDOC: TO } \\
\text { AND FRO, BETWEEN } \\
\text { THEORY AND } \\
\text { PRACTICE, LOCAL } \\
\text { AND GLOBAL }
\end{gathered}
$$

Design research is conducted on different levels of education within overarching research programs. It ranges from the study of historical places to design \& planning principles and practices, including theoretic research aiming to interpret different visions of contemporary world. The School supports a doctoral program (addressing issues from restoration to architectural and urban design \& planning), a postmaster in sustainable building and many postdoc programs. Research issues arise in Sardinia and are developed with a comparative approach that links them to the international dimension.

DATA AND STATISTICS Student numbers: (enrolled a.a. 2015/16): 668 students (476 Bachelor, 192 Master, $30 \mathrm{PhD}$ )

Staff size: 51 Staff members ( 41 full time +10 temporary contracts), 30 visiting lectures and critics.

Facilities: Library: with

74,000 titles and 2,000

periodicals, $\mathrm{Wi}-\mathrm{Fi}, 330$

seats and 20 web workstations.

Graphic LAB: 25 seats.

Models LAB: 3D printer and CNC machines.

LabMAST - Mediterranean

Laboratory for Materials and Historical-Traditional Building of the University of Cagliari: 1. Materials LAB Unit; 2. Survey LAB Unit: Laser Scanner and Drone; 3. Climatic chamber LAB Unit; 4. Mechanical Testing LAB Unit.

Moreover, the University of Cagliari offers the following helpful facilities and services:

Accomodation: ERSU -

Residence Halls, Guest House for Incoming Teachers and students;

Meals: 4 ERSU - Canteens

Students with special needs: the adviser for disabled students runs a comprehensive service dealing with issues including admission arrangements, personal support, learning support, advice on equipment purchase and special exam arrangements. The university has introduced many services in order to allow students to participate in all aspects of university life. Among them, Tutoring Service, Agreement with the Institute of the Blind, Interpreting Service for hearing-impaired students, Supply of specific equipment and aids, Service of note-taking and Transport Service 
that are also offered to graduate students who attend specialization courses, research doctorates, Master's degrees and anything related to postgraduate study.

Curriculum \& Degrees in short: Bachelor of Science, 3-year program, (180 ECTS), Bachelor of Science in Architecture degree;

Master of Science, 2-year program (120 ECTS), with the option between 2 specialized programs (curricula: 1) Architectural and Urban Design, 2) Architectural Restoration), Master of Science in Architecture degree.

Post master program in sustainable building (60 ECTS).

3rd cycle doctoral degree (3 years): PhD (Doctor of Philosophy) and title: dr.

Research, Postdoc \& PhD programs have the support of many cooperation agreements between the School of Architecture and Sardinian Local Authorities (Region, Provinces and Municipalities).

\section{ADDRESS \& \\ PRACTICALITIES}

Scuola di Architettura Universita' degli Studi di Cagliari Via Santa Croce 67 09124 Cagliari - Italy T. + 390706755358 | 5368 M dicaar.unica@pec.it M carlo.atzeni@unica.it | cgiannatt@unica.it http:// sites.unica.it/architettura/
DSA Department of Sciences for Architecture - Polytechnic School, University of Genoa, Italy

\section{GENOVARCHITETTURA

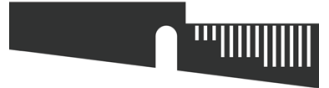

\section{AN ARCHITECTURE SCHOOL WITH SOLID ROOTS TO FACE AN INTERNATIONAL HORIZON}

The Polytechnic School of the University of Genova has a strong tradition that links it to its territory and the Mediterranean basin. Its open and inclusive nature has encouraged many contaminations and influences with the territory outside the city and the University. By offering three-year bachelor courses in the disciplines of the project, restoration and landscape design and two-year master courses based on sustainability, advanced design techniques and heritage valorization, The Department DSA of the Polytechnic School can now look to the challenges of the future with enthusiasm.

\section{AN EDUCATIONAL APPROACH TO ARCHITECTURAL CULTURE AS A CRITICAL AND}

CREATIVE PROCESS Our educational approach lies in the development of research topics related to the issues and emerging needs of contemporary world. Our aim, integrating various contributions and disciplines, is to study the relationships between the environment and inhabitants and to inquiry how the social, political and cultural values influence the design choices. This happens through experiences of basic and applied research, workshops, experiences in collaboration with other universities and institutions, as well as through external contributions that encourage the opportunities for cultural exchanges.

THE SCHOOL AS A CULTURAL INCUBATOR: FROM BASIC TO APPLIED RESEARCH

We develop research by integrating the skills of our professors, researchers and students, in the conviction that only a shared process can bring personal enrichment and collective positive results. Our Department coordinates a PHD program in Architecture and Design and host the School of Specialization in Architectural Heritage and Landscape of the Genoese Athaeneum.

Furthermore, various groups participate in European and National research programs, receiving significant funding, and are responsible for contracts and agreements with local, national and international institutions.

DATA AND STATISTICS Student numbers: Students numbers: 1632 students (1180 Bachelor, 420 Master, $32 \mathrm{PhD}$ in Architecture, 11 Specialization School in Architectural Heritage and Landscape), $20 \%$ foreign. Staff size: Staff size: 64 
Teaching Staff, mostly fulltime +32 Professors in charge +27 StaffT.A.

Facilities: Facilities: "Nino Carboneri" library, with more than 50.000 titles and subscriptions to more than 860 periodicals, maps and final thesis archive. Computer center, fully equipped CAD and informative studio and laboratory. MARSC, Laboratory of Analytic Methods for Building History and Restoration. Geomorfolab, Laboratory of Applied Geomorphology. cts_ColourLAB, culture technology science_Laboratory of Colour.

Curriculum \& Degrees in short: Curriculum \& Degrees in short: Higher Education: Bachelor of Sciences in Architecture (3-years program) - 180 ECTS (National admission test - 172 places available). > Curriculum Architecture, > Curriculum Building and Architectural Engineering, > Curriculum Building and Architectural Engineering. Specialization: Master of Sciences in Architecture (2-years program) - 120 ECTS (80 places available); Master of Sciences in Building and Architectural Engineering (2-years program) - 120 ECTS (70 places available); Master of Sciences in Design of Green Spaces and Landscape (2-years program) - 120 ECTS (60 places available). Post-graduate Courses: School of Specialization for Architectural Heritage and Landscape (2-years program) - 120 ECTS (20 places available); PhD Courses in Architecture and Design (3-years program) - 180 ECTS (11 students in architecture).
The department DSA also offers one Bachelor in Product and Nautical Design; one Bachelor in Nautical Engineering; one Master of Sciences in Product and Event Design; one Master in Science Naval and Nautical Design: with 610 total students.

\section{ADDRESS \&}

PRACTICALITIES

University of Genoa

DSA - Department of

Sciences for Architecture

- Polytechnic School Stra-

done di S. Agostino - 37

16123 GENOVA (ITALY)

Department Secretariat: tel. 010.209.5875 - fax. 010.209.5905 e-mail: segrdip@arch.unige.it http://architettura.unige.it

Institute of Architecture and Planning, University of Liechtenstein, Liechtenstein



$$
\begin{gathered}
\text { THE ALPINE } \\
\text { LABORATORY } \\
\text { COMMITTED TO } \\
\text { CRAFT, BUILDING }
\end{gathered}
$$

CULTURE AND SOCIAL RELEVANCE

Personal and international: One-to-one teaching in small classes and design studios provide a personal, creative and productive learning and research environment at Bachelor-, Master- and PhD-level. Currently, students of more than 30 different nationalities create a unique cosmopolitan atmosphere on a compact campus within a stunning alpine setting.
A global perspective:

A compulsory semester abroad at one of our high-profile partner universities across the globe helps students to test their acquired knowledge in a different cultural and academic environment.

ADRESSING GLOBAL CHALLENGES, MAKING A

DIFFERENCE ON A LOCAL SCALE

We educate visionary architects who act, craft and design with social, ecological and economical responsibility, who are aware of their local projects' global impact, who combine theory and praxis in their work, and who pursue cultural sustainability.

INTERDISCIPLINARY AND COLLABORATIVE RESEARCH BEYOND ACADEMIA

The faculty's focus is on education through research - and on education in research. This also implies the successful mediation of research to and collaboration with various stakeholders, partners from academia and the industry as well as the public. At the University of Liechtenstein, research is being conducted within the following three specifications: Sustainable Design, Sustainable Urban Design and Architectural Design Theory. Students of our Doctoral Degree Programme in Architecture and Planning are fully integrated members of the university's research community. 
DATA AND

STATISTICS

Student numbers: 200 (120

Bachelor, 70 Master, 10

PhD). 55\% female, 45\%

male.

Staff size: 60 , mostly parttime.

Facilities: Atelier in a former spinning factory providing a personal workspace for all students. Extensive model workshop equipped with digital and analogue tools enabling crafting and production on all scales. A library with a panoramic view. State of the art computer labs. A start-up laboratory for future entrepreneurs.

Indoor and outdoor sports facilities on campus and its vicinities, including mountain lakes and rivers as well as countless alpine peaks ready to be conquered on foot, by mountain bike or on skis. On-campus cafeteria and kitchen. A student dormitory within walking distance. An active alumni network opening doors to praxis and future opportunities.

Curriculum \& Degrees in short: Bachelor's Degree Programme in Architecture (BSc): 3 year programme, 180 ECTS, taught in German.

Master's Degree Programme in Architecture (MSc): 2 year programme, 120 ECTS, taught in English.

Doctoral Degree Programme in Architecture and planning (PhD): 3 year programme, taught in English.
Summer School "Arts and Crafts": 2 week workshop, taught in English.

\section{ADDRESS \&}

PRACTICALITIES

University of Liechtenstein

Institute of Architecture and Planning Fürst-Franz-Josef-

Strasse

9490 Vaduz Liechtenstein

Phone +42326511 11

www.uni.li

Vilnius Gediminas Technical University, Lithuania

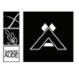

VILNIUS GEDIMINAS TECHNICAL UNIVERSITY FACULTY OF ARCHITECTURE

\section{DYNAMIC CREATOR} AND MODERATOR

The largest Architecture school in the Baltic States aims at bringing together scholars, students, stakeholders from the municipalities, state institutions, business and societal organizations for close cooperation on creatively responding and overcoming the complex architectural and urban challenges of the present and future welfare development in Lithuania.

\section{FOCUS ON SOCIALLY RESPONSIBLE CREATIVITY IN CONSTANTLY CHANGING ENVIRONMENT}

The School attempts the students to carry out architectural activities in holistic, rational and creative way, while solving complex challenges of spatial shaping in constantly changing environment ( $\mathrm{Ba}, \mathrm{Ma}, \mathrm{PhD}$; $\mathrm{LT}+\mathrm{EN})$. Students gain basic knowledge and skills of the profession during the first stage of studies. The later studies encourage the students' personal focus on the their own areas of interest, offering wide range of problem-orientated architectural design topics supplemented by diverse theoretical and practical subjects. ARCHITECTURE BY RESEARCH

Our academics and PhD candidates are making noticeable influence on social processes in the country acting in the fields of research and design meeting the challenges of ever-changing conditions, architectural heritage, history of architecture and its interpretation. From the very early study-years, students are engaged to academic projects within multi-disciplinary teams through theoretical courses, fieldwork and research assistant positions. We believe this practice will help us to expand the limits of architectural practice and theory and to improve the qualities of social welfare.

DATA AND STATISTICS

Student numbers: 391 students: 361 students in Architecture (65 Master, 391 Bachelor), 20

- History and Theory of Architecture (Master), 10 doctoral students (PhD)

Staff size: 43 prominent architects, artists and scholars teach (half of them part time) the subjects of the study programmes

Facilities: The best architec- 
ture library in the city, studios, auditoriums, model workshop, fine arts studios, photographic studio, media lab, acoustics lab and cosy courtyard are the spaces where different generations of architecture lovers meet to implement their ideas

Curriculum \& Degrees

in short: Master of

Architecture, 5-year programme (300 ECTS; admission to the $1 \mathrm{st}$ year from 2016)

Bachelor of Architecture, 4-year programme (240 ECTS; admission to the 1st year until 2015) Master of Architecture, 2-year programme (120 ECTS; admission to the 1st year until 2019) Master of History and Theory of Arts (Architecture), 2-year study programme (120 ECTS) PhD 4-year studies History and Theory of Arts (Architecture), title dr.

\section{ADDRESS \&}

PRACTICALITIES

Faculty of Architecture, Vilnius Gediminas Technical University Traku 1 01132 Vilnius Lithuania archdek@vgtu.It +37052745012 http://ar.vgtu.lt
Bergen School of Architecture, Norway

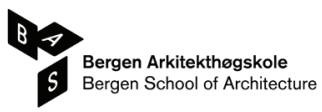

\section{OPEN FORM}

The formative architectural approach at BAS is based on the concept of Open Form as formulated by Oskar Hansen.

“[...] the room of propositions, dedicated to students' experimental works, where they could propose their own concepts to enhance the faculty curriculum [...] to guarantee an effective connection between the academic curriculum and the surroundings, making students sensitive to the needs of the contemporary society in which they would work after graduation."

- Quote from the book; Oscar Hansen, Opening Modernism. On Open Form architecture, art and didactics.

\section{AN ACTIVE ACTOR} WITHIN THE SOCIETY BAS encourage the active exploration of alternative ways of organizing society and offer input to debates concerning the challenges of our time.

BAS challenge and bring up to date the concepts of Open Form and Sustainable in its teaching, as part of a broad academic discourse.

BAS train architects whose understanding of local building traditions and physiography enables them to produce place-specific architecture and support community development. BAS act as a laboratory for experimental work that brings together innovation, tradition and responsibility to society.

\section{REVISITNG THE ROLE OF THE ARCHITECT}

BAS shall help to develop and challenge the profession's discourse concerning what an architect is and can be. Through our education, we seek to explore new methods of responding to complex realities and major challenges of the present. Adding value to space requires innovation, but also a historical overview and suitable tools to understand the forces shifting our differing cultures. BAS shall prepare students to create articulate and polemical architectural visions.

"To build, to form, is to open, not to close, complete or determine..." Svein Hatløy, Byggekunst 1983/6

DATA AND STATISTICS

Student numbers: 168 students, $49 \%$ female, $51 \%$ male

Staff size: 20 FTEs, 40-50 teachers part-time, including guest-teachers and lecturers

Facilities: Library (The Library of BAS has over 10,000 titles in the collection. There are purchased about 100 new books a year and BAS get about 50 different magazines annually. The school has a field library with about 30 titles traveling 
with the students in the field. The library also has four fishing rods and two bicycles available for students and staff - p. 9 of the annual Report) (workshop, wood, metal, CNC milling, outdoor area with a deepwater dock)

Curriculum \& Degrees in short: Master of Architecture (300 ECTS)

\section{ADDRESS \&}

PRACTICALITIES

Bergen School of Architecture PO Box 39

N-5841 Bergen Norway

Tel.: +4755363880

www.bas.org

Trondheim Faculty of Architecture, Norwegian University of Science and Technology, Norway

\section{NTNU}

$$
\begin{gathered}
\text { FORM, CLIMATE AND } \\
\text { IMPACT }
\end{gathered}
$$

NTNU's vision is: Knowledge for a better world. As a tool to achieve this, our faculty has developed a strategic compass where these three elements interact:

Form: We give shape to our physical surroundings and will contribute to restore aesthetic authority in society.

Climate: We work for a sustainable development and will seek climate-friendly solutions Impact: We are willing and able to take leading roles in society in order to promote aesthetic authority and sustainability.

The Faculty's disciplines are Fine Art, Architecture and Urban Planning.

\section{AN EGALITARIAN COOPERATION \\ BETWEEN STUDENTS AND TEACHERS}

Studio based learning centered on "hands on" and problem oriented tasks, assignments and processes. A learning process open for an egalitarian interplay and cooperation between a broad scope of cultures, disciplines and approaches both native to our profession and representative of external stakeholders and participants. This means that the core traditional craft of architecture is constantly re-invigorated by the challenges of art, community and science.

We welcome and sustain our students as individual representatives of cultures vastly broader then the present day Canon of Architecture.

\section{RESEARCH AND ARTISTIC DEVELOPMENT} The faculty hosts two research centers on international top level:

- ZEB (Zero Emission Buildings)

- Metamorphosis, on real estate development and facilities management. In addition we have a leading role at NTNU in developing Smart and Sustainable Cities. Our recently founded center on innovative learning, TRANSark, investigates the "next practice" in learning. Our scientific and artistic staff and PhD's develop new knowledge in many fields. Several are linked to our strategic focus areas. The faculty is a key player on the art scene in Trondheimand, on national and international arenas.

DATA AND STATISTICS

Student numbers: 700 students (70 Bachelor, 630 Master, $51 \mathrm{PhD}), 56 \%$

female, $44 \%$ male

Staff size: Full time equivalent: 129 Staff members

Facilities: Studios with personal permanent workspace for all students, Extensive modeling workshop: including 3D printers, laser cutters and CNC milling machines. CAD - lab, GISlab, light lab, media lab, space lab, living lab, photographic studio, plot center, copy center and printing facilities, sculpture studio, painting studio, Library with more than 61.000 titles and subscriptions to numerous periodicals. An extensive analog and digital collection of PhD theses and student graduation work, bookshop, cafeteria .....

Curriculum \& Degrees in short: Master program in Architecture (5 years) Master program in Architecture (2 years)

Bachelor of Fine Art Master of Fine Art

Master program in Physical Planning

Master program in Real Estate and Facilies Management Master of Science in Urban Ecological Planning

Master of Science in Sustainable Architecture 
Master of Sustainable

Urban Transitions

PhD Architecture Fellow-

ship Program Fine Art

\section{ADDRESS \&}

PRACTICALITIES

NTNU - Faculty of Architec-

ture and Fine Art Sentral-

bygg 1 på Gløshaugen

Alfred Getz vei 3Trondheim

Norway

Tel: +47 73550275

http://www.ntnu.edu/ab/

The Oslo School of

Architecture and Design, Norway

\section{TAIE[0]}

Arkitektur- og designhøgskolen i Oslo The Oslo School of Architecture and Design

\section{A UNIQUE RESEARCH- BASED EDUCATION OF INTERNATIONAL STANDING}

$\mathrm{AHO}$ offers research-based education designed to equip the students to enter professional practice or academia. AHO has a high awareness of the potential for research to impact on society via its mediation in various forms. $\mathrm{AHO}$ has an equal commitment to the development of professional culture in architecture and design in Norway and Internationally. Research at $\mathrm{AHO}$ is integrated into pedagogic strategies that inform all levels of education and continuing practice development.

\section{RESEARCH-BASED \\ TEACHING AND \\ TEACHING - INFORMED RESEARCH}

$\mathrm{AHO}$ believes that architecture practice requires both a holistic overview and a host of specialized competencies. The Architecture program emphasizes originality, craftsmanship and the ability to communicate ideas. Three institutes participate in the Master of Architecture's teaching and research within the areas Architecture \& Culture, Architectural History, Architecture and Landscape, Building Heritage, Cities, Design in Practice, Form, Large Scale Architecture, Mapping, GIS and analytical methods, Materials, Structure \& Ecology, Performance \& Computation, Practice, Space \& Technique Collabo

\section{EXCELLENCE WITHIN AND ACROSS DISCIPLINARY BOUNDARIES}

AHO carries out research in architecture, design, landscape architecture and urbanism. AHO has four Research Centers; Centre for Design Research , Oslo Centre for Urban and Landscape Studies, Research Center of Architecture and Tectonics and Oslo Centre for Critical Architecture Studies. We focus on excellence within and across our disciplinary boundaries and on maximizing our potential as a collaborative partner with other academic institutions, with the design professions and with industry.
DATA AND STATISTICS

Student numbers: 724 students (Master of Architecture 437, Master of Design 186, Master of Landscape Architecture 52, PhD 50)

Staff size: 180 Staff members (60 part time)

Facilities: The AHO library, cafeteria, copy center, gallery, extensive modeling workshop: including 3D printers, laser cutters and CNC milling machines, auditoriums, reseach labs, studios, computer labs, plot center and printing facilities.

\section{Curriculum \& Degrees} in short: Master of Architecture, Master of Design, Master of Landscape Architecture, Master in Urbanism (continued education), Master in Architectural Heritage (continued education), PhD

\section{ADDRESS \&} PRACTICALITIES The Oslo School of Architecture and Design Maridalsveien 29 P.O. Box 6768 St. Olavs plass NO-0130 Olso Norway

Tel: +4722 997000

Fax: +4722 997190 www.aho.no 
Faculty of Architecture, Warsaw University of Technology, Poland

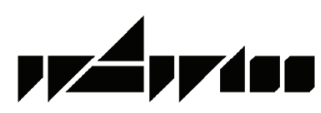

PEDAGOGICAL RESPONSES TO SOCIAL AND

CULTURAL CHANGES

IN CENTRAL EUROPE

The spatial and cultural image of central and eastern European countries has rapidly changed during the last 25 years. Given our current conditions, the Faculty of Architecture at the Warsaw University of Technology has developed an appropriate education model. We are searching for a balance between the local architecture identity and the need for universal communication as a result of globalization. We are responding to the current changes in social needs.

As a consequence, we are shaping new patterns of professional attitudes and new patterns of architectural solutions.

\section{BETWEEN TRADITION AND MODERNITY. ONE HUNDRED YEARS OF PROJECT- BASED LEARNING IN WARSAW}

In 2016, the Faculty of Architecture is celebrating the centenary of its foundation. We owe the present model of architectural education to the experience of facing long evolutionary processes in political, social and cultural meaning.

The program's main objective is to focus education on performing creative tasks in cooperation with experienced practitioners and theorists of architecture and urbanism. The educational profile of FA WUT includes: architectural and urban design, theory and history of architecture, visual communication, engineering, new media and information technology.

\section{FINDING}

ARCHITECTURE IN THE MULTIDISCIPLINARY ENVIRONMENT OF A TECHNICAL UNIVERSITY

The research activity at the FA WUT is performed through masters and PhD programs as well as scientific projects. The faculty is part of the largest technical university in Poland and promotes interdisciplinarity in cooperation with the faculties of engineering, mechatronics, geodesy, and material science, among others.

One of the most important research areas within FA WUT focuses on the use of information technology in architecture. Architecture for the Society of Knowledge - ASK program implements digital apparatus both as a communication tool and as a design medium.

\section{DATA AND STATISTICS}

Student numbers: 1198 students (693 Bachelor, 411 Master, 94 PhD)

Staff size: 152 teaching staff members including 26 professors, mostly fulltime

Facilities: Library with 50.000 titles, about 20 periodicals, computer labs, rapid prototyping lab, sculpture studio, drawing/painting studio, photographic studio

Curriculum \& Degrees in short: Bachelor of Science in Architecture 4-year program (240 ECTS),

Master of Science in Architecture 2-year program (120 ECTS), Graduate studies offer 8 specialized directions:

A1- Architecture of Ideas, A2-Architecture of the Living Environment, A3- Architecture of Technology and Structures, AiU1-Architecture and Urban Planning - the City as a Place for the Development, AiU2 Architecture and Urban Planning - the City as a Place of Life, DA- Architectural Heritage, Al- Information Architecture, AW- Interiors and Industrial Design Master of Science in Architecture; Architecture for Society of Knowledge (ASK), 2-year program (120 ECTS) (taught in English)

PhD program (4 years)

Faculty of Architecture is a member of European associations: EAAE, EASOP and cooperates with eCAADe, ACSA, ACADIA.

Faculty participates in the Erasmus program, bilateral agreement with South Korea, Singapore, Taiwan, Japan, exchange program with University of Detroit Mercy, cooperation with PBL Global Network $L A B$ at Stanford University and other international programs. 


\begin{abstract}
ADDRESS \&
PRACTICALITIES

Faculty of Architecture

Warsaw University of Technology Koszykowa 55; 00-

659 Warsaw Poland

$+48226282887$

http://www.arch.pw.edu.pl/ http://asknow.eu/
\end{abstract}

The Faculty of Architecture, Wroclaw University of

Science and Technology, Poland



ABOUT

The Faculty of Architecture

Wroclaw University of

Science and Technology is

one of the best architecture

schools in Poland. Our standards are confirmed

by: privileges to confer

scientific doctoral and

habilitation degrees, scien-

tific category A (for years

2013-2017), accreditation of

Polish Accreditation Com-

mittee (i.e. distinction for

Architecture) and AESOP

Certificate of Quality for

Spatial Planning. Students

at our faculty can gain

extensive theoretical and

practical knowledge which prepares them for creative work in the field of architectural design and urban planning.

\section{EDUCATION}

The Faculty of Architecture offers study programs to national and international students designed to equip graduates with both technical and humanistic academic knowledge, which is essential for their future careers as architects and urban planners. The studies provide an opportunity for students to develop their interests and skills in designing sustainable spatial and architectural forms. The main goal of education is to provide the necessary knowledge and abilities, which are tested in practice through training and verified by final exams and enable students to obtain professional licence.

\section{SCIENCE}

Researchers at the Faculty of Architecture lead the study in all disciplines connected closely to the educational program as national and international cooperation, working closely to other scientists and employers. This results in a large number of publications, in the diversified fields of Architecture. Moreover, Architectus: scientific journal is published by the Faculty of Architecture University of Technology since 1997. Faculty helds 5-7 international conferences held at the Faculty per year, complemented by national conferences, as well as international, national workshops.

\section{DATA AND STATISTICS}

Student numbers: There are 1566 students (2015/2016); 1308 at Architecture and Urbanism and 258 at Spatial Planning among them over 110 foreigners; 130 PhD Students
(2015/2016); 17 scientific students groups

Staff size: There are 143 scientific workers (2015/2016), 9 professors, 14 habilitation doctors, 106 doctors

Facilities: Main building with auditorium, lecture rooms, design workshop rooms, computer labs (CAD, 3ds Max, Microstation), printing labs, 3d printing lab, history library, sculpture studio, painting studios, photography studio, art and model shop, drawing rooms, students cafeteria; Additional building with lecture rooms, laboratory of technology and conservation, $3 \mathrm{~d}$ printing workshop and 3d scanning lab; New library building with multimedia contemporary library

Curriculum \& Degrees in short: At Architecture Ist level 3,5 year $(210$ ECTS), Ilnd level 1,5 year (90 ECTS), Ilnd level in English language 1,5 year (90 ECTS), At Spatial Planning Ist level 3,5 year $(210$ ECTS), Ilnd level 1,5 year (90 ECTS), Ilnd level in English language 1,5 year (90 ECTS), At Post Graduate Studies: Landscape Architecture 2 years, Urbanism and Spatial Planning 1 year, Industrial Heritage Protection, Maintenance, Adaptation (first edition in 2016), Doctoral Studies $(\mathrm{PhD}) 4$ years

ADDRESS \& PRACTICALITIES

Faculty of Architecture 
Wroclaw University of Science and Technology Prusa St. 53/55 50-317 Wroclaw Poland

tel. +48713206208 http://www.wa.pwr.wroc.pl

Faculty of Architecture, University of Lisbon, Portugal

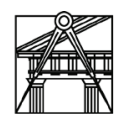

FACULDADE DE ARQUITETURA

UNIVFRSIDADF DF UISBOA

\section{AS A MODERN}

SCHOOL, FA

COMBINES TRADITION AND INNOVATION

The Faculty of Architecture (FA) offers courses leading to the award of the Bachelor's, Master's and PhD degrees in Architecture, Urbanism and Design. It also offers non-degree courses which provide further training for professionals who wish to extend their knowledge. This broad training offer makes the FA the largest and most diversified school in the country in its specialist areas, with an intake of approximately 3,000 students. In addition, it is the oldest school in Portugal, with a history dating back to the 16th century.

ON ALL THE COURSES, STUDIO DESIGN IS SEEN AS CORE DISCIPLINE, DRAWING ON OTHER

SUBJECT AREAS

The main feature is the training offered through design studio project work in the 1st and 2nd cycles, in which the knowledge acquired in all subject areas is applied to the design of a broad range of possible objects, from small-scale to territorial. The FA is also investing in training professionals who can work in Portuguese society and abroad, helping to increase its potential for innovation, competitiveness and exports. For this reason, special emphasis is placed on the development of final projects and dissertations produced in collaboration with external entities.

\section{PROVIDES STIMULUS FOR THE WORK OF YOUNG RESEARCHERS} The School provides professional training for architects, urban planners and designers and is recognised in the field of specialist interdisciplinary research. The Research Centre for Architecture, Urbanism and Design (CIAUD) promotes the advancement of scientific, technological and artistic knowledge with the main objective of creating a critical body of work and foster interaction between the various scientific areas of the FA/ULisboa, providing a framework for cutting-edge teaching whilst also contributing towards economic and social development.

DATA AND STATISTICS

Student numbers: 2633 students (322 Bachelor, 2056 Master, 193 PhD, 243 exchange programs)

Staff size: 220 staff members

Facilities: The FA offers students a wide range of support facilities for the various stages of academic life including the Library, Audiovisual Centre, reprographics service, 24-hour workshop (a space where students can work on their assignments), Publications Centre, Multimedia Centre, Cartography Lab, IT centre, Fashion Atelier, workshops, Rapid Prototyping Centre, Colour Laboratory, Photography and Image Synthesis Laboratory, 3D Digitalisation Laboratory, Intellectual Property and Knowledge Transfer Office and the FA Incubator. The School also offers other facilities that provide important services for students and staff, including a bookshop, a stationer's, a copy and printing centre and a computer shop.

Curriculum \& Degrees in short: Integrated Master's in Architecture has a 1st study cycle corresponding to the Bachelor's in Architectural Studies (180 ECTS), followed by a 2 nd cycle, either with specialization in Architecture (120 ECTS), Interior Architecture and Rehabilitation of the Built (120 ECTS) or Urbanism (120 ECTS).

Bachelor's in Design or in Fashion Design (180 ECTS).

Master's in Product Design, Communication Design or Fashion Design (120 ECTS) PhD in Architecture, Urbanism or Design (180 ECTS) 


\section{ADDRESS \& \\ PRACTICALITIES}

Faculdade de Arquitetura

(Faculty of Architecture)

Address: Rua Sá Nogueira

- Pólo Universitário do Alto da Ajuda 1349-063 Lisboa -

Portugal

Telephone: +351213615

000 www.fa.ulisboa.pt

Faculty of Architecture, University of Porto (FAUP), Portugal

\section{U.PORTO}

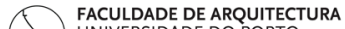

UNIVERSIDADE DO PORTO

\author{
AN UNIQUE \\ SPACE TO STUDY \\ ARCHITECTURE AND \\ URBANISM \\ Located in Porto, FAUP \\ was designed by the Pritz- \\ ker awarded Alvaro Siza. \\ In addition to the unique \\ atmosphere of the city, an \\ added value for students \\ to study architecture, FAUP, \\ also known as 'School of \\ Porto', is internationally \\ recognized and a world- \\ wide reference in architec- \\ ture graduation. The school \\ provides a wide variety of \\ programmes in architec- \\ ture/ urban studies. Here \\ and over the years, gen- \\ erations of architects have \\ been trained with awarded \\ Fernando Tavora, Alvaro \\ Siza and Eduardo Souto de \\ Moura, the best examples \\ of the scientific, artistic and \\ pedagogical skills of the \\ School.
}

A WIDE VARIETY

OF PROGRAMMES

THAT PROVIDE

QUALIFIED AND

MULTIDISCIPLINARY

TRAINING

With a range of different programmes within the school, the Master Degree in Architecture is the main general education offer.

The curriculum emphasizes the importance of freehand drawing and experimentation as a way of thinking and an approach to architecture practice. History and theory are also strong basis on the training of architecture students combined with construction and technology. The curriculum structure allows students to become critical and creative professionals within the complex connection between architecture, society and technology.

ARTISTIC, SCIENTIFIC, TECHNOLOGICAL RESEARCH ACTIVITIES

IN ARCHITECTURE AND URBAN PLANNING

The School offers, in addition to the Master in Architecture, a one-year Programme in Architectural Heritage leading to the Ph.D. Programme in Architecture; a six-month Programme of Advanced Studies in Architectural Design. Research in architecture and urbanism are supported in the Ph.D. Programme structured in 4 major Study Profiles (Housing; Architecture; Urban Forms; Heritage), throughout the curricula of the different courses and, also, as a primary focus in the Centre for Studies in
Architecture and Urbanism, R\&D Center and Research \& Development Unit.

DATA AND STATISTICS

Student numbers: 1.135 students (1.027 Master Degree in Architecture, 97 Ph.D. Programme in Architecture, 11 Advanced Studies Programme in Architectural Heritage), 111 students mobility.

Staff size: 30 Administrative staff, 83 Professors, 114 researchers (CEAU, 54 with a Ph.D.).

Facilities: The complex of buildings housing FAUP is one of the most emblematic creations of Alvaro Siza's career. The buildings, designed and built between 1985 and 1993 at Polo III (Campo Alegre) of the University of Porto, hosts a large number of studios and classrooms, auditoriums, exhibition gallery, administrative offices, cafeteria, bookshop, documentation centre and library. FAUP's Library is integrated in the University of Porto libraries, specialized in Architecture, with special focus on Urbanism, Art and History, contains in its asset more than 30000 monographic titles, and over 300 titles of serial publications, diverse media and cartographic documentation - also in digital formats.

\section{Curriculum \& Degrees in} short: Master Degree in Architecture ( 5 years, 300 ECTS); Degree in Architecture Studies (3 years, 180 ECTS) / 
Advanced Studies in Architectural Design (6 months, 32 ECTS) / Advanced Studies in Architectural Heritage (1 year, 45 ECTS); Master in Spatial Planning and Urban Project (MPPAU) - Joint programme with Faculty of Engineering â€" University of Porto (1 year, 60 ECTS/ 2 years 120 ECTS); Open Training Course Housing in Europe: a century of architecture (1 year).

Ph.D. Programme in Architecture (1 year, 60 ECTS/ 3 years, 180 ECTS) and title: dr.

\section{ADDRESS \&}

PRACTICALITIES

Faculty of Architecture University of Porto (FAUP) Via

Panoramica / S/N

4150-564 Porto Portugal servicos.academicos@arq. up.pt www.fa.up.pt

visitas@arq.up.pt

\section{Ion Mincu University of} Architecture and Urbanism, Romania

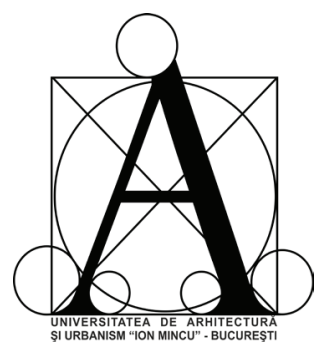

$$
\begin{gathered}
\text { ARTISTIC } \\
\text { EXPRESSION, }
\end{gathered}
$$

CRITICAL THINKING, CULTURAL IDENTITY

The current configuration of academic training in architecture is the result of the reform based on the
Romanian tradition in architectural education, contemporary information and influences, as well as on the collaboration with the professional international bodies (UIA -UNESCO, EAAE, ACE) and European schools of architecture.

The training of professionals with higher education in the fields and specializations of ARCHITECTURE, URBANISM, ARCHITECTURAL DESIGN and RESTORATION OF ARCHITECTURAL MONUMENTS and in their subsumed areas at various stages of undergraduate and postgraduate training.

\section{TRADITION, CREATIVITY, INNOVATION}

In the past 10 years, one of the major concerns of the University was the modernization of teaching and learning methods.

Periodic evaluation of the educational process also by committees of experts from abroad (France, United Kingdom - RIBA) in order to maintain the recognition of diplomas in those countries.

Organization of final assessment sessions (diplomas) with the participation of guests from abroad (an average of 4 professors and specialists/committee from the European countries, North America, both America, Canada and Asia).

\section{INTERDISCIPLINARY INTERNATIONAL COOPERATION}

The desire of renewal, of assimilation and develop- ment of knowledge and new orientations in the spirit of scientific truth, artistic beauty and functionality. The assertion in this context of the national cultural identity and Romanian participation in the development of art and universal science.

We have several research centers of excellence through the opportunities offered by the new information technologies, which would attract the best researchers and professionals in the field, in order to obtain valuable results; Inter-university collaboration is our main priority.

\section{DATA AND STATISTICS}

Student numbers: 2885

students (2356Bachelor+Master Integrated Architecture and Interior Architecture, 275Bachelor Urbanism 125Master Urbanism, $129 \mathrm{PhD} 54 \%$ female, $46 \%$ male, $4 \%$ foreign

Staff size: 409 Staff members (249 Full time members, 160 Associated members, ) 80 Visiting lectures and critics

Facilities: Library with 200.000 volumes and subscription to numerous periodicals, online access, Virtual Library, contain an extensive collection of PhD thesis and Student graduation work Archive of diploma projects,Bookshop and Printing house, Museum of architectural profession (1000 objects) and Gallery of the Romanian Architectural Creators (90 pieces), Gallery that 
collect paintings and drowning by famous architects, modeling workshop and $3 d$ printing , plot center, media lab, CAD lab, drawing, painting and sculpture labs, light lab, cafeteria, copy center, 3 student dorms, Study Centre for Vernacular Architecture in Dealu Frumos, Center for Architectural and Urban Studies, Research Center and Data Bank in Construction, Architecture and Urbanism, Center for Research, Design, Building Evaluation and Consulting, Stadium, Swimming pool, Sport hall. Two establishment Bucharest \& Sibiu (Transylvania).

Curriculum \& Degrees in short: Architecture integrated bachelor's and master's degree programme -6 years 360 ECTS Credits;

Interior Architecture, Product Design, Integrated Bachelor's and Master's Degree Programme, 5 years, 300 ECTS Credits;

Urban Design and Planning, Landscape Design and Planning Bachelor's Degree Programme, 4 years, 240 ECTS Credits;

Territorial Planning and Regional Development, Urban Mobility, Urban Management for Competitive Cities, Landscape and Territory , Urban Design , Urbanism and Public Policies, Master's Degree Programme, 2 years, 120 ECTS Credits;

Architectural Conservation and Restoration - SIBIU bachelor's degree programme -3 years 180 ECTS Credits;

Urbanism and Territorial Management Bachelor's Degree Programme, 3 years, 180 ECTS Credits;

Furniture and Interior Design Bachelor's Degree Programme, 3 years, 180 ECTS Credits;

\section{ADDRESS \&}

PRACTICALITIES

18-20 Academiei st. 010014 / Bucharest

ROMANIA

E-mail: dep.international@ uauim.ro rectorat.uauim@ gmail.com

Phone: 0040213077112

Fax: 0040213077109

\section{Faculty of Architecture, Slovak University of Technology in Bratislava, Slovakia}

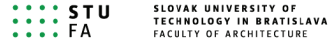

$$
\begin{aligned}
& \text { OUR FACULTY } \\
& \text { IS ONE OF THE } \\
& \text { SEVEN FACULTIES } \\
& \text { OF THE STU, ONE } \\
& \text { OF THE BIGGEST } \\
& \text { UNIVERSITIES IN } \\
& \text { SLOVAKIA }
\end{aligned}
$$

The ambition of the FA STU is to contribute to extending knowledge through its acquisition from science and to foster its dissemination via education as well as its application in direct co-operation with industry. The Faculty has nine institutes: Architecture of Residential Buildings; Architecture of Public Buildings, Sustainable and Experimental Architecture; History and Theory of Architecture and Heritage Restoration; Architectural and Engineering Structures; Interior and Exhibition Design; Design and Urban Planning; Industrial and Product Design.

\section{WE OFFER ACADEMIC EDUCATION AND CARRIES OUT RESEARCH AT AN INTERNATIONALLY COMPATIBLE LEVEL} The Faculty offers academic education and carries out research at an internationally compatible level in the following study fields: Architecture and Urban Design, Industrial and Product Design. Since 2002, in coherence with the Bologna Declaration, the study model consists of Bachelor's degree programmes in the study fields Architecture and Urban Design, Industrial and Product Design. The Master's degree programmes are in Architecture, in Urban Design, and Industrial and Product Design. These as well as the PhD. programmes can be taken also in English.

\section{RESEARCH-ORIENTED UNIVERSITY, PRACTICE UNDER GRANT PROGRAMMES, EXHIBITIONS, WORKSHOPS, COMPETITIONS}

STU is a research-oriented university. During its existence has contributed significantly to the development, dissemination and use of scientific knowledge. FA has a specialized library equipped with modern communication facilities. Own periodicals and specialized units contribute 
significantly to the research profile of the Faculty. Thematic research is being done by staff and co-researchers from the Academy of Sciences, other Faculties or practice under various grant programmes, complemented by exhibitions, workshops and competitions (e.g. Ecocity project, Oikodomos programme or urbANNAtur).

DATA AND STATISTICS

Student numbers: 1300 students (850 Bachelor, 400 Master, 50 PhD) $4 \%$ foreign

Staff size: 143 Staff members (105 full-time and approx. 38 visiting lectures and critics)

Facilities: Specialized library with study centre, bookshop, fully equipped CAD studio, photo laboratory, clay modelling-workshop, Laboratory of spatial simulation, Colour science laboratory, Training and research centre in Banska Stiavnica, stationery shop and copy service, student canteens, Audio - Lab, Bookshop, CAD - Lab, Cafeteria, Computing service, Copycenter, Exhibition hall, , Extensivemodelling workshop, Library, Plot centre, sculpture studio, painting studio.

Curriculum \& Degrees in short: Bachelor study programmes provide fundamental architectural education and prepare students for the master programmes. The Study Programme in Architecture and Urban Design (based on the EU guidelines)

focuses on theoretical knowledge as well as development of creative skills through design studios. In the fourth year students can choose from nine thematic modules. The final bachelor degree project consists of a theoretical seminar and an architectural or urban design, it is defended in the form of a state exam. The Study Programme Product Design offers a complex information basis in design theory, history of arts, ergonomics, technology and product engineering, material machining, ecology. Design studios ara important part of the study. The Master study programme in Industrial and Product Design is open to graduates of the Bachelor study programme in Product Design or related fields of study. The doctoral programme includes a number of courses and seminars and participants are invited to participate in research projects of the Faculty.

Bachelor study 4-year

Bachelor in Architecture and Urban Design

Bachelor in Product Design

Master study 2-year

Master in Architecture - Ing. arch.

Master in Urban Design Ing.arch.

Master of Arts in Product Design - Mgr.art.

Doctoral study 3-year (parttime 5-years)

Architecture PhD.

Urban Design PhD.
Industrial and Product Design ArtD.

ADDRESS \& PRACTICALITIES

Faculty of Architecture STU in Bratislava Namestie slobody 19

81245 Bratislava +421257276215 +421252921533 www.fa.stuba.sk

\section{Escuela Politécnica Superior de Arquitectura de Sevilla Polythecnic, Spain}

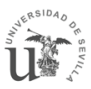

arquitectura
Escuela Técnica Superior
Universidad de sevilta

AN EXPERIENCED SCHOOL OF ARCHITECTURE (FOUNDED IN 1965) AND FOURTH IN AMOUNT OF STUDENTS IN SPAIN. Our institution provides a degree that qualifies the graduate to develop four main branches of professional activity, among others possible: the project of architecture, taking in consideration both social-environmental and technical dimensions; the building-regeneration project, with the same degree of involvement in cultural and constructive issues; the development of works of regional and urban planning, as leading figure or essential advisor of interdisciplinary teams; and, last but not least, as consultant in all fields of building engineering. 
THE INTEGRATION

EFFORT: TRAINING

THE ARCHITECT AS

MULTIDISCIPLINARY

PROFESSIONAL.

The architecture teaching nowadays encompass several and diverse fields of expertise and understands all of them like an unavoidable basis for future professional practice and research. Nevertheless, our School is also deeply conscious about concept of architectural practice as a synthesis of all these disciplinary fields that implies to surpass that conceptual and teaching fragmentation. Regarding this, the Architecture Workshop is our formative device of choice in order to produce integration of the diverse contents through a series of seven urban/architectonical exercises.

OUR MAIN AIM IS LINKING RESEARCH AND PROFESSIONAL DEVELOPMENT.

We are initiating a renovated $\mathrm{PhD}$ in Architecture Program, with a cross-disciplinary curriculum and the participation of 59 professors from 10 fields of expertise; mostly from the School of Architecture and also from the Schools of Building Engineering and Engineering. Main aims: designing of an Internationalization Plan, the effort to encourage companies with R\&D Departments to collaborate with us and the disseminating of research generated. Some numbers: 254 Doctoral Dissertations in our School, 85 of them from 2013. Other items: 26 teams for research; "Catedra Holcin" and TransArq Prizes.

DATA AND STATISTICS

Student numbers: nearly 3000, divided in: Graduates: 1850

Diverse Masters: 200

PhD: 150

Architect (Old Plan, currently expiring): 700

Staff size: Teaching Staff: 305 Administrative Staff: 60

Facilities: As one of the bigger Architecture Schools in Spain, there is wide teaching space in terms of classrooms (41 conventional units and many others for specific needs: construction technology laboratory, an assembly hall for 350 people, etc.)

There is also a Center of Innovation and Design that is defined as the central area of organization of the services of digital and technological support within the School of Architecture.

Linked with this service but independent there is a Digital Manufacturing Facility (Fab-lab) that share the same technology and processes with other laboratories worldwide in the same field, that allow our students and professors to elaborate projects internationally in order to, among other purposes, collaborate in research.

Our library is inside the ample catalogue of resources of the University of Seville (two millions of titles, with an important share of electronic ones). Other main features: remote access (connect to resources outside the campus), work rooms for groups (3 of them in architecture, with availability and reservation online, and 21 more in the same campus), consultation room, availability of printers, scanners and $\mathrm{Wi}-\mathrm{Fi}$, electronic consultations.

Curriculum \& Degrees in short: Bachelor Studies, 5 years program and 300 ECTS credits; Master in Architecture, 1 year program, and 60 ECTS credits; both are necessary to obtain the complete qualification as a professional Architect under the Spanish Regulations. Professional Masters, Brief Description and a complete list:These programs are useful resources to reach new skills in specific fields for both professional development and research; they are not focus only in architects, but in any possible professional that needs to improve their knowledge in such areas. The list is as follows: Master in Architecture and Heritage Conservation, Master in Architecture and Innovation; Master in Sustainable Architecture and Urban Sustainability; Master in Damage Assessment and Building Repair; Master in Town Planning and Urban Design; Master in Re-Design and Structural Regeneration of Existing Buildings; Master in Management of Industrial Heritage; Master in Sustainable Construction Project Management. All of them encompass 60 ECTS credits 
and one year of studies.

PhD program: 254 Doctoral

Dissertations in our School, 85 of them from 2013.

\section{ADDRESS \& \\ PRACTICALITIES \\ AV.REINA MERCEDES,2 \\ C.P: 41012 (SEVILLA)-SPAIN \\ Telephone: 95.455.65.01 \\ FAX: 95.455.65.34 \\ directoretsa@us.es \\ www.etsa.us.es}

\section{School of Architecture, University of Valencia, Spain

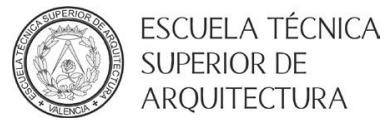

FIFTY YEARS OF EXPERIENCE IN TRAINING FOR ARCHITECTURE Since its foundation in 1966, the School of Architecture has conducted different curricula for the title of architect. The School has therefore fifty years of experience in training and qualifying for the practice of the profession of architect.

To get an official formal qualification as an architect in Spain, you must complete a five years Bachelor program integrating Architecture, Urbanism and Building Technology (Degree in Fundamentals of Architecture), plus one year Master program (Master in Architecture).

\section{A PROJECT \\ ORIENTED APPROACH TO EDUCATION, THAT BALANCES DESIGN +TECHNOLOGY The educational criteria applied to balance the disciplines involved are to maintain the high quality of architectural design togeth- er with the long time tra- dition concerning the high technical skills of Spanish architects. \\ The Teaching Method- ologies used in training include lectures, group work, problem-based learn- ing, case study, project based learning, exercises and problem resolution; laboratory; supervision, evaluation activities; theo- retical work, practical work, theoretical study; practical study, complementary ac- tivities; virtual work; learn- ing agreement.}

\section{A COMPLETE OFFER OF ACADEMIC PROGRAMS, FROM BACHELOR TO MASTER, POSTDOC AND PERMANENT TRAINING}

The integrated academic program of Bachelor in Fundamentals of Architecture and Master in Architecture is completed in our School with some specialization curricula: a Master in Advanced Architecture, Landscape, Urbanism and Design; a Master in Preservation of Architectural Heritage; and a Master in Landscape Architecture. The School of Architecture has also a PhD Program in Architecture, Building, Urbanism, and Landscape and supports open access research journal VLC arquitectura and postdoc third cycle doctoral education addressing the full scope of architecture and urbanism.

DATA AND STATISTICS

Student numbers: 3073 students (2839 Bachelor, 229 Master, $50 \%$ female, 50 male, $4 \%$ foreign.

Staff size: 204 teachers, 61 $\%$ full time teachers, 78 $\%$ architects, $52 \% \mathrm{PhD}$.

Facilities: Lecture Rooms, Acoustic Lab, Architectural Model Lab, Audio Visual Lab, Blackboard learn platform, Bookshop, Building Material Lab, Building Technology Laboratory, Cafeteria, Cartographic and Arch. Info. Lab, Computer Room, Computing service, Conference auditorium, Copycenter, Library and Documentation center, Exhibition hall, Exhibition Room, Photographic Studio, Printing facilities, Wi-Fi, Sports facilities, Stationery.

Curriculum \& Degrees in short: Bachelor Degree in Fundamentals of Architecture, 5 year program (300 ECTS). Master in Architecture, 1 year program (60 ECTS). Master in Advanced Architecture, Landscape, Urbanism and Design, 1 year program (72 ECTS), Master in Preservation of Architectural Heritage, 1 year program (72 ECTS), Master in Landscape Architecture, 2 year program (120 ECTS). 3rd cycle: PhD Program in Architecture, Building, Urbanism, and Landscape. 


\section{ADDRESS \&}

PRACTICALITIES

Polytechnic University of

Valencia School of Archi-

tecture

Camino de Vera s/n. 46022 Valencia (Spain). www.arq.upv.es

\section{A Coruña School of Architecture (ETSAC), University of A Coruña, Spain}

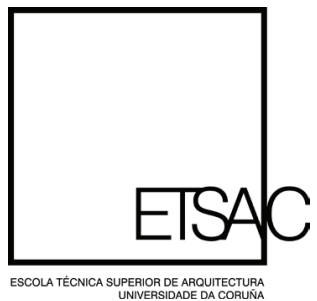

TO JOIN THE BEST DESIGN WITH A HIGH TECHNICAL ABILITY IS THE MAIN AIM OF OUR SCHOOL OF ARCHITECTURE ETSAC is the only school of architecture in Galicia, it was created in 1975. From the first years our academic and research interests are focused on Galicia. Four decades later, we keep this original goal, but we are in a transformative process of internationalization. In the Spanish tradition, the studies of Architecture have a high level of technical knowledge, joining this with artistic excellence is part of our academic identity. Our School has become an essential center for the architectural culture in our country, and we are increasing our social involvement.
TO KEEP A GENERAL TRAINING IN AN EVER WIDENING OUTLOOK IS OUR

FIRST EDUCATIONAL CHALLENGE

The professional profile of architects has changed significantly in the last years in Spain. Our School provides a general training for our students, particularly hard in design, urban planning, structures, construction and theory. We are convinced that all these skills are necessary to renovate a landscape, restoring an old building, to look for the best structural solution, to design a piece of furniture... But, all these architects' tasks are nowadays collaborative, for this our subjects take place in workshops, where all the skills and knowledges are integrated.

THE RESEARCH NOURISHES THE TEACHING AND RETURNS TO THE SOCIETY THE RESOURCES.

From the graduate, master and doctoral programs, our different research groups work towards these goals: to transfer to the society the results; to connect the research results with teaching contents; to place the architectural project as a main part of the research activity; to put in relation our school with other institutions, increasing opportunities of knowledge; and to include other scientific disciplines and arts in our workstreams.
DATA AND STATISTICS

Student numbers: 1468 students: 1302 bachelors; 77 master; 89 PhD. (Until 2015 the Diploma of Architect unscheduled a master program, the existing curriculum has five years for graduate degree and one year for master

Staff size: 118 academic staff (mostly full time), 28 administrative assistants.

Facilities: Study center, Secondary building (professors offices and lecture halls for master program). Library with 55.000 titles, subscriptions to periodicals, historic archive and map archive, access to architectural databases, as DoCoMoMo one. The UDC repository contains a broad digital archive of $\mathrm{PhD}$ theses and graduation works. Digital Lab, plot center and printing facilities. Photographic studio. Painting studio. FabLab with 3D printers and laser cutters. Exhibition areas. Offices for student organizations. Cafeteria and dinning hall.

Curriculum \& Degrees in short: Bachelor in architecture, 5 year program (300 ECTS). Master in architecture, 1 year program, just for bachelors in architecture (60 ECTS).

Master in architectural renovation, 1 year program (60 ECTS)

Master in landscape, shared with Santiago University, 1 year program (60 ECTS). 3rd 
cycle doctoral degree in Architecture and Urbanism (3-5 years): PhD, Dr.

\author{
ADDRESS \& \\ PRACTICALITIES \\ University of A Coruña \\ (UDC) \\ A Coruña School of Archi- \\ tecture (ETSAC). Campus \\ da Zapateira \\ Rúa da Fraga 23 \\ 15008 A Coruña Spain \\ +34981167056 \\ http://etsa.udc.es/web/
}

Lucerne University of Applied Sciences and Arts, Switzerland

\section{Lucerne University of \\ Applied Sciences and Arts \\ HOCHSCHULE LUZERN}

Technik \& Architektur

THE LUCERNE SCHOOL OF ENGINEERING AND ARCHITECTURE

Since 1958, the Lucerne School of Engineering and Architecture has been providing bachelor's and master's degree programs, continuing education programs and applied research. The practical degree programs and interdisciplinary study programs prepare students for the everyday work they will face as engineers and architects. The School conducts applied research in building, architecture and engineering and offers services in the two key specializations in Building as a System and in Intelligent Energy Solutions.
"I SEE THE TASK OF ARCHITECTURE AS

THE DEFENSE OF THE AUTHENTICITY OF HUMAN EXPERIENCE “ The statement by the Finnish architect and theorist Juhani Pallasmaa reflects the basis of our didactics in architecture education and not at least a modest attempt of a shared departement culture, which is obliged to the following triad: human experience, authenticity and architecture. We are convinced that a contemporary architecture education should attach great value to craftsmanship. We believe that architecture is generated through the sedimentation of our experiences, through the specific training of our senses and not at least through a free spirit.

THE COMPETENCE CENTER TYPOLOGY

\& PLANNING IN ARCHITECTURE (CCTP) The CCTP in Architecture investigates the interaction between man and the built environment. The main focus of this scientific research is the strategic transformation of buildings and urban districts. Our buildings and cities are under constant pressure to adapt. Responding appropriately to this situation is a responsibility of great social relevance. The CCTP analyses the status quo, develops concepts and collaborates with partners to find solutions and puts them into practice to generate added value for man and the environment.
DATA AND STATISTICS

Student numbers: 450

Staff size: 150

Facilities: studio, wood workshop, model making rooms, fotostudio, lecture hall, classroom

Curriculum \& Degrees in short: Bachelor, Master

ADDRESS \& PRACTICALITIES Lucerne University of Applied Sciences and Arts , The Lucerne School of Engineering and Architecture Technikumsstrasse 21 CH-6048 Horw

Switzerland https://www. hslu.ch/

\section{Section d'architecture Faculté Environnement naturel et construit, Ecole polytechnique fédérale de Lausanne, Switzerland}



ÉCOLE POLYTECHNIQUE FÉDÉRALE DE LAUSANNE

POLYTECHNICAL CULTURE, CRITICAL THOUGHT, PRACTICAL EXPERIENCE

The Lausanne Architecture School is a key component of a vast and articulate polytechnical environment. Many scientific disciplines cohabit within that environment and students from different departments pursue courses together in human and social sciences at the College of the Humanities. The School's mission is to train professionals and researchers within a solid technical culture. The latter is founded on the principle that intellec- 
tual thought and civic conscience must consistently inform the scientific and empirical methodologies.

\section{ADVANCED \\ TECHNICAL \\ DISCIPLINES,}

HUMAN AND SOCIAL

SCIENCES, CREATIVE EXPRESSION

Teaching architecture requires three fundamental principles: trying out and experimenting with different construction techniques, training in the ethos of architectural concrete, and the development of an individual expressive conscience that is coherent with collective needs and aspirations. These three pillars cannot be separated; they frame the architecture project and embody independent experiences towards which advanced technical disciplines, the human and social sciences, and creative expression converge. Thus, the project becomes an intellectual construct that exists thanks to architec

\section{ARCHITECTURE AS RESEARCH}

The main goal of the Institut d'architecture et de la ville (IA) is to develop research. This is a central task underlying architecture and requires the prioritisation of the quality of construction, the fitting into the surrounding environment, and the respect of natural and urban landscapes and of the cultural setting. The Institute's output spans six areas: the architecture project, theory and history, construction, technology and sustainable develop- ment, art and architectural expression, and finally, urbanism.

\section{DATA AND STATISTICS}

Student numbers: Students numbers: 1101 students (850 Bachelor [281 1st year], 251

Master, $101 \mathrm{PHD}$ ), 47\% female, $53 \%$ male, $38 \%$ foreign.

Staff size: Staff size: 170 staff members, mostly part time +60 visiting lecturers and critics (+ 75 experts during the graduation work).

Facilities: Facilities: Study Center, Library with 40 â $\% 000$ titles and subscriptions to periodicals, comprised electronical collections. Map archive. Modern and contemporary architecture archive. Vernacular architecture archive \& library. Infoscience (digital collection of scientific publications, $\mathrm{PHD}$ theses and students graduation work, 7000 entries, 2000 in full text). Bookshop. Cafeteria \& Restaurant. CAD lab. Extensive modeling workshop including 3D printers, laser cutters and CNC milling machines. Light lab, plot center and printing facilities, sculpture studio, engraving studio.

Curriculum \& Degrees in short: Curriculum \& Degrees in short: Bachelor of Science, 3-year program (180 ECTS), Bachelor of Science in Architecture degree. Master of Science, 2-year program (120 ECTS),
Master of Science in Architecture degree. (Interdisciplinary) Minor in Urban Studies and Planning.

(Interdisciplinary) Minor in Integrated Design Architecture and Sustainability (IDEAS).

\section{ADDRESS \&}

PRACTICALITIES EPFL ENAC SAR-GE

BÃ ctiment BP

Station 16

$\mathrm{CH}-1015$ Lausanne

enac.epfl.ch/architecture

Accademia di architettura, Università della Svizzera italiana, Switzerland

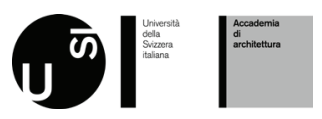

$$
\begin{gathered}
\text { THE STUDY } \\
\text { PROGRAM: AN } \\
\text { ORIGINAL SWISS } \\
\text { EDUCATIONAL } \\
\text { CURRICULUM } \\
\text { COMPLYING WITH } \\
\text { EUROPE-WIDE } \\
\text { PROTOCOLS }
\end{gathered}
$$

The curriculum offered at the Accademia di architettura in Mendrisio is integrated in the Swiss Education System and complies with the with the European University Studies regulations, and the final degree MSc (Master of Science in Architecture) is thus recognised by the European Community.

The full BSC curriculum includes a three-year program completed by two semesters of practical training in an acknowledged architectural firm. Follows a full MSc program with four very intense semesters. The 
whole suggested cycle of studies, where Design has a central role, last a total of six years.

\section{A FACULTY OF ARCHITECTURE WITH A STRONG INTERDISCIPLINARY, HUMANISTIC AND GENERALIST APPROACH}

Seeking to counter-act the fragmentation of knowledge threatened by over-specialization, the Accademia di architettura will ensure that the future architects will acquire skills based on an open and critical approach, ranging from architectural design to urban planning and landscape design, from the rethinking of historical heritage to developing sustainable projects. The practice in the Design Studios goes together with technical and scientific courses open to the issues affecting the contemporary world, and courses in history and the humanities: the arts, philosophy, criticism and sociology.

\section{PROMOTING AN UNDERSTANDING OF THE COMPLEX ARTISTIC AND ARCHITECTURAL HAPPENINGS}

Without limiting any of the potential fields of research, it is one of the important aims of the School to work towards a better comprehension of the complex processes in artistic and architectural creation. Advanced studies are available, leading to the degree of Doctor of Architecture (DrArch), Doctor of Techni- cal Sciences (DrScTech) or Doctor of Philosophy (PhD). Doctoral studies are usually linked to a National Research Fund acquired by a professor of the Accademia. Competitive research projects are financed by the National Research Fund and the

Swiss University Conference.

DATA AND STATISTICS

Student numbers: 800 students (500 Bachelor, 275 Master, $25 \mathrm{PhD}$ ), $50 \%$ female, $50 \%$ male, $25 \%$ Swiss, $75 \%$ Foreign

Staff size: 90 among Professors and Visiting Lecturers, 120 among Researcher and Assistants, 25 among Dean's Office and Administration

Facilities: The catalogue of the Biblioteca dell'Accademia (the faculty Library) includes no less than 120,000 volumes, more than 600 specialist journals, and thousands of periodicals in electronic format, while giving access to the best international academic data-bases. It is also a member of artlibraries.net.

The Archivio del Moderno (the archive for Modern Architecture) preserves more than 50 archives of architects, engineers, urban planners and designers, who have played a significant role in the development of modernity, a heritage that is constantly being updated. The books published by Mendrisio Academy Press (MAP) range from architecture to the history of art and to human ecology, from the history of science to philosophy. September 2017 will open the Teatro dell'architettura. The new museum is articulated over four levels, for a total exhibit area of $2300 \mathrm{sm}$. It will include a multi-purpose hall seating 350 people for conferences, symposiums, performances and concerts.

Further facilities: extensive modeling workshops including 3D printers, laser cutters and all kind of analogic machines. A dedicated model shop to cast concrete and gypsum, photographic studio, plot center, and printing facilities. Cafeteria and dining room at the Villa Argentina historical park.

Curriculum \& Degrees in short: Bachelor of Science, 3-year program +1 year of practice, (180 ECTS), Bachelor of Science in Architecture degree;

Master of Science, 2-year program (120 ECTS), Master of Science in Architecture degree; Research: National Research Fund projects, Swiss University Conference projects Doctoral degree: doctoral studies leading to a degree of Doctor in Architecture (DrArch), Doctor of Technical Sciences (DrScTec) or Doctor of Philosophy (PhD).

\section{ADDRESS \&}

PRACTICALITIES

Accademia di architettura Universita' della Svizzera 
italiana Villa Argentina

Largo Bernasconi $2 \mathrm{CH}$ -

6850 Mendrisio $\mathrm{Ph}+4158$

6665000

Fax +4158 6665868

E-mai info.arc@usi.ch

www.arc.usi.ch

Faculty of Architecture, Zurich University of Applied

Sciences \& Arts, Switzerland

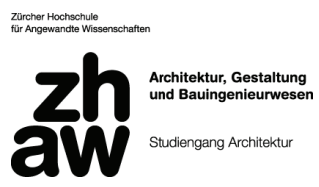

A SECOND WAY

TO BECOMING AN ARCHITECT

The Swiss system of education offers two ways of becoming an architect: a academical at the universities, and a second path based on apprenticeship. The universities of applied sciences offer courses that build on such professional training. Since its foundation in 1874 the ZHAW has focussed on providing a practice-oriented education. The introduction of the bachelor and master programs in 2005 according to the Bologna model allowed new concepts of teaching as well as research/development. This was also the time to strengthen relations with partner schools in B, GB, P, SLO, E, among others.

\section{ACTING LOCALLY -} WITHIN A EUROPEAN NETWORK

The Bachelor leads to a first title. 1st year: General introduction to architectural thinking, designing and working. 2nd year: Housing - the rooms of a house and the aggregation of houses in an urban context. 3rd year: Public building - diverse spatial program in a urban setting -relation between surface and structure, influence of building technology. The Master is organized in vertical studios. Programs and questions in the design studio are formulated by students and teachers. The hierarchies are flat: no chairs, no teaching assistants. Teachers mostly run their own offices.

\section{RESEARCH CONNECTING TEACHING, THEORY AND PRACTICE}

Research is carried out in two units: the Institute for Urban Landscape and the Institute for Constructive Design. The connection between teaching, research and professional practice is central. This includes specifically research by design. The focus of research work done at IUL is on the development of methods and instruments for describing and evaluating urban and urbanized spaces as well the process of their transformation (scenario-technique method). The IKE deals with the interaction between the technical, material and aesthetic requirements of construction (synchronous design method).

DATA AND STATISTICS Student numbers: 290 students (230 BacheIor, 60 Master, no PhD students), $32 \%$ female, $68 \%$ male, $25 \%$ Non-
Swiss

Staff size: 95 staff members, mostly part-time, and visiting lecturers and critics. Advisory council

Facilities: Since 1991 the ZHAW's faculty of architecture is housed in Hall 180 - a former boilermakers shop of the Sulzer machine company Winterthur built in 1924. Here students and staff have at their disposal a spacious and inspiring learning environment. The impressive architectural space is part of the didactic program. All students have access to a personal workspace 24 hours a day, a library specialised in architecture and construction, a science center with an extensive collection of building materials' samples and documentation (maps, plans, and photographs), a models workshop with 3D printers, laser cutters, CNC machines, 3D sanners, a plot center, and a photographic studio. The building also offers a mensa and a cafeteria. An addition to the school is under construction and will be opened 2017.

Curriculum \& Degrees in short: Bachelor of Arts, 3-year program (180 ECTS, Bachelor of Arts ZFH in Architecture degree)

Master of Arts, 2-year program

(120 ECTS, Master of Arts ZFH in Architecture degree) Various courses in continuing education 


\begin{abstract}
ADDRESS \&
PRACTICALITIES

Zürcher Hochschule für Angewandte Wissenschaften (ZHAW) Departement Architektur

Gestaltung und Bauingenieurwesen Studiengang Architektur Halle 180/Postfach 8401 Winterthur Schweiz www. zhaw.ch
\end{abstract}

\section{Amsterdam Academy of Architecture, the Netherlands}

\section{Academy of Architecture}

COMBINE STUDY AND PROFESSIONAL PRACTICE IN AMSTERDAM The Amsterdam Academy of Architecture is a distinguished educational institution. Year in year out, professionals and students alike have ranked our master's programmes as excellent. The courses combine both study and work. Half of the master's courses consists of design education, the other half consists of acquiring professional work experience. Graduates are immediately admitted to the Dutch professional register of architects, urbanists and landscape architects (BNA). Over the years our students have won prestigious prizes such as the Archiprix and the Prix de Rome.

\section{FOR DESIGNERS BY DESIGNERS}

The Amsterdam Academy of Architecture prepares students to practice spatial design as a discipline at the interface of art, science and technology. The Academy challenges you to develop into an excellent architect, landscape designer or urbanist. Here you work in conjunction with other design disciplines in an international context on research-led projects. This synergy and breadth is unique to our training programmes. Our tutors are leading designers who combine their roles of designer and educator. Our students receive a thorough academic training in combination with practical experience.

\section{AMSTERDAM AS LABORATORY}

Specific locations in the Netherlands and abroad are the designer's laboratory. The city of Amsterdam is actively deployed in the courses as a permanent laboratory for design projects. The Academy maintains strong ties with the professional community in the region, with public services, clients and project developers. The Academy has three research groups, one for each of the master's programmes, that give an important impulse to the interaction between the 'state of the art' in art practice, and the teaching and research of the Amsterdam University of the Arts and the separate faculties.

\section{DATA AND STATISTICS}

Student numbers: 250 students, $57 \%$ male, $43 \%$ female, $40 \%$ foreign.

Staff size: 30

Facilities: The premises of the Amsterdam Acad- emy of Architecture consist of a number of historic buildings with a unique atmosphere. A radical renovation has been undertaken by Claus and Kaan Architects in 2007. The Academy has a number of classrooms, most of which are adapted to the different types of lesson and equipped with digital presentation facilities, an improved auditorium, and an exhibition space which is also used as a model workshop.

The Academy also has a specialised library and a large canteen.

Curriculum \& Degrees in short: Master of Architecture (MArch), Master of Urbanism (MUrb), Master of Landscape Architecture (MLA). All graduates are entitled to the title of 'Master of Science'.

\section{ADDRESS \&} PRACTICALITIES Amsterdam Academy of Architecture Amsterdam School of the Arts Waterlooplein 211-213 NL-1011 PG Amsterdam www.academyofarchitecture.nl +31 (0)20-5318218 info@bwk.ahk.nl 
Faculty of Architecture and the Built Environment (A+BE), Delft University of Technology, the Netherlands

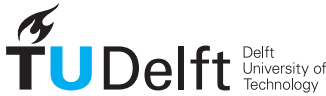

\author{
A BROAD AND \\ GLOBALLY \\ ORIENTATED \\ ARCHITECTURE \\ FACULTY
}

The combination of a strong research profile linked to the educational, along with the passion and creativity of its academic community, are the (inter) nationally driving forces of the Faculty $A+B E$. Led by societal relevance, education and research are closely intertwined in the internationally orientated and English spoken master program. After starting with a broad, three years Bachelors program integrating Architecture, Urbanism, Landscape Architecture, Building Technology, and Management in the Built Environment, students specialize in a in one of these fields or choose for the new MSc Geomatics master track.

\section{A PROCESS AND PROBLEM ORIENTED APPROACH TO DESIGN EDUCATION}

The problem and process oriented approach to architecture and the built environment combines learning by doing, often based on case studies, and scientific rigor with technical knowledge. Within this approach design studio teaching constitutes the backbone. Education also includes courses in theory, research methods, communication patterns and scientific critique. From architecture to building technology, landscape architecture, urbanism, geomatics and management, the faculty is unique in dealing with all aspects of the built environment.

\section{RESEARCH \\ EDUCATION RANGING FROM MASTERS \\ LEVEL TO POSTDOC, PHD AND PERMANENT TRAINING OF PROFESSIONALS}

Design research is conducted on different levels of education within overarching research programs. This research includes evaluation research, historical (archival) research, conceptual research and practical (design) research. The Delft Graduate School specifically supports post doc and third circle doctoral education that addresses the full scope of architecture and urban design, history, architectural engineering, planning, management, and real estate and housing.

DATA AND STATISTICS

Students numbers: 2750 students (1250 Bachelor, 1500 Master, 220 PhD), 45\%

female, $55 \%$ male, $31 \%$ foreign

Staff size: 521 Staff members, mostly part-time +215 visiting lectures and critics Facilities: Study center, library with 41,000 titles and subscriptions to numer- ous periodicals, map archive. The Delft library repository contains an extensive digital collection of $\mathrm{PhD}$ theses and student graduation work. Bookshop, CAD - lab, cafeteria, copy center, dining hall, documentation center, C.E.D.A.T: catalogues, data files, CD-rom, video-discs. Extensive modelling workshop: including 3D printers, laser cutters and CNC milling machines. Library, light lab, media lab, model shop, photographic studio, plot center, and printing facilities, sculpture studio, painting studio.

Curriculum \& Degrees in short: Bachelor of Science, 3-year program, (180 ECTS), Bachelor of Science in Architecture degree;

Master of Science, 2-year program (120 ECTS), Master of Science in Architecture degree;

Master of Science in Building Technology degree;

Master of Science in Urbanism, and Master of Science in Landscape Architecture degree; Master of Science in Management in the Built Environment degree, and Master of Geomatics.

Research, Postdoc \& PhD programs; Graduate School of $A B+E$; Post master programs: The Berlage ( 1,5 year, 90 ects) and EMU

(European Post-master in Urbanism); Participation in the Master City Developer program, together with Munici- 
pality of Rotterdam and

Erasmus University

Rotterdam.

3rd cycle doctoral degree

(4 years): PhD (Doctor

of Philosophy) and title:

dr.

\section{ADDRESS \&}

PRACTICALITIES

Delft University of Technol-

ogy Faculty of Architecture and the Built Environment Julianalaan 134

PO Box 5043

NL-2600 GA Delft

www.tudelft.nl

\section{Rotterdam Academy of \\ Architecture and Urban \\ Design, the Netherlands



\section{EMBEDDED \\ CRAFTSMANSHIP}

The Rotterdam Academy

of Architecture and Urban

Design, part of the Rotter-

dam University of Applied

Sciences, offers two 4-year, design driven, professional

Master programs: one in

Architecture and one in

Urban Design. The gradu-

ates of both Dutch spoken

Master programs position

themselves in contempo-

rary professional practice

on the basis of their em-

bedded craftsmanship. This

embedded craftsmanship

is characterized by the con-

tinuous interplay between

design craftsmanship,

professionality and societal engagement.

\section{THE CONCURRENT EDUCATIONAL MODEL}

Quintessential to the Master programs of the Academy is the concurrent educational model: the parallel and intertwining trajectories of work and study. This implies that students work in professional practice for (at least) 20 hours a week and study at the Academy for 20 hours a week. Working in practice and simultaneously studying at the Academy provides training leading to qualification as an architect or urban designer who has a broad experience with everyday professional reality as well as has experimented comprehensively with state of the art and new instruments and methods.

\section{RESEARCH BY DESIGN}

Research by Design is a pivotal part of the design craftsmanship of architects and urban designers, because design is about formulating, imagining and giving insight into possible futures. Therefore the Rotterdam Academy of Architecture and Urban Design focusses on research by design in both its curriculum and in its collaboration with research units within the Rotterdam University of Applied Sciences as well as with the research group Future Urban Regions, which is a partnership between the six Academies of Architecture in the Netherlands.

\author{
DATA AND \\ STATISTICS
}

Student numbers: 140

MSc students (110 in

Architecture, 30 in Urbanism).

Staff size: 13 tenured members of Staff (mostly part-time) +100 guest professors, 60 visiting critics and 80 visiting lecturers per year. All the guest tutors work in professional practice.

Facilities: The Rotterdam Academy of Architecture and Urbanism is situated in the port area of Rotterdam, in the former headquarters of RDM. This area has been transformed into an area with a focus on research, design and manufacturing. Within the building of the Academy, the central place is the exhibition and community hall, with a library and a 24/7 work space right next to it. In Innovation Dock, one of the huge former production warehouses on the site, there is an extensive modelling workshop, including CNC milling machines and 3D printing facilities. In the adjacent garden village of Heijplaat, there is the Academy House (Villa Heijplaat), for students to sleep overnight. In the vicinity of the Academy - the Rotterdam metropolitan region - there is an abundance of great, innovative and experimental architectural and urbanistic design offices to work at.

Curriculum \& Degrees in short: Master of Sci- 
ence, 4-year concurrent program (240 ECTS), Master of Science in Architecture degree or Master of Science in Urbanism degree.

\section{ADDRESS \&}

PRACTICALITIES

Rotterdam Academy of

Architecture and Urban

Design / Rotterdamse Academie van Bouwkunst

Heijplaatstraat 23

NL-3089 JB Rotterdam PO

Box 25035

NL-3001 HA Rotterdam www.ravb.nl

Unit Architectural Urban Design and Engineering (AUDE) in the Department of the Built Environment, Eindhoven University of Technology, the Netherlands

\section{$T U / e$}

BUILDING THE FUTURE: A BROAD, INTERNATIONAL AND FUTURE ORIENTED ARCHITECTURE UNIT AUDE is one of the four units making up the Department of the Built Environment. The unit consists of four chairs. Spatial design is both the raison d'être of the unit as a whole as well as the binding force between the chairs. AUDE's education is research- and demand-driven with international orientation. All programs are taught in English: A 3-year BSc (Architecture, Urbanism, Building sciences), a 2-year MSc(Architecture, Building and Planning), a 2-year PDEng (Smart Energy Buildings and Cities), and 4-year PhD program.

\section{A RESEARCH-AND DEMAND-DRIVEN ARCHITECTURAL EDUCATION WITH INTERNATIONAL ORIENTATION}

The educational strategy of AUDE is based on a broad conception of architecture. It interrelates architecture, urban design, urban studies, history and theory, building technology and associated fields. Thereby education combines research and societal relevance within a global orientation. Core teaching elements are the combined research- and design-studios, in which theory in practice, rigorous analysis, and experimentation are central.

$$
\begin{gathered}
\text { RESEARCH } \\
\text { EDUCATION RANGING } \\
\text { FROM MASTERS } \\
\text { LEVEL TO PDENG, PHD } \\
\text { AND POSTDOC }
\end{gathered}
$$

Design research is central within AUDE's education bringing together a broad range of perspectives, expertise and methods. AUDE's research is framed through the Living Cities Research Program through thematic clusters (i) Cultural Heritage, (ii) Sustainability and Circular Cities, (iii) Active Mobility and Health, (iv) Smart Cities and Buildings, and (v) Emerging Materials and Building Technologies aiming to contribute to architectural discourses and design practices by exploring in its research heterogeneous actors, elements and perspectives, and diverse spatial and temporal scales.
DATA AND STATISTICS

Student numbers: 1706

students (Bachelor intake 131, HBO intake 149, Bachelor diplomas 203, Master diplomas 269, PhD defences 12, PDEng diplomas 8) [data for BE 2014]

Staff size: 380 Staff members (27 Professors, 4 Fellows, 14 Associate professors, 37

Assistant professors, 39 Lecturers, 105 PhDs, 22 PDEng trainees, 29 Researchers, 7 Postdocs,

96 Support) $\pm 33 \%$ nonDutch

Facilities: Library providing access to an extensive collection of printed and digital resources, Pieter van Musschenbroek laboratory (structural design and materials properties), Building Physics and Services laboratory (experiments in all aspects of building physics like light, air quality, moisture and heat, airflow, materials, urban climate), Lighting room (simulating daylight), Laboratory for Acoustics, Laboratory for Design Systems, Model workshop for students, Atmospheric Boundary Layer Wind Tunnel, and 3D Concrete Printing laboratory (consisting of a four axis gantry robot with a print bed of approximately $10 \mathrm{~m} \times 5 \mathrm{~m} \times 3 \mathrm{~m}$ )

Curriculum \& Degrees in short: Bachelor College

Bachelor of Science, 3-year program, (180 ECTS), BSc Architecture, Urbanism \& Building Sciences; 
Graduate School:

Master of Science, 2-year program (120 ECTS), MSc Architecture, Building and Planning, MSc Construction Management and Engineering (3TU):

PDEng designer's programs, 2-year program, PDEng Smart Energy Buildings and Cities; $\mathrm{PhD}$ research, 4-year program, PhD

\section{ADDRESS \&}

PRACTICALITIES

Eindhoven University of Technology? Department of the Built Environment Unit AUDE

Vertigo 7

Den Dolech 2

5612 AZ Eindhoven

the Netherlands

Faculty of Fine Arts, Design and Architecture Department of Architecture, Atilim University, Turkey

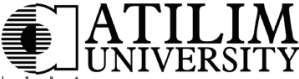

\author{
DEPARTMENT OF
} ARCHITECTURE WITH AN INNOVATIVE AND COLLABORATIVE APPROACH

The purpose of the Department is to train and educate well-equipped architects who are conscious about professional ethics, socially aware and environmentally sensitive within the modern educational atmosphere that it offers. In this regard the overall program is constituted of developing thinking and designing patterns based on innovative, collaborative approach and criticism, and acquiring the students the skills of researching, reaching and converting information.

\section{“LEAVE YOUR MARK ON THE FUTURE"}

Department of Architecture gives education in contemporary facilities with the aim of graduating architects sensitive to the environmental and ethical issues; discover the means to reach scientific and art related sources pertaining to the profession; can think critically and flexibly. With regard to the universitys goal of 'leaving a mark on the future', great importance is given to interdisciplinary collaboration, production of scientific studies at both national and international levels, not only by acquisition of knowledge but also by developing an awareness to social responsibilities.

INCORPORATING UNDERGRADUATE AND GRADUATE RESEARCH Incorporating research at all levels of education is the main aim. During bachelor years, for establishing a culture of research, supporting team work and raising students who are creative and inquisitive, a support program called Undergraduate Research Projects (URP) is established. Department of Architecture has ongoing scientific and design research projects that are carried out by undergraduate students. In addition to the already existing Integrated $\mathrm{PhD}$ in Architecture, a new Non-Thesis Master's pro- gram focused on New Settlements and Housing will be established by Fall, 2016-2017.

DATA AND STATISTICS

Student numbers: 299 students | 285 Bachelor, 14 Integrated $\mathrm{PhD}$ in Architecture

Staff size: 48 Academic Staff members | 11 Full Time Academic Staff, 5 Teaching Academic Staff from Other Departments within Faculty, 27 Part Time Academic Staff and Many Visiting Critics \& Lecturers

Facilities: 19 architectural design studios, 4 computer labs, 4 classrooms and an Architectural Acoustics Laboratory

Atilim University Library with 75305 published books, more than 92000 e-books, subscriptions to 1681 published periodicals and more than 29000 e-periodicals. The library repository contains an extensive digital collection of MS and $\mathrm{PhD}$ thesis.

Cafeteria, copy center, dining hall, archive center, photographic studio, plot center and printing facilities, sculpture studio, painting studio.

Curriculum \& Degrees in short: Bachelor of Science, 4-year program, (240 ECTS), Bachelor of Science in Architecture degree

Integrated $\mathrm{PhD}$ in Architecture, 5-year program, $\mathrm{PhD}$ (Doctor of Philosophy) in Architecture degree and title: $d r$ 


\author{
ADDRESS \& \\ PRACTICALITIES \\ Atilim University | Faculty \\ of Fine Arts Design and \\ Architecture \\ Department of Architecture \\ Kizilcasar Mahallesi \\ Incek / Ankara \\ +903125868000 \\ info@ atilim.edu.tr http:// \\ mim.atilim.edu.tr/
}

Faculty of Architecture, Eastern Mediterranean University, Turkey

\section{Eastern}

Mediterranean

University

"For Your International Career"

\section{INTERNATIONALLY RECOGNIZED \\ EDUCATION WITHIN \\ A MULTI-CULTURAL CAMPUS}

Containing three bachelor programs (architecture and interior architecture) besides seven master programs (including master programs with thesis and without thesis in architecture and interior architecture) and two PhD programs (in architecture and interior architecture), the education is realized within a multi-cultural campus environment. Except one Turkish bachelor program, speaking language is English. Duration of bachelor programs is four years. Normal duration of master programs change between one and two years. Normal duration for PhD programs is four years.

\section{STUDIO BASED EDUCATION IN WHICH DESIGN STUDIO BECOMES THE MELTING POINT FOR THEORETICAL KNOWLEDGE}

Both of the two bachelor programs follow the requirements of studio based education. The first year studio is realized together with the students of both bachelor programs. Programs separate from each other after the first year. Students are introduced to individual design gradually. This is realized through having group teachers at the beginning, getting critics from various staff later and getting less critics during the graduation project. All design studios deal with all aspects of design including functionality, aesthetics/meaning, urban design, structural design, construction, issues etc

\section{DEVELOPMENT OF RESEARCH ABILITIES \\ AND INTEGRITY IN RESEARCH FROM BACHELOR TO MASTER AND PHD}

Bachelor students are asked to make research in many theory courses as well as design courses. The issues of research ethics have also been gradually introduced to them. Academic research education starts with the master of science programs at the end of which students are asked to produce thesis. There are two master of science programs which accept students for various areas (such as design theory, history of architecture, structures etc.) which take place within the fields of architecture and interior architecture. Contribution to advancement of knowledge is expected at $\mathrm{PhD}$ level.

DATA AND STATISTICS

Student numbers: 1288 students from 53 countries (1038 Bachelor, 156 Master, $94 \mathrm{PhD}$ ) -

90\% Foreign

Staff size: 42 Staff members ( 26 Full-time ( 7 Professors, 8 Associate Professors, 11 Assistant Professors) and 17 Part-time))- 23 Teaching Assistant.

Facilities: Design studios, Lecture Halls, Computer-based laboratories, Environmental/Physical laboratory, Library, exhibition Hall, Conference Hall, Printing office and stationary, Canteen and cafeteria, Fixed LCD in Classes, Model-making laboratory, Archive

Curriculum \& Degrees in short: Bachelor of Architecture, 4-years program Master of Science in Architecture, 2-years program

Master in Architecture, 1year program

Master of Science in Urban Design, 2-years program Master in Urban design, 1-year program

Master of Science in Culture and Heritage Studies $\mathrm{PhD}$ in Architecture

ADDRESS \& PRACTICALITIES

Eastern Mediterranean University Faculty of Architecture Famagusta North Cyprus Mersin 10 Turkey

Tel: +90 3926301346 
Fax: +90 3926302365

E-mail: faculty.arch@emu.

edu.tr Web: http://arch.emu. edu.tr

\section{Fatih Sultan Mehmet Vakif University, Turkey}

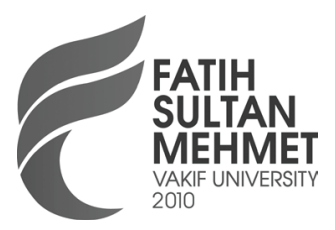

FROM THE DEPTHS OF HISTORY TO

THE FAR-REACHING HORIZONS OF

SCIENCE AND ART

The University is a higher education institute, established in 2010 by the Republic ofTurkey General Directorate of Foundations whose goal is to be at the forefront of Turkish higher education and research. The University is subsidized by the famously old Fatih Sultan Mehmet Waqf (charitable trust), which was founded in 1471 by Sultan Mehmet II who preserve and protect the Hagia Sophia Mosque, which was later extended to provide funding for education and has continued to provide funds for learning since then. We feel privileged to have our origins in such a venerable academic heritage.

\section{FOLLOWING THE CONTINUITY \\ OF CULTURE IN \\ ACHIEVING THE \\ ADVANCED FUTURE \\ PROGRESSION}

The faculty aims to teach both the Eastern and West- ern architecture and cultur-

al heritage besides teaching the new technologies.

Furthermore, to cultivate students with traits such as comprehensive technical knowledge, advanced technical skills, a genuine interest in culture and art and a caring for the rich cultural heritage of our civilization with the help of our meticulously prepared curriculum.

\section{FROM BARCH TO PHD BETWEEN THE PAST AND THE FUTURE}

The faculty aims to conduct culture and art-oriented research model. The physical characteristics of Istanbul, which has been risen in the 3000 years-old urban culture and futuristic urban environment, makes the architectural education occur in the blend of historical and modern. The faculty aims to develop projections facing future developments starting with the cultural and architectural heritage of the famously old Fatih Sultan Mehmet Waqf. The taught research abilities will prepare the students to both a PhD in architecture and a career outside the university.

\section{DATA AND STATISTICS}

Student numbers: 900 Students (573 department of architecture, 192 department of interior architecture, 111 master level, 24 PhD level)

Staff size: 74 Staff (35 academic Staff, 39 visiting instructors)

Facilities: 5 classrooms, 3 architecture studios, 2 computer labs, model making atelier, 3D print atelier, research center

\section{(KURAM)}

Curriculum \& Degrees in short: According to the Bologna Accord:

Bachelor of Architecture, 4 th ranked of the Department, one English preparatory, 240 ECTS, Bachelor of Interior Architecture, 4th ranked of the Department, one English preparatory, 240 ECTS,

MSc. in Architecture, professional degree with thesis, 2 years program

MSc. in Architecture, in English, professional degree with thesis, 2 years program MSc. in Conservation-Restoration, professional degree with thesis, 2 years program MSc. in Cultural Heritage Conservation and Management, with thesis, 2 years program $\mathrm{PhD}$ of Architecture, 4 years program

ADDRESS \& PRACTICALITIES

Faculty of Architecture and Design Halic Campus (Golden Horn)

Address: Sutluce Mah. Karaagac Cad. No:12 Beyoglu ISTANBUL/TURKEY

Phone : +90 2123698162 Fax: +90 2123698164 Web: http://mtf.fsm.edu.tr/ http://iro.fatihsultan.edu.tr/ 
Faculty of Architecture, Gazi University, Turkey



AN ARCHITECTURE FACULTY THAT INTEGRATES

PROMINENT PRACTICE \& ACADEMIC/ SCIENTIFIC EDUCATION

Collaborations between part-time eminent practicing professionals and expert academics provide students with the realities of ongoing (inter)national professional practice and the latest knowledge-based ways of dealing with it. Students of all levels are given reality-based tasks that require research, methodology and materialization. Students who complete 4-year Bachelor program become professionals, can register to related professional organizations and perform their occupation. Specializations through 2 years $\mathrm{MSc}+4$ years $\mathrm{PhD}$ levels are also possible.

AN ARCHITECTURAL DESIGN EDUCATION

IN WHICH THE

STUDENT IS IN FOCI Individuality, independency and creativity of candidates are given priority. Students are given daily, (inter)national, realistic problems in all scales and are asked to develop unique solutions.
Besides research-based design studio teaching, theoretical courses, elective courses run by distinguished university professors and the seminars given by eminent professionals support students' understanding architecture. Students become candidates for the jobs suitable for their personal expectations and adapt to their first jobs easily. Graduates have wide-range of areas for (inter)national work.

\section{RESEARCH IN}

ARCHITECTURE IN EVERY PHASE

Main areas of research; Architectural Theory\&Building, Construction, Restoration and History. Each course and studio in undergraduate education is supported by semi-scientific research specific to content. Some courses; research techniques, programming, criticism, post-occupancy evaluation, design theories, ecology, energy-efficient design, illumination, acoustics, fire safety, design methodologies, aesthetics, design for all, design for earthquake, quality management, risk management, project management, preservation\&restoration, sustainability and traditional construction techniques.

DATA AND STATISTICS

Student numbers: Architecture: 505 (BSc) + $358(\mathrm{MSc})+72(\mathrm{PhD})$ students

Staff size: 92 full-time staff members +20 part-time professionals +40 visiting lecturers and critics

Facilities: The faculty takes place in the city center of Ankara (Turkey), close to dining areas, stationary and book shops. In the faculty; studios (different sizes), library, a big corridor (works like a study center), a courtyard, classrooms, computer labs, print \& plot facilities and a conference hall.

Curriculum \& Degrees in short: Bachelor of Science, 4-year program, 240 ECTS, Bachelor of Science in Architecture degree, title: Arch.;

Master of Science, 2-year program, 120 ECTS, Master of Science in Architecture degree, MSc Arch;

Philosophy degree, 4-year program, 180 ECTS, PhD (Doctor of Philosophy), title: Arch, Dr

ADDRESS \& PRACTICALITIES Gazi University Faculty of Architecture Department of Architecture

Eti Mahallesi Yukselis Sokak No:5

Maltepe / Ankara -Turkey www.gazi.edu.tr

Department of Architecture, Istanbul Kemerburgaz University, Turkey

A SCHOOL AS A FORCE TO SEARCH FOR NEW WAYS IN ARCHITECTURAL EDUCATION

The education offered in the Department of Architecture at Istanbul Kemerburgaz University is based on an innovative educational approach that inquires recent developments in architecture both nation- 
ally and internationally, supports interdisciplinary design culture through teaching and research, and offers an environment for integrating experiences of research and practice. Our faculty and students aim to develop the knowledge and skills needed for addressing complex contemporary issues of 'design' that is the bridge connecting and synthesizing varied issues regarding the built environment.

\section{AN EDUCATION THAT ADDRESSES THE MULTIDIMENSIONAL ASPECTS OF \\ ARCHITECTURE}

A learner-centered educational approach is taken as a basis by encouraging the active participation of students to the learning process. The curricular approach integrates practical, ethical, aesthetic, social thought and action and is informed by an integrative and interdisciplinary approach to the learning of architecture. The curricular emphasis is placed on the design studio, where the focus is on hands-on and project-based learning for the development of students' knowledge base, creative and critical thinking skills and problem-solving abilities.

\section{AN ENVIRONMENT \\ OF RESEARCH-BASED TEACHING AND \\ LEARNING}

The Department of Architecture aims to bring our school to a well-respected level of research both nationally and internationally. In this regard, it promotes activities for the creation and dissemination of knowledge that informs the critical study of the built environment. The Department of Architecture supports research-based teaching and learning by offering environments that rely on collective engagement of both academics and students in research throughout the educational process at undergraduate level. Research-based teaching encourages students to actively learn through inquiry.

\section{DATA AND STATISTICS}

Student numbers: 125

Staff size: 4 full-time assistant professors, 3 part-time instructors, 3 research assistants

Facilities: 2015-2016 Academic Year 1 Book publications (International)

4 Paper publications (National)

6 Paper publications (International) 3 Conference papers (National)

2 Conference papers (International) 2 Research Projects (National)

1 Scientific Meeting Organization (National) 7 Workshop Organization (National)

\section{Curriculum \& Degrees in} short: Istanbul Kemerburgaz University Department of Architecture is offering Bachelor of Architecture program. The undergraduate curriculum is designed in accordance with the Bologna criteria in terms of the topics, ECTS credits and must course-elective course distribution, all arranged for the development of subject-specific and generic competences of its graduates. The un- dergraduate curriculum is composed of 22 subject specific must courses, 22 generic must courses, 5 area elective courses and 8 free elective courses. The curriculum is also offering some generic must courses such as "Culture and Society", "Social Responsibility Project", "Occupational Health and Safety" and "Professional Ethics" with the aim of enhancing the social and ethical consciousness of the graduates and introducing them the culture of architectural practice as a profession in order to develop a sense of commitment to architecture beyond employment. It is one of the distinctive aspects of the undergraduate curriculum to offer students the freedom to choose a wide range of subjects from varied disciplinary fields according to the areas of their interests. Undergraduate students are expected to fulfill two 20-days summer practices -Architectural Practice I and Architectural Practice II-- in the 2. and 3. years.

\section{ADDRESS \&} PRACTICALITIES Istanbul Kemerburgaz University Department of Architecture Mahmutbey Dilmenler Cad. No:26 Bagcilar 34217?

IstanbulTurkey

http://www.kemerburgaz. edu.tr/en/academic-units/ schools/school-of-engineering-and-natural-sci ences/ bachelor-of-architecture 
Faculty of Architecture, Istanbul Kultur University, Turkey

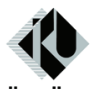

ISTANBUL KÜLTÜR UNIVERSITY

\author{
A MODERN \\ AND DYNAMIC \\ INSTITUTION \\ PROVIDING \\ ARCHITECTURAL \\ EDUCATION IN \\ GLOBAL LEVELS
}

Highly qualified, inter-

nationally oriented and

quantitatively sufficient full

time architecture faculty,

supported by successful

part-time professionals.

Department of Architec-

ture has the highest num-

ber of full-time academic

staff in a foundation univer-

sity in Turkey.

Since 2016, IKU Faculty

of Architecture includes

both the Department of

Architecture and the De-

partment of Interior Archi-

tecture and Environmental

Design. These two depart-

ments also provide Master

Level programs and a Ph.D.

program is available in

Architectural Design field.

\section{AN ACCREDITED \\ QUALITY OF \\ ARCHITECTURAL \\ EDUCATION}

IKU Department of Archi-

tecture is the first and only

Department of Architecture

in a foundation university

in Turkey to receive accreditation.

In 2010, Department of Architecture was deemed accreditation for 3 years by MiAK (Architectural Accrediting Board of Turkey). In 2014, the accreditation was extended by MiAK for the next 6 years.

Education at IKU is bilingual. Beginning in Fall 2016/2017, both departments of Architecture and Interior Architecture \& Environmental Design are going to have undergraduate programs in Turkish and English.

\section{PROVISION OF VARIOUS TRACKS IN EDUCATION}

Students are able to enroll Master of Architecture programs with and without theses. Master program without thesis in Architectural Design takes 3 semesters. Master program with thesis takes 4 semesters and provides specialization in Architectural Design, Urban Design, Restoration, Architectural Engineering, Construction Management areas.

Master of Interior Architecture is with thesis and continues for 4 semesters. Ph.D. at Architectural Design program is available and continues for 8 semesters

DATA AND STATISTICS

Student numbers: Department of Architecure: 654 Bachelor (483 in Turkish Program, 171 in English Program), 32 Master, 2 Ph.D. students

Department of Interior Architecture: 74 Bachelor, 4 Master students

Staff size: 88 staff members (66 in Architecture Department, 22 in Interior Architecture Department), 23 of which are visiting lecturers

Facilities: Faculty of Architecture is at IKU
Atakoy Campus, which is quite accessible by public transportation. University Library is at Atakoy Campus, Faculty of Architecture has around 1000 books in the library and targets to have 4000 in a short time period, also memberships to many periodicals and digital databases are provided. Faculty has a broad PC lab, a model making studio containing laser-cutters, 2 materials lab, a lighting lab and 4 architectural design studios. A seramics lab and a photography studio are also available.

Curriculum \& Degrees in short: Bachelor Degree in separate Turkish and English Programs. 8 semesters (240 ECTS)

Master Degree in Architecture Program with thesis (Turkish): 4 semesters (120 ECTS). Specialization in Architectural Design, Urban Design, Construction Management, Architectural Engineering, Restoration Master Degree in Architectural Design Program (Turkish): 3 semesters (90 ECTS)

Master Degree in Interior Architecture and Environmental Design Program with thesis (Turkish): 4 semesters (120 ECTS)

Ph.D. Degree in Architectural Design Program (Turkish): 8 semesters (240 ECTS)

ADDRESS \&

PRACTICALITIES Istanbul Kultur University Faculty of Architecture Istanbul Kultur Universitesi 
Atakoy Yerleskesi E5 Karayolu uzeri Bakirkoy

PO Box 34156

Istanbul www.iku.edu.tr

Faculty of Architecture

Phone: +90 2124984730

archfaculty@iku.edu.tr

Department of Architecture, Middle East Technical University, Turkey

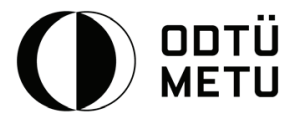

PROMINENT

ARCHITECTURE

SCHOOL OF TURKEY

Established in 1956 as the

first Department of METU,

the public university of

Turkey to enter top world university lists, the Department aims to equip students with requisite global and local knowledge, and critical understanding. With a distinguished faculty of diverse interests and education in English, the Department ranks among prominent national architecture schools. Its professional undergraduate program and several graduate programs value the initiative to challenge the mainstream in order to promote leadership in professional and academic practices of architecture.

CONTEXTUAL AND ETHICAL APPROACH IN ARCHITECTURAL EDUCATION

The undergraduate program is structured around design studios, supported by compulsory and elective courses on the tracks of building science, design and presentation, history, and theory and criticism. The graduate programs grant degrees in five branches, including architectural design, building science, computational design and fabrication technologies, conservation of cultural heritage, and history of architecture. The Department aims to develop creative and critical skills of students, and emphasizes responsibility for physical and cultural contexts and commitment to professional ethics.

\section{CRITICAL APPROACH IN ARCHITECTURAL SCHOLARSHIP}

The graduate programs conduct advanced theoretical, historical and practical research and scholarship in the discipline with creative explorations across disciplines. The emphasis is on social, environmental and technological issues of the built environment in order to produce knowledge with a critical approach on the broad spectrum of architectural and urban studies. Academic works of the faculty developed in graduate courses are also supportive for the research-based design studios that form the core of the undergraduate program of the Department.

\section{DATA AND STATISTICS}

Student numbers: 745 students (400 bachelor, 212 master, 133 doctorate), $64.3 \%$ female,

$35.7 \%$ male, $13 \%$ foreign

Staff size: 78 full-time, about 30 part-time faculty members
Facilities: METU campus, situated on a $45.76 \mathrm{~km} 2$ forested land, hosting a nature reserve with a private lake, has extensive facilities for educational and recreational activities, including a large library, and museums of science and technology and archaeology. The Department is located in the two buildings of the Faculty of Architecture, specifically designed as an architecture school with sufficient studio spaces. For teaching and research, the resources of the Department and the Faculty include laboratories (Building Simulation Laboratory, Building Materials Library, Computer Lab, Digital Design Lab, Model Making Workshops, Materials Conservation Laboratory, Photogrammetry Laboratory, Photograph Laboratory) and an archive with about 80000 slides, 1200 graduate theses, selected reference books and journals, and student works, as well as the special documentary materials at its Maps and Plans Documentation Unit and Cultural Properties Archive Unit. The resources of the Research and Implementation Center for Built Environment and Design, and Centre of Research and Assessment of Historical Environment of the University also contribute to departmental research. 
Curriculum \& Degrees in short: B.Arch., 4-year program; M.Arch., 2-year program;

M.Sc. in Building Science, 2-year program;

M.Sc. in Computational Design and Fabrication Technologies in Architecture, 2-year program; M.Sc. in Conservation of Cultural Heritage, 2-year program;

M.A. in History of Architecture, 2-year program; Ph.D. in Architecture, 4-year program;

Ph.D. in Building Science, 4-year program;

Ph.D. in Conservation of Cultural Heritage, 4-year program; Ph.D. in History of Architecture, 4-year program;

Post-Doctorate Research program

ADDRESS \& PRACTICALITIES Middle East Technical University Department of Architecture Universiteler Mahallesi Dumlupinar Bulvari No: 1

06800 Cankaya Ankara/ TURKEY archweb.metu. edu.tr

\section{Faculty of Architecture, Ondokuz Mayis University, Turkey}

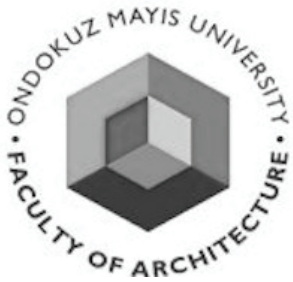

A MULTIFACETED AND DYNAMIC EDUCATIONAL MILIEU The school has a vision of educating and guiding the future architects/designers/ city planners as professionals who have sensitivity to the natural, built, historical and traditional environments; who take into consideration the varying needs and expectations of society; who care about professional ethics, who are conscious about the local values and informed about international development, who prioritise research, who has wide knowledge of technology, who can work and collaborate in an interdisciplinary context, and who are innovative, creative, and competitive in all types of milieus.

\section{A HOLISTIC AND ENVIRONMENT- FRIENDLY APPROACH TO EDUCATION}

An environment-friendly educational approach to architecture and the built environment which combines learning on site, learning by doing and scientific rigor with technical knowledge through projects rooted in real urban concerns. Teaching to develop creative design skills, and learn about construction techniques, materials and environment informed by an understanding of architectural history, urban design, culture, ecology and theory.

\section{AN INTER- \\ DISCIPLINARY AND \\ INTERNATIONAL RESEARCH \\ PERSPECTIVE}

The Faculty of Architecture has been a partner in an international research consortium to work on EU funded projects focusing on sustainable and resilient urbanism. An interdisciplinary PhD Programme titled 'Future Cities, Environment and Sustainability' has been established in cooperation with the Department of Environmental Engineering. The programme aims to generate knowledge through a holistic approach to development and/or redevelopment of cities that are faced with serious environmental problems. A Master of Architecture programme will be initiated in the near future as well.

DATA AND STATISTICS

Student numbers: Architecture - Student numbers: $187+60$ (new intake) students Female: 55\% Male: $45 \%$

Staff size: 8 Full-time; 6 Part-time; 4 Research assistants (new staff to be joined soon)

Facilities: 24/7 design studio, Architectural Model Lab, CAD - Lab, Main library, Faculty library, Cafeteria, Copycenter, Exhibition, Inner courtyard for educational and social activities, Sports facilities, Theatre Hall

\section{Curriculum \& Degrees in} short: B.Arch in Architecture programme (Four-years education)

B. City and Regional Planning programme (Four- 
years education *to be active next year)

ADDRESS \&

PRACTICALITIES

Faculty of Architecture Ondokuz Mayis University Fine Arts Campus Ilkadim 55139 Samsun -Turkey www.mimarlik.omu.tr www.arch.omu.edu.tr

\section{Faculty of Architecture and Design (FAD), Özyegin University, Turkey

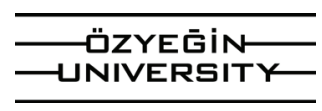

\section{AN ENTREPRENEURIAL RESEARCH \& EDUCATION IN THE SERVICE OF SOCIETY}

Özyegin University (ÖzU) adopts a multidimensional approach offering different possibilities and characteristics, and develops an environment including different cultures and points of view, and evolves in an environment of diversity providing various opportunities for intercultural exchange, and supporting creativity, learning and discovery. Great importance is attached to collaborations and mobility, interdisciplinary and cross-disciplinary studies, and internationalization- exchange programs for students and staff, and international academic cooperation in research and education.

\section{AN ARCHITECTURE AND DESIGN EDUCATION \\ THAT INSPIRES \\ TO CONSTANTLY \\ LEARN, SEARCH AND INNOVATE}

In close alignment with the values and vision of the university, Faculty of Architecture and Design aspires to become one of the leading accredited schools in architecture. The school not only offers an applied learning environment that encourages students to proactively put their theoretical knowledge into practice and find practical and sustainable solutions to real life problems but also adopts an educational philosophy that inspires students to constantly learn, search and innovate to be able to respond to revolutionary transformation in architectural realm and other fields.

\section{EXCELLENCE IN RESEARCH AND GRADUATE STUDIES - EXCELLENCE IN UNDERGRADUATE EDUCATION}

\section{RESEARCH IN EVERY STAGE OF EDUCATION}

The school place importance to excellence in research and graduate studies as much as to excellence in undergraduate education. One of the main missions of the school is to be a leader in creating solutions to the problems of the humankind via cutting-edge research. We are motivated to conduct research which is relevant to real life, beneficial to the humankind in- creasing the quality of our daily lives. As a research university, we also aim to educate future leaders and qualified team members through the process of discovery and creation of new knowledge

DATA AND STATISTICS

Student numbers: 939 students (909 Bachelor, 10 Master, $20 \mathrm{PhD}$ ) , 61\% female, \%39 male,

$\% 10$ foreign

Staff size: 40 Staff members, 12 part-time

Facilities: Library -The library collection includes thousands of printed and electronic books and journals, databases, CDs, DVDs, multimedia resources in a wide range of subject areas as well as a rich variety of daily newspapers and board games. Bookshop, stationary, copy center, computer lab (PC), MAC Lab, Istanbul Institute of Design, Archive, 24/7 design studios, Building Material Lab, CAD - Lab, computer room, computing service, auditorium, copycenter, documentation center, workshops, graphic design studio, lecture rooms, materials lab, model workshop, modelling room, CNC, Laser Cutters, 3D-printing, enclosed personal workplaces, cafeteria, dining hall, photographic studio, printing facilities, publishing department.

\section{Curriculum \& Degrees in} short: Undergraduate Programs: 4- year (240 ECTS)

- Architecture 
- Industrial Design

- Communication Design

- Interior Architecture and Environmental Design

Graduate Programs and Degrees:

MSc in Architecture (with thesis) 2-year program (120 ECTS) MSc in Architecture (non-thesis) 1,5 year program (90 ECTS)

MSc in Design, Technology and Society (with thesis / non-thesis) 2-year program (120 ECTS) MSc in Design, Technology and Society (non-thesis) $-1,5$ year program (90 ECTS)

PhD in Design, Technology and Society

ADDRESS \& PRACTICALITIES Özyegin University (OzU) Faculty of Architecture and Design (FAD)

Alemdag Çekmeköy 34794 IstanbulTURKEY

T: +90 2165649000 PBX / +902165649561

Fax: +90 2165649050

www.ozyegin.edu.tr

Department of Architecture, Tobb University of Economics and Technology, Turkey

$\Delta$

\section{ARCHITECTURE EDUCATION \\ BEYOND ANY}

\section{CLASSIFICATIONS}

Architecture should remain beyond any classifications in order to develop original and essential human qualities. These more humanistic approaches should be aug- mented and let increasingly guide our architecture and therefore its education. Accordingly, our department adopt a sensible approach which considers the equilibrium of the natural and the cultural, thinking and making, qualities and opportunities in the center and the edge of the profession, fundamentals and the emerging issues, physical conditions and ethical grounds, thus rooting the things while going with the flow.

\section{ENTREPRENEURSHIP ORIENTED \\ ARCHITECTURE DEPARTMENT}

Four-year undergraduate curriculum (8 semesters of education +3 cooperative education semesters) consists of five principal modules: Architectural Design Studios; Architectural Theories, Histories and Cultures; Design, Presentation and Research Methods and Techniques; Building Technologies; Elective subjects. The principal is to utilize progressive and updatable characteristics of the modules and therefore keep the curriculum sustainable. The program aims to produce innovative knowledge and organize strategies that foster both thinking and making of architecture.

\section{MULTI-DISCIPLINARY RESEARCH PROGRAM IN ARCHITECTURE} The Architecture Department acknowledges the key role of architecture between primary and applied sciences, the link between theory and application, the creativity that sails between science and the arts and the impacts that close the gap between the academic and real world. In this respect our English spoken Master of Architecture program promotes an educational model that is based on strong and continuous collaboration with all areas of design, engineering, cultural studies, psychology etc.

DATA AND STATISTICS

Student numbers: 150 students (135 Bachelor, 15 Master), $74 \%$ female, $26 \%$ male, $1 \%$ foreign.

Staff size: 25 Staff members, mostly part-time + 10 visiting lectures and critics.

Facilities: Study center, extensive modeling workshop (including laser cutters and $\mathrm{CNC}$ milling machines), library, cafeterias, CAD - lab, media lab, photographic studio, painting studio.

Curriculum \& Degrees in short: 4-year undergraduate program, $(240$ ECTS), Bachelor of Architecture degree;

2-year graduate program (120 ECTS), Master of Architecture degree.

ADDRESS \& PRACTICALITIES TOBB UNIVERSITY OF ECONOMICS ANDTECHNOLOGY

Faculty of Fine Arts Design and Architecture Department of Architecture Sögütözü Caddesi No:43 Sögütözü Ankara 06560 TURKEY www.etu.edu.tr 
Kent School of Architecture, United Kingdom

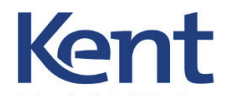

School of Architecture

WHO WE ARE

Kent School of Architecture (KSA) was established in 2005. The school is located in the Marlowe Building and is part of the Faculty of Humanities at the University of Kent, alongside the Faculty of Sciences and the Faculty of Social Sciences.

When the school was founded, it was established as a "teaching only" school. From 2007, the development of research became a major focus for the school, and the increase in staff research appointments allowed the growing body of research expertise to be incorporated into teaching in an accretionary manner. There is now a thriving research community.

WHAT WE TEACH KSA is distinctive in its provision in five key territories: 1. Fine art embedded with digital technology - fine art processes and proficiency in digital technology are valued at all levels

2. Operating in Europe and the region - We make full use of our proximity to the European mainland 3. Grounded in practice our studio design tutors are engaged in a wide range of private practice

4. World class researchers teach at all levels - members of our research cen- tres, CREAte and CASE, teach at all levels in the school

5. Our students teach our MArch pedagogy module engages Part 2 students

\section{OUR RESEARCH}

Our researchers work out of two research centres; CREAte (Centre for Research in European Architecture) in the field of history, theory and architectural and urban design studies and CASE (Centre for Architecture and Sustainable Environment) in the field of sustainability, low energy design and history of environmental design and technology and recently in social sustainability. We made a strong submission to REF 2014, ranking 8th for research intensity and 8th for research output in the UK.

DATA AND STATISTICS

Student numbers: Total number of students: 366 on our BA (Hons) Architecture RIBA Part 1 course, 73 on our MArch RIBA Part 2 course, 34 students on our Postgraduate Taught programmes and 20 students on our $\mathrm{PhD}$ course

Staff size: 50.5 Full-time staff members, with 33 Assistant and Associate Lecturers

Facilities: Digital Crit Space, Studio A (Stage 1 students), Studio B (Stage 2 \& 3 students), Architecture-only workshop which includes laser cutting, 3D site scanning and 3D printing facilities, photographic dark room, model-making studio, life drawing studio, metal workshop, CAD lab, campus library with online resource and journal facilities

Curriculum \& Degrees in short: BA (Hons) Architecture, 3 year programme, RIBA Part 1

MArch, 2 year programme, RIBA Part 2

MA Architecture and Urban Design (Canterbury only), 1 year full-time / 2 years part-time, based at the University of Kent, Canterbury campus only

MA Architecture and Urban Design (Canterbury and Paris), 1 year full-time / 2 years part-time, based at University of Kent, Canterbury and Paris campus

MSc Architectural Conservation, 1 year full-time / 2 years part-time MA Architectural Visualisation, 1 year full-time / 2 years part-time

MSc Architecture and the Sustainable Environment, 1 year full-time / 2 years part-time $\mathrm{PhD}$ Architecture (Research degree), 3-4 years fulltime / 5-6 years parttime

ADDRESS \& PRACTICALITIES Kent School of Architecture Marlowe Building University of Kent Canterbury CT2 7NR www.kent.ac.uk/architecture 
Agrasar, Fernando

A Coruña School of

Architecture, A CORUÑA

Spain, etsacdir@udc.es

Ahnfeldt-Mollerup, Merete

KADK, Denmark,

Merete.Ahnfeldt@kadk.dk

Alkan, Alper

Delft University of

Technology, DELFT,

Netherlands,

a.s.alkan@tudelft.nl

Altan, Tomris Elvan

Middle East Technical

University, ANKARA,

Turkey

tomris@metu.edu.tr

Andersson, Cecilie

Bergen School of

Architecture, BERGEN,

Norway, ca@bas.org

Asselbergs, Thijs

Delft University

of Technology,

DELFT, Netherlands,

M.F.Asselbergs@tudelft.nl

Atalay Franck, Oya,

ZHAW, WINTERTHUR,

Switzerland,

oya.atalay@zhaw.ch

Avidar, Pnina

Fontys Hogescholen

Tilburg, TILBURG,

Nederland

p.avidar@fontys.nl

Bachmann, Balint

University of Pécs Faculty

of Engineering and

Information Technology,

PÉCS, Hungary,

bachmann@mik.pte.hu

Bacic, Dubravko

Architects' Council of

Europe, BRUXELLES,

Belgium,

dbacic@arhitekt.hr
Bekkering, Juliette

TU Eindhoven,

EINDHOVEN, Nederland, j.d.bekkering@tue.nl

Biechteler, Heike

Hochschule Technik

\& Architektur Luzern,

HORW, Switzerland,

heike.biechteler@hslu.ch

Bobbink, Inge

Delft University of

Technology, DELFT,

Netherlands,

i.bobbink@tudelft.nl

Bock, Thomas

Technische Universitat

Munchen, , Germany,

Bourgeois, Carl, KU

Leuven - Faculty of

Architecture, GENT,

Belgium, carl.bourgeois@

kuleuven.be

Boursin, Séverine

Versailles National

School of Architecture,

VERSAILLES, France,

severine.boursin@

versailles.archi.fr

Boutsen, Dag

KU Leuven - Faculty

of Architecture,

BRUSSEL, Belgium,

dag.boutsen@kuleuven.be

Braghieri, Nicola

EPFL, LAUSANNE,

Switzerland,

nicola.braghieri@epfl.ch

Brito, Oscar

Central Saint Martins,

LONDON, United

Kingdom,

o.brito@csm.arts.ac.uk

Buehler, Herbert

FBTA ( German Deans

Conference), MÜNSTER,

Germany, teambuehler@

fh-muenster.de
Cabrera i Fausto, Ivan

Escola Tècnica Superior

d'Arquitectura de

la Universitat

Politècnica de València,

VALENCIA, Spain,

ivcabfau@mes.upv.es

Çaglar, Nur

TOBB-ETU, ANKARA,

Turkey,

alar.nur@gmail.com

Cardinale, Maria Vittoria

Politecnico di Milano,

MILANO, Italy,

arch_vittoria.cardinale@

hotmail.it

Caso, Olindo

Delft University of

Technology, DELFT,

Netherlands,

O.Caso@tudelft.nl

Cavallo, Roberto

Faculty of Architecture

\& the Built Environment,

Delft University of

Technology, DELFT,

Netherlands,

r.cavallo@tudelft.nl

Chénot, Martin

EnsapBx, TALENCE

CEDEX, France,

martin.chenot@

bordeaux.archi.fr

Christossek, Tim

Fachhochschule Münster,

MÜNSTER, Germany,

tim.christossek@

fh-muenster.de

Couceiro da Costa, Manuel

Faculty of Architecture,

University of Lisbon,

LISBON, Portugal,

mcoucy@arquetipo.com.pt

Cuyvers, Rob,

Hasselt University,

DIEPENBEEK, Belgium, rob.cuyvers@uhasselt.be 
De Ventos, Maria

Urban Laboratory of

Barcelona ETSAB, Spain

Del Bo, Adalberto, Politecnico Di Milano, MILANO, Italy, adalberto.delbo@polimi.it

Della Torre, Marco

Accademia di architettura, Università della Svizzera italiana, MENDRISIO, Switzerland, marco.dellatorre@usi.ch

Deutzmann, Mark MSA | Münster School of Architecture, MÜNSTER, Germany, mark.deutzmann@ fh-muenster.de

Dinc Kalayci, Pinar

Gazi University, ANKARA, Turkey, pinarpinardinc@gmail.com

Dostoglu, Neslihan Istanbul Kultur University, ISTANBUL, Turkey, neslihandost@yahoo.com

Dubourthoumieu, Marie-Elisabeth EnsapBx, TALENCE, France, m-e.dubourthoumieu@ bordeaux.archi.fr

Duin, van, Leendert

Delft University of Technology, DELFT, Netherlands, leendertvanduin@ gmail.com

Dworzak, Hugo

University of Liechtenstein, VADUZ, Liechtenstein, ines.hartmann@uni.li
Echevarria, Juan Bautista

School of Architecture

University of Navarra,

PAMPLONA, Spain,

jbecheverria@unav.es

Efler, Tomas

Czech Technical University

in Prague - Faculty of

Architecture, PRAGUE,

Czech Republic,

eflerus@seznam.cz

Ellefsen, Karl Otto

EAAE, OSLO, Norway,

karl.o.ellefsen@

aho.no, Fitzsimons

Kent, EnsapBx

TALENCE, France,

kent.fitzsimons@

bordeaux.archi.fr

Franquesa, Jordi

ETSAB, BARCELONA,

Spain, jordi.franquesa@

upc.edu

Ghirardo, Diane

University of Southern

California, United States

of America

Giofre, Francesca

Faculty of Architecture,

Sapienza, ROME, Italy,

francesca.giofre@

uniroma1.it

Gochet, Bernard

Université Catholique

de Louvain - U.C.L.,

LOUVAIN-LA-NEUVE,

Belgium, bernard.gochet@

uclouvain.be

\section{Grulois, Geoffrey}

Université libre de

Bruxelles, BRUSSELS,

Belgium,

geoffrey.grulois@ulb.ac.be
Gustavsen, Ole

Oslo School of

Architecture and Design,

OSLO, Norway,

ole.gustavsen@aho.no

Haddad, Elie

Lebanese American

University, BEIRUT,

Lebanon,

ehaddad@lau.edu.lb

Hannes, Els

Hasselt University,

DIEPENBEEK, Belgium,

els.hannes@uhasselt.be

Harteveld, Maurice

Delft University

of Technology,

DELFT, Netherlands,

m.g.a.d.harteveld@

tudelft.nl

Heuvel, van den, Dirk

TU Delft / Het

Nieuwe Instituut,

DELFT, Nederland,

d.vandenheuvel@tudelft.nl

Hlavacek, Dalibor

Czech Technical University

in Prague, PRAGUE,

Czech Republic,

dhlavacek@fa.cvut.cz

Hoogendoorn Yolande

Technical University

of Munich, MÜNCHEN,

Germany, hoogendoorn@

tum.de

Hoskara, Sebnem

Eastern Mediterranean

University, GAZIMAGUSA/

KKTC, Turkey,

sebnem.hoskara@

gmail.com,

Janssen, Dirk

University of Antwerp,

ANTWERPEN, Belgium,

dirk.janssen@

uantwerpen.be 
Kikkert, Jan-Richard

Academy of Architecture

Amsterdam, AMSTERDAM,

Netherlands,

erin.tjin-a-ton@ahk.nl

Klok, Arjan

Academy of Architecture

Amsterdam, AMSTERDAM,

Netherlands,

erin.tjin-a-ton@ahk.nl

Komossa, Susanne

Delft University of

Technology, DELFT,

Nederland

s.komossa@tudelft.nl

Koponen, Olli-Paavo

Tampere University

of Technology,

TAMPERE, Finland,

olli-paavo.koponen@tut.fi

Kormoss, Bernard

Université de Liège (ULg)،

Faculté of Architecture,

LIÈGE, Belgium,

b.kormoss@ulg.ac.be

Langen, van, Chris

Rotterdamse Academie

van Bouwkunst,

ROTTERDAM,

Netherlands,

c.r.van.langen@hr.nl

Lee, Laura

Carnegie Mellon

University, PITTSBURGH,

United States of America

Lens, Inge

EAAE, DIEPENBEEK,

Belgium,

inge.lens@uhasselt.be

Lokce, Sevgi,

Atilim University, Faculty

Fine Arts, Design \&

Architecture, ANKARA,

Turkey,

sevgi.lokce@atilim.edu.tr
Loukotova, Regina

ARCHIP, PRAHA 7,

Czech Republic,

regina.loukotova@

archip.eu

Lundevall, Trond Tarald

AHO, OSLO, Norway,

tarald@snohetta.com

Maaskant, Madeleine

Academy of Architecture

Amsterdam, AMSTERDAM,

Netherlands,

erin.tjin-a-ton@ahk.nl

Maeder, Stephan

ZHAW, WINTERTHUR,

Switzerland,

mdrs@zhaw.ch

Mani, Victor

Fachhochschule Münster, MÜNSTER, Germany,

mani@luna.nl

Marzot, Nicola

Universita' Di Ferrera,

FERRARA, Italy,

GBS@UNIFE.IT

Mas Llorens, Vicente

Escuela Tecnica Superior

Arquitectura UPV,

VALENCIA, Spain,

vmas@pra.upv.es

McQuillan, Thomas

AHO, OSLO, Norway,

thomas.mcquillan@aho.no

Medvegy, Gabriella

University of Pécs,

Faculty of Engineering and Information Technology,

PÉCS, Hungary, medvegygabriella@

mik.pte.hu

Meers, Joseph

University of Antwerp,

ANTWERP, Belgium,

joseph.meers@

uantwerpen.be
Melgaard, Ebbe

School of Architecture

Copenhagen, NIVÅ,

Denmark,melg@mail.dk

Miley, Garry

Waterford Institute of

Technology, WATERFORD,

Ireland,gmiley@wit.ie

Monti, Michael

Association of Collegiate

Schools of Architecture,

WASHINGTON, DC

United States of America, mmonti@acsa-arch.org

Musso, Stefano Francesco

University of Genoa,

GENOVA, Italy,

etienne@arch.unige.it

Nekrosius, Liutauras

Vilnius Gediminas

Technical University,

VILNIUS, Lithuania,

liutauras.nekrosius@

vgtu.It

Nemes, Gabor

Budapest University

of Technology and

Economics, BUDAPEST,

Hungary,

ndh@epitesz.bme.hu

Nilsson, Fredrik

Chalmers University

of Technology,

GOTHENBURG, Sweden,

fredrik.nilsson@

chalmers.se,

Numan, Ibrahim

Fati Sultan Mehmet

Vakif University,

ISTANBUL, Turkey,

numan.ibrahim@

gmail.com

Oktay, Derya

Ondokuz Mayis University,

SAMSUN, Turkey,

de.oktay@gmail.com 
Oktay, Derya

Ondokuz Mayis University,

SAMSUN, Turkey,

de.oktay@gmail.com

Parelius, Gunnar

Norwegian University of

Science and Technology,

TRONDHEIM, Norway,

gunnar.parelius@ntnu.no

Patterson, Richard

SCHOSA, LANCING,

United Kingdom,

schosa@btinternet.com

Pham, Nicolas

University of Applied

Sciences and Arts Western

Switzerland, GENEVA,

Switzerland,

nicolas.pham@hesge.ch

Ramos Sanz, Anna,

ETSAB Barcelona

School of Architecture,

BARCELONA, Spain,

anna.ramos-sanz@upc.edu

Rettondini, Lara

University of Westminster,

LONDON, United

Kingdom,

lara@stxdesign.com

Robiglio, Matteo

Politecnico di Torino,

TORINO, Italy,

matteo.robiglio@polito.it,

Rosbottom, Daniel

Delft University

of Technology,

DELFT, Netherlands,

D.J.Rosbottom@tudelft.nl

Ruhi Sipahioglu, Isil

Tobb University

of Economics and

Technology, ANKARA,

Turkey, isilruhi@gmail.com
Ruisch, Patricia

Academy of Architecture

Amsterdam, AMSTERDAM,

Netherlands,

erin.tjin-a-ton@ahk.nl

Russell, Peter

Delft University of

Technology, DELFT,

Netherlands,

P.J.Russell@tudelft.nl

Sahin, Murat

Ozyegin University,

ISTANBUL, Turkey,

murat.sahin@

ozyegin.edu.tr

Sanaan Bensi, Negar

Delft University of

Technology, ROTTERDAM,

Netherlands,

N.SanaanBensi@tudelft.nl

Scheerlinck, Kris

KU Leuven - Faculty of

Architecture, BRUSSELS,

Belgium, kris.scheerlinck@

kuleuven.be

Schreurs, Eirene

Delft University

of Technology,

DELFT, Netherlands,

E.P.N.Schreurs@tudelft.nl

Shetelig, Fredrik

NTNU, TRONDHEIM,

Norway, fredrik.shetelig@

ntnu.no

Siddi, Cesarina

University of Cagliari,

CAGLIARI, Italy,

csiddi@unica.it

Slapeta, Vladimir

Faculty of Architecture,

Brno University of

Technology, BRNO,

Czech Republic,

slapeta@fa.vutbr.cz,
Slyk, Jan

Warsaw University

of Technology,

WARSZAWA, Poland,

jan.slyk@arch.pw.edu.pl

Sotoca, Adolfo

UPC, SANT CUGAT DEL

VALLÈS, Spain,

vicedean.internationals@

etsav.upc.edu

Spanedda, Francesco

Università degli Studi di

Sassari, ALGHERO, Italy, francesco.spanedda@

uniss.it

Staub, Peter A.

University of

Liechtenstein, VADUZ,

Liechtenstein,

ines.hartmann@uni.li

Stewart, Sally

Mackintosch School of

Architecture, GLASGOW,

United Kingdom,

s.stewart@gsa.ac.uk

Strid, Marie

Chalmers, GOTEBORG,

Sweden, marie.strid@

chalmers.se

Tornatora, R. Marina

Università degli Studi

Mediterranea, REGGIO

CALABRIA, Italy,

mtornatora@unirc.it

Trocka-Leszczynska

Elzbieta, Wroclaw

University of Science and

Technology, WROCLAW,

Poland, elzbieta.trocka-

leszczynska@pwr.edu.pl,

Valente, Ilaria

Politecnico di Milano,

MILANO, Italy,

ilaria.valente@polimi.it 
Trova, Vasileia

University of Thessaly,

VOLOS, Greece,

vatrova2@gmail.com

Van Cleempoel, Koenraad

Hasselt University,

DIEPENBEEK, Belgium,

koenraad.vancleempoel@

uhasselt.be

Vázquez Carretero,

Narciso Jesús

University of Seville,

SEVILLE, Spain,

narciso@us.es

Verbeke, Johan

KU Leuven - Faculty of

Architecture, BRUSSEL,

Belgium, johan.verbeke@

kuleuven.be

Vitkova, Lubica

Faculty of Architecture

Slovak University of

Technology in Bratislava,

BRATISLAVA, Slovakia,

lubica.vitkova@fa.stuba.sk

Walsche, de, Johan

University of Antwerp,

ANTWERP, Belgium,

johan.dewalsche@

uantwerpen.be

Weischer, Martin

Fachhochschule Münster,

MÜNSTER, Germany,

m.weischer@

fh-muenster.de

Wilms Floet, Willemijn

Delft University

of Technology,

DELFT, Netherlands,

W.W.L.M.WilmsFloet@

tudelft.nl

Wrona, Stefan

Faculty of Architecture

Warsaw University of

Technology, WARSAW,

Poland,

wrona@arch.pw.edu.pl
Xavier, João Pedro

University of Porto,

PORTO, Portugal,

jpx@arq.up.pt

Yorgancioglu, Derya

Istanbul Kemerburgaz

University, ISTANBUL,

Turkey, derya.

yorgancioglu@

kemerburgaz.edu.tr

Zavrel, Zdenek

Faculty of Architecture,

CTU in Prague, PRAGUE,

Czech Republic,

zzavrel@fa.cvut.cz 
Organizing Committee

Susanne Komossa

Roberto Cavallo

Maurice Harteveld

\section{Scientific Committee}

Karl Otto Ellefsen

Adalberto Del Bo

Koenrad van Cleempoel

Susanne Komossa

Roberto Cavallo

Maurice Harteveld
Venue

European Association of Architectural Education (EAAE)

Conference \& GA, Delft, The Netherlands

31 August - 3 September 2016

Faculty of Architecture and the Built Environment Delft University of

Technology

Julianalaan 134

NL-2628BL

Publisher

TU Delft Open

ISBN 978-94-92516-28-2

Website

http://eaae2016delft.org/

Poster Exhibition

Joran Kuijper, Susanne

Komossa

Conference Graphic

Design

Hans Gremmen,

Amsterdam

Website

Marek Nosek, Delft

Conference Administration Salma Ibrahim (TUD), Inge Lens (EAAE)

Conference Registration Eveline Vogels (OTB)

Students Assistants

Monica Lelieveld

Gichuki Rugoiyo

Anna Golubovska

Editors \& Copyright

Susanne Komossa, Roberto Cavallo, Maurice Harteveld Delft, September 2016
We like to thank all speakers, respondents, moderators, and representatives from professional practice, student assistants and colleagues from the TU Delft Faculty of Architecture who made this venue possible. Het Nieuwe Instituut, $\mathrm{HNI}$ and the Amsterdam Institute for Advanced Metropolitan Solutions, AMS opened their doors for us to host professional discussion.

We are also thankful for the financial support of European Association of Architectural Education, EAAE, the Faculty of Architecture's Dean Office and Departments of Architecture and Urbanism.

The Open Access Workshop was supported by the Nederlandse Organisatie voor Wetenschappelijk Onderzoek, NWO (The Netherlands' Organization for Scientific Research).
TUDelft 生 EAAA压AAE
